María Villarroya Gaudó SANDRA BALDASSARR I Pilar Molina Gaudó (Editoras)

\title{
El mundo necesita ingenieras ¿Quieres ser una?
}
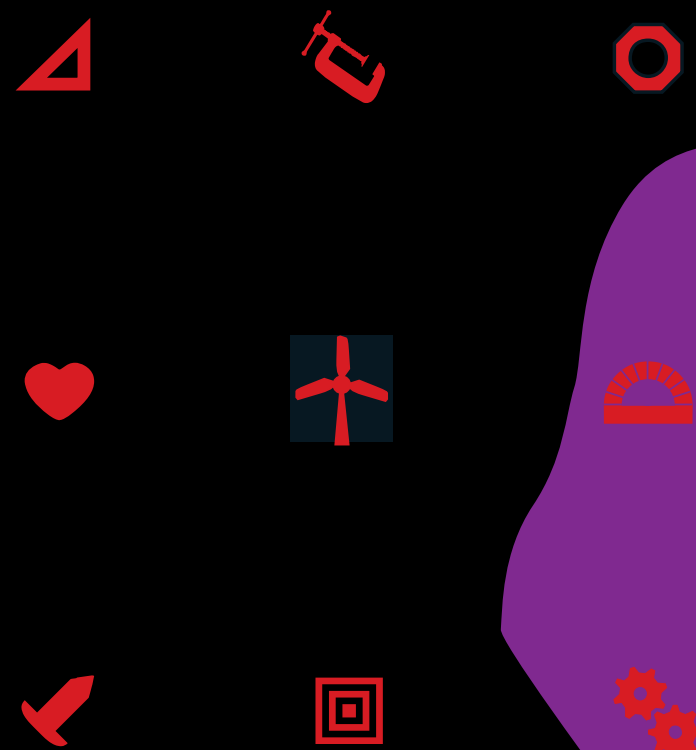

El mundo necesita ingenieras

¿Quieres ser una? 

María Villarroya Gaudó

SANDRA BALDASSARRI

Pilar Molina Gaudó

(EDitoras)

\section{El mundo \\ necesita \\ ingenieras \\ ¿Quieres ser una?}


El MUNDO necesita ingenieras : ¿quieres ser una? / María Villarroya Gaudó, Sandra Baldassarri, Pilar Molina Gaudó (editoras). - Zaragoza : Prensas de la Universidad de Zaragoza, 2013

133 p. : il. ; $22 \mathrm{~cm}$

ISBN 978-84-15770-80-0

1. Mujeres-Igualdad de oportunidades. 2. Estudiantes universitarias-Aragón. 3. Ingenieras-Aragón

VILLARROYA GAUDÓ, María

331.58-055.2(460.22)

378.4-055.2(460.22)

$62-055.2(460.22)$

Cualquier forma de reproducción, distribución, comunicación pública o transformación de esta obra solo puede ser realizada con la autorización de sus titulares, salvo excepción prevista por la ley. Diríjase a CEDRO (Centro Español de Derechos Reprográficos, www.cedro.org) si necesita fotocopiar o escanear algún fragmento de esta obra.

(C) María Villarroya Gaudó, Sandra Baldassarri y Pilar Molina Gaudó

(C) De la presente edición, Prensas de la Universidad de Zaragoza 1. ${ }^{\mathrm{a}}$ edición, 2013

Diseño de la cubierta: Inma García. Prensas de la Universidad de Zaragoza.

La edición de este libro ha sido financiada por el Instituto de la Mujer. Ministerio de Sanidad, Servicios Sociales e Igualdad.

Prensas de la Universidad de Zaragoza. Edificio de Ciencias Geológicas, c/Pedro Cerbuna,12 50009 Zaragoza, España. Tel.: 976761 330. Fax: 976761063

puz@unizar.es http://puz.unizar.es

U17e Esta editorial es miembro de la UNE, lo que garantiza la difusión y comercialización de sus publicaciones a nivel nacional e internacional.

Impreso en España

Imprime: Servicio de Publicaciones. Universidad de Zaragoza

D.L.: Z 1449-2013 
A nuestras hijas, ingenieras y tecnólogas del futuro y a quienes contribuís a hacerlo posible.

Tenemos el compromiso de hacer más fácil el camino para las mujeres que vendrán detrás.

Rosalyn Sussman Yalow Premio Nobel de Medicina en 1977 


\section{Presentación}


Las mujeres constituyen actualmente la mayoría del alumnado de grado (en este curso son el 53,4\%) de la Universidad de Zaragoza y, en una proporción superior, de quienes finalizan sus estudios universitarios. Sin embargo, esta proporción, acorde con la que las mujeres representan en el conjunto de la sociedad, no se distribuye de una forma equilibrada entre las diversas titulaciones.

A pesar de que en las últimas décadas se ha tendido a una situación de equilibrio, las diferencias entre unas y otras siguen siendo muy marcadas $y$, mientras en algunas de ellas predominan claramente las mujeres, en otras son los hombres los que constituyen una amplia mayoría. Esto ocurre en la rama de Ingeniería y Arquitectura, donde las mujeres apenas constituyen el $22,9 \%$ del alumnado.

La tradición y el desconocimiento de la realidad de las enseñanzas técnicas juegan un papel muy importante en la pervivencia de esta situación. Para corregirla es necesario que las futuras estudiantes universitarias conozcan de primera mano la realidad de dichas enseñanzas, y con ese objetivo se puso en marcha el Girls' Day.

La Universidad de Zaragoza fue, en 2008, la primera de las españolas en organizar el Girls' Day, cuyo objetivo es acercar a las jóvenes al ámbito de la Ingeniería y la Arquitectura, y promover en ellas más vocaciones tecnológicas. Su organización ha sido fruto de la colaboración entre la Asociación de Mujeres Científicas y Técnicas (MUCIT), surgida en 1999 en Aragón para fomentar el debate sobre la desigual presencia de mujeres en la ciencia y la tecnología, y el Observatorio de Igualdad de Género de la Universidad de Zaragoza, creado en 2008.

Desde entonces, mujeres profesionales de empresas, instituciones, laboratorios y grupos de investigación han explicado a miles de jóvenes estudiantes sus experiencias personales y les han mostrado que las tecnológicas también son profesiones de mujeres. El libro que el lector tiene en sus manos, coordinado por Sandra Baldassarri, Pilar Molina y María Villarroya, recoge la experiencia acumulada durante este periodo, y es un excelente punto de partida para conseguir alcanzar esa situación equilibrada que deseamos.

Manuel J. López Pérez

Rector de la Universidad de Zaragoza 
Prólogo 
La Asociación de Mujeres Científicas y Técnicas (MUCIT) surge en 1999 en Aragón con el fin de concienciar sobre la desigual presencia de mujeres y hombres en la ciencia y la tecnología, los motivos que llevan a esta situación y buscar soluciones. Trabajamos desde el convencimiento de que no es un problema específico de las mujeres, sino que atañe al conjunto de la sociedad.

Desde junio de 2006, MUCIT está adscrita a la Asociación de Mujeres Investigadoras y Tecnólogas (AMIT), de ámbito estatal, $y$, desde entonces, ambas colaboramos en todas las acciones. En particular hemos organizado actividades para promover la presencia de mujeres en ciencia y tecnología, siendo pioneras en España con la realización del evento Girls' Day en Aragón.

Como actual presidenta de MUCIT es un orgullo observar cómo el esfuerzo de organización de las primeras cuatro ediciones Girls' Day, de los análisis de los distintos estudios sociológicos y las distintas vivencias salen a la luz en este volumen.

Era necesario organizar las ideas y prácticas vividas para demostrar que la igualdad de género todavía no se ha alcanzado en la sociedad, tampoco en la universidad y menos en un campo como es la ingeniería y la tecnología. Con esta publicación queremos ayudar a otras compañeras con nuestra experiencia, visibilizar el trabajo de las ingenieras y también mostrar a la sociedad en qué consiste la ingeniería, «esa gran desconocida», pero sobre todo demostrarles a las futuras ingenieras que pueden llegar a serlo y que, además, son necesarias. 


\section{Agradecimientos}


El libro que estás leyendo es fruto del esfuerzo personal y el trabajo voluntario de muchas personas, en su mayoría ingenieras y tecnólogas, que juntas han considerado que es preciso divulgar y dar a conocer en qué consiste su trabajo, convencidas de que el talento no puede desperdiciarse, menos en tiempos de crisis, y por ello debe potenciarse la presencia de mujeres en ingeniería.

Numerarlas a todas sería imposible, si bien es preciso señalar de quiénes hablamos: desde el alumnado de secundaria que ha participado en las distintas ediciones, acompañado por sus profesoras y profesores; pasando por las estudiantes de ingeniería que han guiado a los grupos en sus visitas a los distintos laboratorios y empresas; siguiendo por el personal responsable de los citados centros de investigación y compañías, así como las ingenieras que allí trabajan, que han mostrado en qué consiste su profesión. Y, por supuesto, el grupo de profesoras de la Universidad de Zaragoza que ha llevado a cabo toda la gestión de los eventos en las distintas ediciones. También, a todas aquellas que han revisado o participado con sus textos en algunas secciones de este volumen.

Sinceramente, gracias por haber dedicado parte de vuestro tiempo y esfuerzo a mostrar qué hacéis y que vuestra labor es precisa para el avance de la sociedad.

Así mismo, hacemos un reconocimiento público al apoyo y la financiación que el Girls' Day (en sus distintas ediciones en Aragón) y el presente libro han recibido, en particular, de la Universidad de Zaragoza (con todos los centros implicados), el Instituto de la Mujer, el Gobierno de Aragón (a través del Instituto Aragonés de la Mujer y el Departamento de Educación) y el Ayuntamiento de Zaragoza a través de la Casa de la Mujer. 


\section{Introducción}

María Villarroya Gaudó 
El 8 de marzo de 1910, se publicó la Real Orden que permitía el libre acceso de las mujeres a los estudios de Bachillerato y universitarios. Más de un siglo después, hemos visto cómo la presencia de mujeres en las aulas se ha ido incrementando. Desde los años setenta, las estudiantes de Bachillerato son mayoría, una década después, las mujeres acceden masivamente a la universidad y, desde entonces, el alumnado universitario está compuesto en más de un $50 \%$ por mujeres. Parece, por tanto, que el acceso a la formación, al menos teóricamente, se da en condiciones de igualdad para mujeres y hombres en España. Si preguntamos a las generaciones jóvenes, su percepción particular es que ellas y ellos son iguales. Tienen los mismos derechos, pueden hacer las mismas cosas y, de modo individual, afirman que las desigualdades de género son cosa del pasado. No obstante, comprobamos continuamente que nuestra sociedad todavía mantiene muchos roles tradicionales masculinos y otros tantos femeninos. Estos roles están muy interiorizados y no son fáciles de cambiar, de modo que la igualdad de responsabilidades, de formación o de educación, no es tan real como aparenta.

Los datos estadísticos nos llevan a concluir que no se alcanza esta igualdad real. En particular, la elección de las distintas ramas del saber no se produce en condiciones de igualdad de oportunidades, como se constata en este libro que ocurre en el caso del alumnado de ingeniería. No se impulsa igual a una chica que a un chico a que acceda a una determinada formación.

Año tras año, los datos del Instituto Nacional de Estadística (INE) muestran una notable brecha salarial entre mujeres y hombres en nuestro país. Las primeras siguen teniendo sueldos inferiores a los de ellos en ámbitos laborales y categorías similares. Si analizamos por sectores, nos encontramos sectores más feminizados, como son los sectores dedicados al cuidado o la limpieza, donde los sueldos son inferiores y la presencia de mujeres es mayor. Por el contrario, en sectores como la ingeniería, la construcción o las finanzas, con sueldos superiores, la presencia de mujeres es menor. Además, el progreso a las escalas superiores y los puestos de dirección, en todos los sectores, es más dificultoso para las mujeres. Por tanto, el desigual acceso a la formación tiene consecuencias sociales importantes, pues limita el poder económico que, a su vez, limita el poder político y social. 
El Girls' Day es una jornada para acercar a las alumnas de Enseñanza Secundaria y Bachillerato al mundo de la ciencia, la tecnología y la investigación de la mano de mujeres que desempeñan papeles relevantes tanto en el ámbito empresarial como en el académico.

Conocíamos iniciativas similares en otros países, pero necesitábamos cierto apoyo para su organización, ya que desde nuestra situación como profesoras e investigadoras de la Escuela de Ingeniería y Arquitectura de la Universidad de Zaragozanos faltaba una pequeña ayuda para la planificación completa de la actividad. Hace años un grupo de estudiantes de último curso de ingeniería industrial propuso a la Asociación de Mujeres Científicas y Técnicas, MUCIT, elaborar un proyecto de una actividad, como trabajo de una asignatura. Desde la asociación entendimos que era la oportunidad de hacer un plan de trabajo para poder organizar, por primera vez en España, el Girls' Day.

En 2007, se acababa de publicar la Ley de Igualdad efectiva entre mujeres y hombres. Gracias a este momento legislativo y al interesante proyecto que presentamos, llegaron las subvenciones, el apoyo económico e institucional. La financiación fue fundamental sobre todo en aquella primera edición de 2008. El soporte institucional ha sido a la larga el más importante, puesto que ha sido creciente en el tiempo, y es el que poco a poco va calando en la sociedad.

Así, hemos organizado cuatro ediciones del Girls' Day en Aragón (11 de noviembre de 2008, 28 de octubre de 2009, 23 de marzo de 2011 y 28 de marzo de 2012). Este libro recoge las razones de su organización, las experiencias y las conclusiones obtenidas.

Aquel trabajo académico sentó las bases de los requerimientos organizativos de la jornada e hizo que un conjunto de profesoras e investigadoras hiciéramos realidad algo que creíamos necesario: dar a conocer a qué se dedican las ingenieras y tecnólogas.

Personalmente, habíamos estudiado aquello que habíamos querido. Encontramos en nuestras familias y entornos los apoyos necesarios para estudiar, primero, y desarrollar nuestra carrera profesional, después. Sin embargo, en algún momento de nuestras vidas nos habíamos preguntado, y algunas seguimos haciéndolo: ¿Somos distintas? ¿Por qué somos tan pocas mujeres? ¿Qué ocurre en las empresas? La mayor parte de nuestros compañeros nos habían tratado como iguales y habíamos conseguido hacer aquello que anhelábamos: disfrutar con nuestro trabajo. Desgraciadamente, hemos visto compañeras que han abandonado la carrera profesional, o que no han progresado en su carrera igual que otros varones con trayectorias similares. Incluso hemos sufrido cómo 


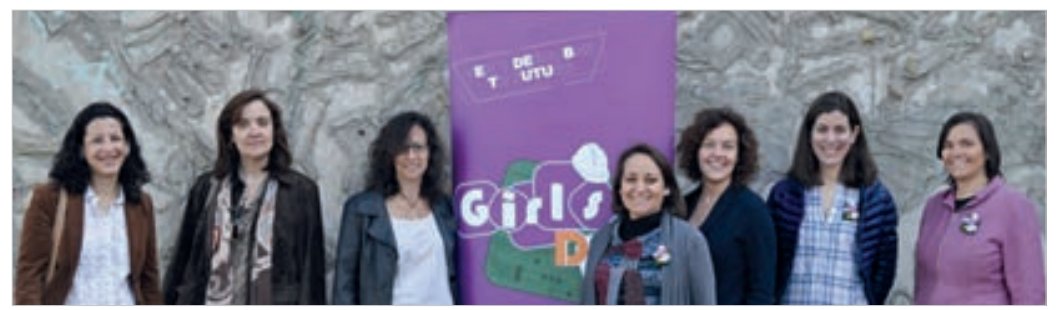

Organizadoras del Girls' Day en Aragón: (de izquierda a derecha) Sagrario Embid, Carmen Mayoral, Sandra Baldassarri, Mayte Lozano, Pilar Molina, Raquel Trillo y María Villarroya.

nuestros compañeros, con menos méritos, conseguían posiciones superiores a las nuestras. ¿Se trataba de casos aislados? Podrían parecer casualidades, porque en nuestro grupo de trabajo, nuestra institución o empresa, hemos sido tan pocas las mujeres que no teníamos suficiente masa crítica para comparar.

Después de varios años en la organización del Girls' Day, con la experiencia adquirida a través de la evaluación continua realizada por asistentes, alumnado y profesorado, y con el bagaje obtenido en los estudios sociológicos llevados a cabo, podemos afirmar que la celebración del Girls' Day es un éxito. Por ello, hemos decidido compartir esta experiencia que seguro aportará instrumentos útiles a quienes, bien dentro de la comunidad educativa o bien fuera de ella, persigan con la organización de eventos similares la transformación a una sociedad más igualitaria, en particular en el campo de la ciencia y la tecnología. 


\section{¿Por qué es necesario un Girls' Day?}

María Villarroya Gaudó 
Las mujeres no llegan al 30\% del alumnado de estudios de las ramas técnicas (ingenierías y arquitectura). Esta proporción, lejos de aumentar con el paso de los años, se ha estabilizado en la última década e incluso está sufriendo un retroceso. Está constatado que en promedio las mujeres obtienen mejores calificaciones $y$, además, finalizan antes sus estudios superiores; pero a la hora de decidir acerca de su futuro profesional se decantan, en general, por una serie de profesiones consideradas como «típicamente femeninas», fundamentalmente porque la presión social sigue marcando este papel.

A modo de ilustración, mostramos qué ocurre en la Universidad de Zaragoza; si bien hemos analizado estadísticas de distintas regiones y países y siempre predomina la infra representación de las mujeres, podemos encontrar pequeñas variaciones de unos lugares a otros y, también, dentro de las distintas disciplinas técnicas, casi anecdóticas. Así, Aragón no es una excepción.

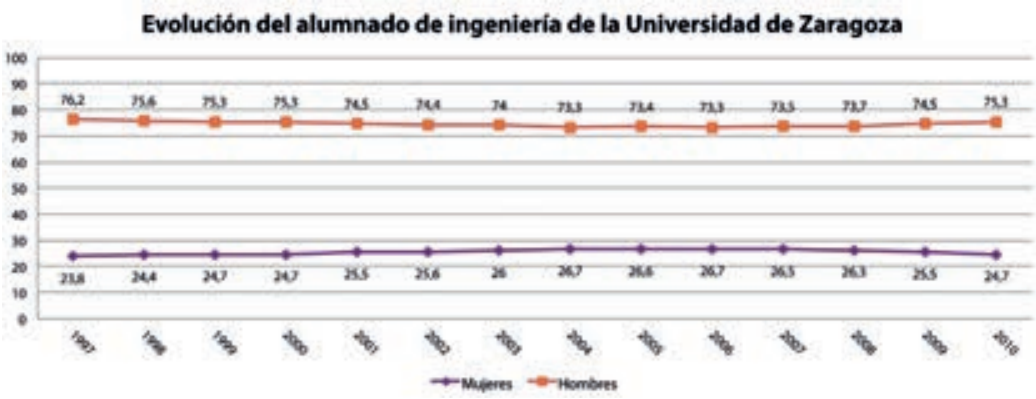

Gráfica 1. Evolución del alumnado matriculado en estudios de ingeniería en la Universidad de Zaragoza, entre los años 1997 y 2010. Fuente: Datos obtenidos del Diagnóstico de la Situación Respecto a la Igualdad de Género en la Universidad de Zaragoza, elaboración propia. 
Consultando el «Diagnóstico de la Situación Respecto a la Igualdad de Género en la Universidad de Zaragoza», editado en el año 2011, observamos que en el curso 1985-1986 las mujeres formaban el $51 \%$ del alumnado que finalizaba estudios de ciclo largo y el $70 \%$ en el caso de estudios de ciclo corto. Al analizar en detalle el caso de los estudios de ingeniería y arquitectura, que es el de interés en este caso, solo el $7,8 \%$ de quienes acababan ingenierías superiores eran mujeres $y$, en el caso de las ingenierías técnicas, esta proporción aumentaba al $17,6 \%$.

Del citado estudio comprobamos que la presencia de mujeres en ingeniería se ha mantenido estable. En la gráfica 1 observamos que, entre los años 1997 a 2010 , la presencia de mujeres en ingeniería ha pasado del $23,8 \%$ al $24,7 \%$, alcanzando un máximo entre los años 2004 y 2006 del 26,7\%. Es preciso conocer que en estos años han aparecido nuevas titulaciones, como arquitectura e ingeniería de diseño industrial, con amplios porcentajes de mujeres matriculadas, con lo cual esta tendencia al alza no es proporcional en cada titulación. Estos datos indican que dejar pasar el tiempo no va a cambiar la situación.

Conforme se progresa en la escala profesional y académica, la presencia de mujeres en ingeniería y tecnología va disminuyendo, tal y como ocurre en otras ramas profesionales o de conocimiento.

La gráfica 2 muestra la evolución del profesorado en áreas técnicas en la Universidad de Zaragoza desde 1999, según datos del Observatorio de Igualdad

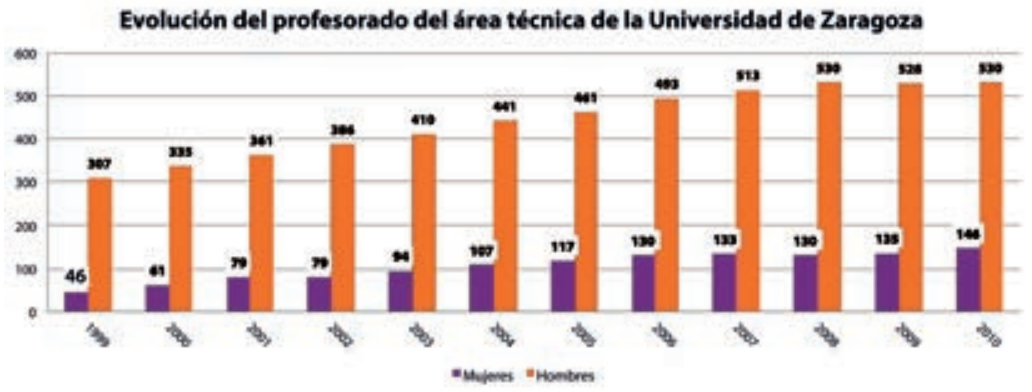

Gráfica 2. Evolución del profesorado en áreas técnicas de la Universidad de Zaragoza, entre los años 1999 y 2010. Fuente: Datos obtenidos del Diagnóstico de la Situación Respecto a la Igualdad de Género en la Universidad de Zaragoza, elaboración propia. 
de Género de la Universidad. La presencia de mujeres ha crecido ligeramente (también el número de puestos totales en este periodo), creciendo el porcentaje de mujeres profesoras del $13,0 \%$ al $21,6 \%$ en el periodo representado. Fijando la atención en la categoría más alta, en la escala de Cátedras de Universidad en ingeniería y tecnología, solo el 7,2\% son mujeres, en el promedio de toda la universidad, alcanzan el $16,2 \%$.

Distintos estudios sociológicos indican que una presencia inferior al $30 \%$ supone ser una minoría y, como tal, debe ser tratada, para evitar así riesgos de exclusión. Es decir, las mujeres en ingeniería son una minoría y es recomendable trabajar por cambiar esta tendencia.

Atraer a las chicas a la ingeniería no es una tarea fácil, algunos estudios demuestran que ellas tienen más actitudes negativas hacia las tecnologías de la información que ellos. Llegar al porqué de esta situación podría ayudarnos a motivar a algunas. Desde luego no hay una solución simple, pero tratar de acercar a las chicas en la enseñanza primaria y secundaria a la tecnología e ingeniería puede ayudar.

En teoría, las chicas y los chicos tienen libertad de elección de profesión y, por tanto, de estudios. Sabemos que estas elecciones están condicionadas por el entorno familiar, la educación reglada y no reglada, la motivación por realizar diversas actividades $y$, sobre todo, el apoyo recibido. La sociedad en la que vivimos es la herencia de un sistema patriarcal, donde los hombres han sido quienes se han dedicado a los trabajos fuera del hogar y las mujeres a las tareas de cuidado de la familia. Los impedimentos legales existentes para que las mujeres accediesen a la formación y a la educación y también al desempeño de las distintas profesiones han ido desapareciendo en el último siglo. Si bien, estos roles tradicionales todavía perviven en la sociedad y consciente o inconscientemente se siguen transmitiendo de madres y padres a hijas e hijos.

En las últimas décadas ha habido grandes cambios en esta línea, pero todavía queda un gran camino para alcanzar esta igualdad efectiva, lo que nos lleva a la necesidad de realizar actividades que, en cierto modo, compensen las desigualdades de oportunidades reales que algunas chicas encuentran para poder realizar estudios de ingeniería.

Con la intención de ampliar este espectro de posibilidades sobre el que las chicas puedan decidir su futuro académico y profesional, surge la idea de organizar este evento de manera pionera en nuestro país. Pretendemos con esta jornada despertar más vocaciones técnicas entre las alumnas participantes. 


\section{Acciones para promover la presencia de mujeres en ingeniería en el mundo}

M. Carmen Mayoral Gastón

Pilar de Luis Carnicer 


\section{Antecedentes}

En 2001, en Alemania se establece una iniciativa conjunta entre el Ministerio de Educación, Ministerio de Asuntos Familiares, el Fondo Social Europeo y la Unión Europea en la que empresas predominantemente industriales y tecnológicas invitan a alumnas de primaria y secundaria a visitar sus instalaciones. El 26 abril de ese año, se realiza la primera jornada denominada Girls' Day. Desde entonces, cada año, un día de abril, miles de entidades, empresas del ámbito tecnológico y científico, departamentos de $\mathrm{I}+\mathrm{D}+\mathrm{i}$, universidades y centros de investigación organizan una jornada de puertas abiertas en la que las alumnas de entre 10 y 15 años contemplan un gran número de actividades y opciones profesionales, consideradas tradicionalmente como masculinas, con el fin de influir de forma positiva en su futura selección de estudios. Las estudiantes toman parte activa en las visitas, diseñadas con la intención de motivarlas a ampliar sus opciones de futuro laboral e incluso a decidirse a favor de una formación técnica.

El éxito de la campaña ha sido tal que, en la actualidad, cada año se reciben más de 120000 alumnas en más de 1000 eventos diferentes en todo el país en la jornada Girls' Day. Ya son más de un millón de alumnas participantes desde el inicio.

La organización del Girls' Day ha pretendido, desde el principio, involucrar también al entorno de las estudiantes (familias, centros educativos y medios de comunicación) a participar en la campaña para cambiar la actitud tradicional sobre la orientación vocacional, aportando información y asesoría personalizada y realizando estudios y evaluaciones estadísticas sobre la influencia de distintos parámetros sobre la intención vocacional de las alumnas.

La campaña ha permitido, a su vez, obtener una gran cantidad de datos estadísticos en los dos campos de trabajo: en el alumnado y en las empresas. Estos datos se encuentran publicados (en alemán) en la página web de la organización; como uno de los resultados más importantes se destaca la evolución positiva de las empresas en la tasa de contratación de mujeres en puestos 


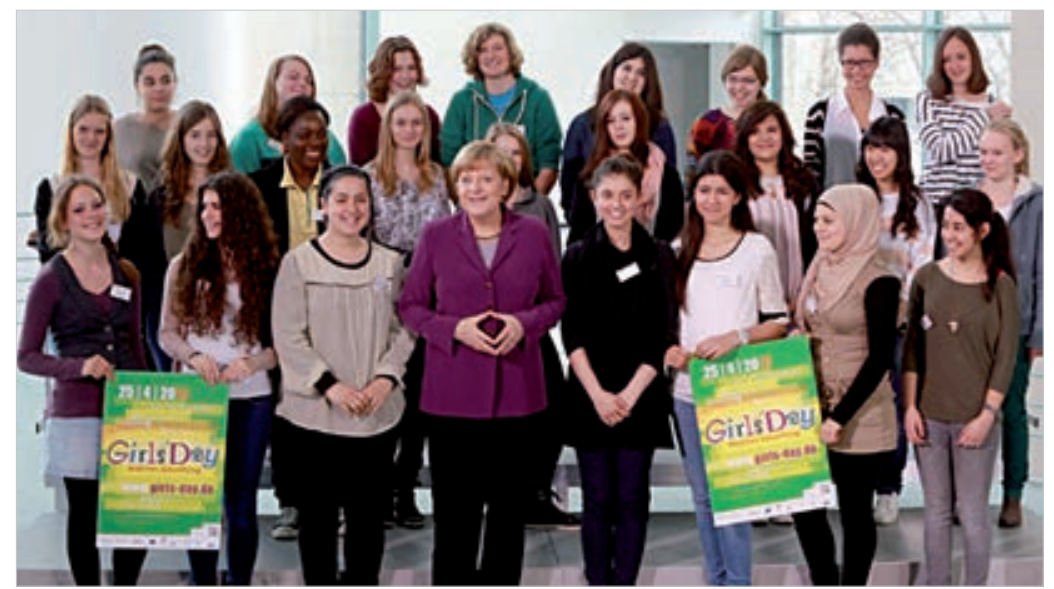

La presidenta de Alemania, Ángela Merkel, inaugurando el Girls' Day de 2013.

técnicos. Además, se observa la tendencia por parte de las empresas a ofrecer prácticas y contratos y a proporcionar más información sobre oportunidades laborales a los grupos de estudiantes que han participado en la actividad. Este resultado se considera un éxito ya que el objetivo principal de la jornada Girls' Day era aprovechar el talento y aptitudes para las ramas técnicas y científicas de las alumnas, normalmente dirigido a otras áreas por tendencias de género tradicionales.

Desde el punto de vista del impacto de las jornadas Girls' Day sobre las vocaciones de las alumnas, el estudio refleja que el grado de satisfacción con la organización del evento es muy alto ya que:

- Más de un $37 \%$ de las alumnas se ven a sí mismas trabajando en un puesto similar al que han visitado en la jornada.

- Los centros educativos participantes han mejorado en la evaluación de aptitudes y vocaciones disminuyendo los sesgos de género.

- Desde 2007 ha habido un significativo crecimiento en el número de alumnas que eligen carreras tecnológicas.

La iniciativa alemana fue paulatinamente emulada en países como Austria, Luxemburgo, Holanda, Bélgica, Polonia, Suiza, España y Liechtenstein, con distintos modelos de colaboración entre las instituciones educativas y las empresas, y con financiación nacional y local. El evento Girls' Day también se está iniciando en otros países como República Checa, Kosovo y Hungría. 
En general, todas estas iniciativas difieren del ejemplo alemán en la estructura organizativa. En Alemania, las instituciones detectaron un déficit de profesionales técnicos, por lo que establecieron un vínculo entre las empresas y las estudiantes de secundaria para aumentar su interés por ese futuro profesional. La participación empresarial y el compromiso de continuidad es lo que ha estructurado el crecimiento anual del evento. En el resto de los países, con menor tejido empresarial, la iniciativa suele partir o bien de los propios centros educativos o de las universidades, con la intención de eliminar los sesgos de género en la elección académica y profesional. Este es el caso de la iniciativa española, que comenzó en 2008 en la Universidad de Zaragoza, partiendo del interés de un grupo de docentes de la Escuela de Ingeniería y Arquitectura en mostrar las carreras técnicas a alumnas de secundaria y, con ello, compensar el bajo porcentaje de matriculación de alumnas.

\section{El Girls’ Day en España}

Las distintas iniciativas Girls' Day en España tienen un denominador común: parten del interés de grupos de profesoras de universidad que han encontrando apoyo y financiación en su universidad y en otras instituciones. Las otras universidades donde también se ha realizado o se realiza la celebración del Girls' Day en España son:

La Universidad de Oviedo introdujo el primer Girls' Day en diciembre de 2009. Para su organización, la Fundación Universidad de Oviedo y la Escuela Politécnica Superior de Ingeniería de Gijón (EPI) han colaborado con el Vicerrectorado de Estudiantes y Empleo de la Universidad de Oviedo, con entidades como AMIT (Asociación de Mujeres Investigadoras y Tecnólogas), la Universidad de Zaragoza, el IEEE (Institute of Electrical and Electronics Engineers), o el Colegio Oficial de Ingenieros Superiores Industriales de Asturias y León, así como la asociación de alumnos y alumnas de la Escuela y el profesorado. La primera edición, en la que participaron 212 alumnas y alumnos de secundaria, fue en diciembre de 2009, en el marco del proyecto GENIUNIOVI, y consistió en una mesa redonda titulada Decide sin estereotipos, con posteriores visitas grupales a laboratorios. La segunda edición, en marzo de 2011, acogió a más de 120 participantes; consistió en una mesa redonda titulada ¿En qué puedes trabajar si estudias una Ingeniería? y, de nuevo, las visitas a los laboratorios del campus. La tercera fue en febrero de 2012, con un contenido similar a las anteriores ediciones y en ella participaron más de 200 estudiantes de Bachillerato y $4 .{ }^{\circ}$ de la ESO, procedentes de centros educativos de distintos municipios de Asturias. 
La Universidad de Lleida realizó, el 5 de noviembre de 2010, la jornada titulada Per què no puc fer-ho? (¿Por qué no puedo hacerlo yo?), dirigida al alumnado de $4 .^{\circ}$ de la ESO para la presentación de los estudios universitarios sin estereotipos de género. Se presentaron los estudios de la Escuela Politécnica Superior (ingenierías) a las alumnas con visitas guiadas a diversos laboratorios de investigación. Por otra parte, se presentaron a los alumnos profesiones feminizadas, como son las de la rama de educación en la Facultad de Ciencias de la Educación (Educación Social), con talleres prácticos en aulas de enseñanza. Fue organizada por el Centre Dolors Piera d'Igualtat d'Oportunitats i Promoción de les Dones de la Universitat de Lleida, con el apoyo del Instituto de Ciencias de la Educación, de la Escuela Politécnica Superior, de la Facultad de Ciencias de la Educación y del Vicerrectorado del Estudiantado de la Universitat de Lleida, y la colaboración del Ministerio de Igualdad, Instituto de la Mujer y el Fondo Social Europeo. En su segunda edición, el 28 de octubre de 2011, se presentaron los estudios de la Escuela Técnica Superior de Ingeniería Agraria, concretamente el grado de Ingeniería Forestal, a las chicas, aprovechando que fue el Año Internacional de los Bosques y los estudios de la Facultad de Enfermería, a los chicos. Las actividades previstas incluyeron una presentación de los estudios mencionados, sus salidas profesionales y visitas guiadas a diversos laboratorios de investigación de la Escuela Técnica Superior de Ingeniería Agraria y de la Facultad de Enfermería donde se realizaron talleres prácticos. En su tercera edición, el 9 de noviembre de 2012, se presentaron las ingenierías de la Escuela Politécnica Superior a las chicas y los estudios de la Facultad de Letras, concretamente los grados de Filología, a los chicos.

La Escuela Técnica Superior d'Enginyeria (ETSE) de la Universidad Rovira i Virgili de Tarragona celebró, el 28 de mayo de 2010, la jornada de Girls' Day en colaboración con el Observatorio de Igualdad. La actividad consistió en la invitación a alumnas de tercero de la ESO de diversos centros de Secundaria de la provincia de Tarragona a asistir a una jornada para conocer las titulaciones de ingeniería en la ETSE. En aquella edición la participación fue de unas cuarenta alumnas. Durante la actividad se dieron a conocer las diferentes opciones de titulaciones en ingeniería que ofrece la universidad, y participaron de la realización de experimentos en los laboratorios donde pudieron manipular algunos de los equipamientos de la Escuela. Hablaron con investigadoras e ingenieras sobre la profesión y las diferentes opciones laborales. También, hicieron una visita por el Campus para ver las instalaciones y conocer el ambiente universitario. La celebración acabó con la entrega de un certificado de asistencia a las alumnas participantes. 
En el curso 2012-2013, se está trabajando para hacer una nueva edición que dé continuidad a esta iniciativa y, así, dar cumplimiento al II Plan de Igualdad de la Universidad Rovira i Virgili.

La Universidad Politécnica de Cataluña (UPC) se sumó a la iniciativa internacional Girls' Day con una jornada de reflexión y debate sobre el papel de la mujer en el mundo de la ciencia y la tecnología, en formato de mesas redondas: una sobre la visión desde el mundo académico y empresarial sobre la igualdad de oportunidades en el mundo profesional y otra sobre la opinión de los y las estudiantes sobre qué significa ser una estudiante en la UPC. Fue un éxito inesperado, con la participación de jóvenes investigadoras que se congratularon de encontrar aquel espacio de reflexión. La jornada no se centró en la captación de nuevas alumnas, ya que, para la promoción de los estudios, la UPC cuenta con el Servicio de Comunicación y Promoción (SPC), que programa las diferentes acciones en este ámbito. Sin embargo, sí se le dio importancia a la colaboración entre la enseñanza secundaria y universitaria en el fomento de vocaciones científicas y tecnológicas entre las estudiantes en una sesión de trabajo con el Instituto de Ciencias de la Educación de la UPC. En esta sesión se analizó la demanda de vocaciones en el ámbito de las ingenierías, y se realizó un taller con el objetivo de proporcionar herramientas y recursos aplicables al aula para incentivar las vocaciones científicas y tecnológicas, especialmente en las niñas.

\section{Campañas más recientes}

\section{Science: it's a girls' thing! de la Comisión Europea}

El 21 de junio de 2012, la Comisión Europea lanzó una campaña de comunicación para animar a las adolescentes al estudio de materias del ámbito científico y promover las vocaciones en carreras investigadoras. ' Este lanzamiento tuvo lugar en la explanada del Parlamento Europeo en Bruselas, donde chicas y chicos tuvieron la oportunidad de tomar parte en distintas actividades para ponerse en contacto con la ciencia, la experimentación, la investigación y el debate, de forma lúdica.

La campaña continúa todo el año 2012 viajando con una exposición interactiva móvil visitando distintas ciudades de Austria, Alemania, Italia, Holanda y Polonia, estando prevista su continuidad por otros países a lo largo de 2013. 
El motivo de esta campaña es que la baja presencia de mujeres en ciencia, tecnología e investigación se considera como una pérdida del potencial talento de las chicas. La campaña pretende cambiar los estereotipos de género en ciencia, mostrando a la juventud, especialmente a las chicas, que la ciencia es una gran oportunidad de futuro. Está organizada por la Dirección General de Investigación e Innovación de la Comisión Europea.

Los distintos talleres fueron organizados por las tres instituciones participantes:

- European Schoolnet (EUN, www.eun.org), red de treinta ministerios de Educación europeos, creada hace diez años para estimular la innovación en enseñanza, con el soporte de la Unión Europea.

- INQUIRE, proyecto financiado por la EU para potenciar el aprendizaje y conocimiento por la investigación, búsqueda de información y cuestionamiento.

- Greenlight for Girls Foundation, organización de Bruselas fundada en noviembre de 2011 para promover una mayor presencia femenina en la ciencia, la tecnología, la ingeniería y las matemáticas (STEM).

La campaña tiene sus dos pilares básicos en la comunicación directa con las y los estudiantes, a través de una página web dinámica y Facebook, para que se acerquen a la ciencia, y en el concepto role model, mujeres profesionales jóvenes y maduras de la ciencia que transmitan su pasión a las adolescentes. Difiere de otras campañas en que no hay una intervención directa ni de los centros educativos, ni de universidades, ni de empresas, sino que se pretende encontrar el interés personal de las adolescentes al mundo de la ciencia y ponerla en contacto con ejemplos de mujeres profesionales. En este sentido se puede considerar como una campaña más moderna y potente que otras más estructuradas como el Girls' Day alemán, centrado en las visitas a empresas, o el modelo español, que parte de la iniciativa docente universitaria.

\section{Día Internacional de las niñas en las Tecnologías de la Información y las Comunicaciones}

Se trata de una campaña anual organizada por UIT (Unión Internacional de Comunicaciones) que viene desarrollándose desde 2011, cada cuarto jueves de abril, en diversos países de América Latina, coordinada por la Cátedra Unesco. ${ }^{2}$ 
Su fin es alentar a las niñas y mujeres jóvenes a interesarse y, eventualmente, optar por carreras en Tecnologías de la Información y la Comunicación. Se trata también de empoderarlas para desempeñar su profesión satisfactoriamente en este campo. Ese día, la UIT invita y alienta a los Ministerios de Comunicación, Educación, los organismos reguladores nacionales, las empresas del sector privado, instituciones docentes y ONG a organizar eventos locales o nacionales relacionados con el Día Internacional de las Niñas en las TIC, dirigidos a las adolescentes y estudiantes universitarias, de modo que comprendan las oportunidades que ofrece el sector de las TIC para su futuro. 


\section{¿Cómo se organiza el Girls’ Day?}

SANDRA BALDASSARRI

Mayte Lozano Albalate

Ana Cris Murillo Arnal

RaQuel Trillo Lado 
El objetivo perseguido con el Girls' Day consiste en la organización de un evento de impacto autonómico, de forma que todas las alumnas de Enseñanza Secundaria y Bachillerato de la Comunidad Autónoma de Aragón puedan vivir un acercamiento al mundo de la ingeniería, la tecnología y la investigación. La metodología empleada para llevar a cabo dicho objetivo se describe a continuación, detallando las diferencias entre las distintas ediciones.

Con más de un mes previo al evento se remitió por correo electrónico información, a todos los centros públicos, concertados y privados de la comunidad autónoma. Se presentaban sus objetivos y se explicaba la forma de participación de los mismos. En la primera edición, también se envió material de presentación de la actividad para las familias, y documentación para que el profesorado de los centros expusiera la actividad a sus clases. Además, se remitió a los centros un cuestionario previo para recabar información acerca de la motivación del alumnado y su conocimiento acerca de la ingeniería, tecnología, ciencia, etc.

Para solicitar su participación en el evento, los centros educativos debían inscribirse indicando número de alumnos y alumnas participantes, curso, etc. El número total de participantes que se podía acoger en cada edición sufrió grandes variaciones, debidas principalmente a temas presupuestarios. Este hecho ocasionó, por tanto, diferencias a la hora de seleccionar los centros participantes, aunque en todos los casos se intentó mantener una selección representativa de centros.

Durante la participación en el Girls' Day, las personas asistentes reciben información y realizan visitas guiadas por los laboratorios de investigación de los distintos campus tecnológicos. De forma combinada, las estudiantes visitan empresas en aquellos sectores industriales y tecnológicos donde las mujeres se encuentran subrepresentadas. Dada la extensión geográfica de nuestra comunidad, se planificaron visitas que combinen aspectos científicos y empresariales, en función de la ubicación del centro escolar y de las instituciones y empresas participantes en cada ocasión. 


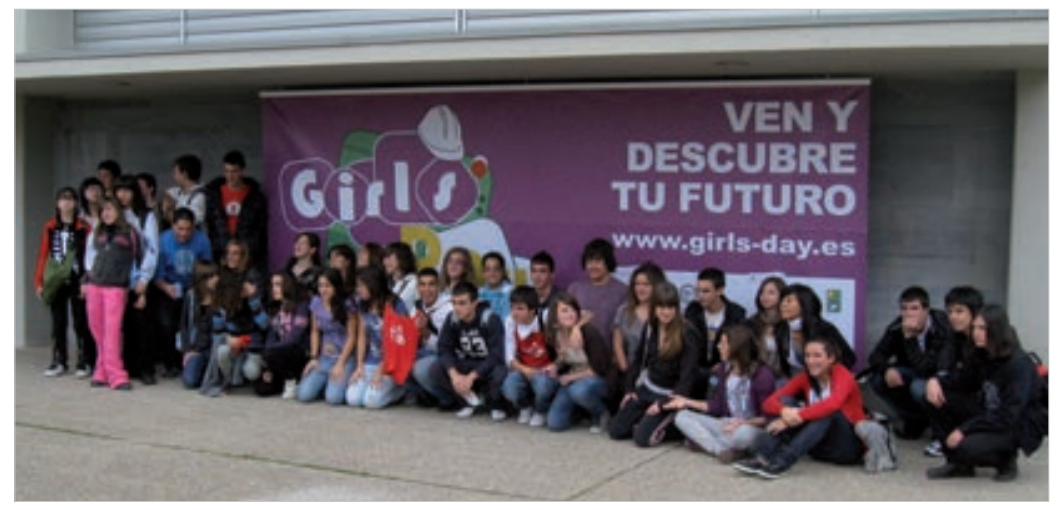

Un grupo de estudiantes de secundaria que participó en la edición del Girls’ Day 2011, en la puerta del edificio Ada Byron de la Escuela de Ingeniería y Arquitectura.

Las visitas se organizaron de forma similar en las diferentes ediciones de las jornadas: asistencia a sesiones plenarias, organización en grupos reducidos y actividades en paralelo, y realización de encuestas de satisfacción y despedida. Las principales diferencias entre unas ediciones y otras radicaron en el modo de llegada del grupo (transporte subvencionado, transporte público, etc.), la duración de las visitas (jornada completa o media jornada), el tamaño de los grupos en que se organizaban las diferentes actividades y el tipo de representación de las empresas (en un stand o con visitas guiadas).

En relación con el perfil del alumnado, la primera edición se orientó a cuarto curso de Educación Secundaria Obligatoria (ESO) y primer curso de Bachillerato. En la segunda ocasión, debido a que las encuestas realizadas el año anterior demostraban que en cuarto curso la mayor parte ya había tomado una decisión sobre los estudios a realizar y, por lo tanto, el nivel de influencia sobre el alumnado de estos cursos era muy bajo, se decidió centrar el objetivo en alumnado de tercer curso de la ESO. La tercera edición se orientó nuevamente al alumnado de tercer curso de la ESO. Sin embargo, en la cuarta edición, se optó por fijar el grupo objetivo en aquellas personas que quisieran acudir libremente al evento. En este caso, para que el alumnado de secundaria pudiera asistir, la jornada se planificó solo en horario de tarde. En esta última edición, hay que destacar como positivo que el interés por las actividades ha sido mucho mayor debido en gran medida a que nadie había sido obligado a asistir, como podía pasar en alguno de los grupos de ediciones anteriores, donde el profesorado venía en la 


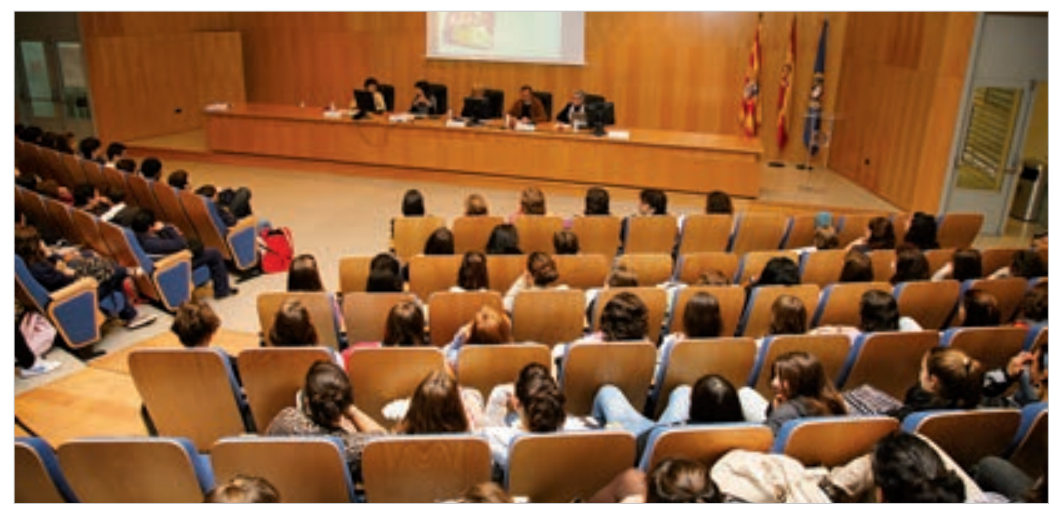

Acto inaugural del Girls’ Day 2009 en la Escuela de Ingeniería y Arquitectura de la Universidad de Zaragoza.

mayor parte de los casos con toda su clase, independientemente de su motivación y/o interés.

Las sesiones plenarias son comunes a todos los grupos asistentes y persiguen formar y motivar la elección de titulaciones relacionadas con la ingeniería y la tecnología mediante una charla o conferencia de entre treinta y cuarenta y cinco minutos. Las diferentes sesiones que se han organizado abarcan desde conferencias impartidas por investigadoras expertas en ciencia y género, como Eulalia Pérez Sedeño (profesora de Investigación del CSIC, Consejo Superior de Investigaciones Científicas), conferencias de presentación de las diferentes carreras y salidas profesionales en el campo científico-tecnológico que se ofrecen en los diferentes Campus de la Universidad de Zaragoza, hasta charlas de antiguas alumnas, como la impartida por la ingeniera Laura Lacarra (reciente titulada en Ingeniería Informática de la Universidad de Zaragoza). Al alumnado asistente le resultaron particularmente atractivas las charlas en que una recién licenciada explicaba puntos de vista sobre las ingenierías y sobre su propia carrera profesional (formación previa, estudios universitarios, adaptación al mundo laboral, etc.), probablemente debido a que ofrecía una imagen más cercana y se identificaban en mayor medida con la persona que impartía la charla.

En cada edición se realiza un acto institucional, con la participación de diferentes personas en representación de diversas instituciones, tanto de la propia universidad, como del gobierno local y autonómico. Estos actos institucionales están abiertos al público general, pero se destinan principalmente al profesorado 


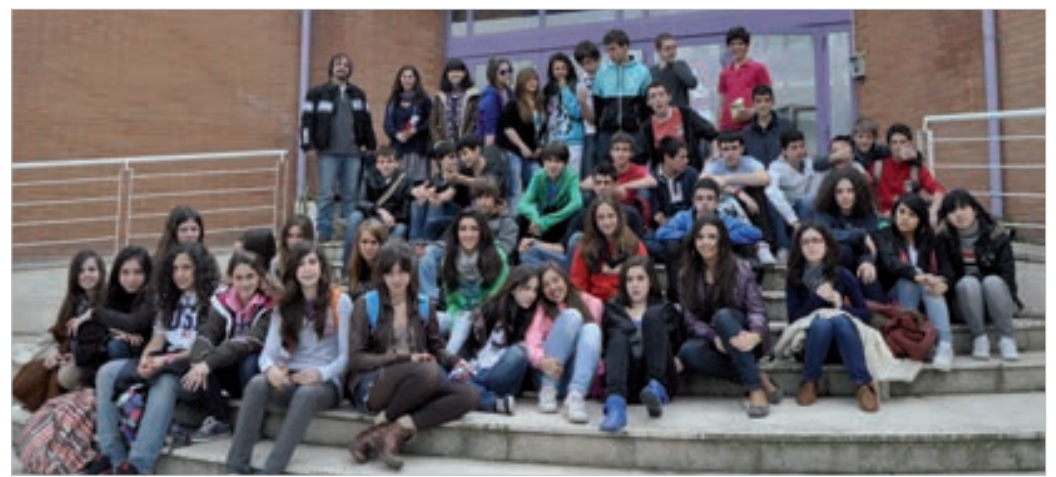

Estudiantes a la salida de la visita del Instituto de Carboquímica del CSIC en 2011.

de educación secundaria y a los medios de comunicación, y suelen incluir una rueda de prensa.

Las actividades, llevadas a cabo en grupos reducidos (generalmente entre 8 y 15 estudiantes), tienen como objetivo que se entre en contacto con diferentes ramas del sector de la ingeniería y tecnología mediante la realización de pequeñas tareas que resulten atractivas. Durante las cuatro ediciones del Girls' Day en Zaragoza, se han llevado a cabo múltiples visitas y talleres organizados por diferentes grupos de investigación de distintos departamentos y centros de la Universidad de Zaragoza o vinculados de algún modo con la misma (cátedras empresa-universidad, institutos universitarios de investigación, spin-off, fundaciones, etc.). También se ha contado con la participación de numerosas empresas relacionadas con el sector de la ingeniería y las tecnologías de la información y la comunicación. Durante las visitas a los laboratorios y empresas, los grupos de estudiantes eran acompañados por voluntarias, todas ellas estudiantes de diversas carreras de ingeniería. De este modo, mientras se desplazaban de un lugar a otro, las voluntarias podían contar sus experiencias y los alumnos y alumnas podían tener información de primera mano, y de alguien cercano a ellas y ellos en edad e intereses, acerca del mundo de la universidad y los estudios, y en particular en las áreas técnicas. Por otra parte, los proyectos en los laboratorios fueron presentados, prácticamente en su totalidad, por investigadoras de las áreas correspondientes. Y, en el caso de las empresas, generalmente, eran directivas, ingenieras o desarrolladoras quienes presentaban su trabajo y sus productos. 


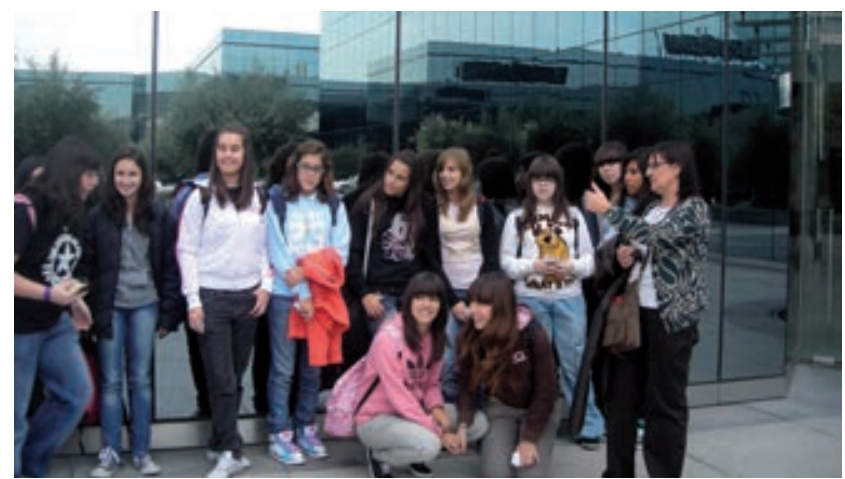

Estudiantes visitando Microsoft en el Girls’ Day 2009.

Durante la jornada, los grupos de alumnas y alumnos podían visitar, al menos, dos laboratorios de investigación y una empresa, en aproximadamente unas tres horas. Las compañías ofrecían la oportunidad de observar y experimentar diferentes tecnologías, generalmente relacionadas con temas punteros en desarrollo, innovación e investigación (por ejemplo, cocinas de inducción, aplicaciones informáticas, resistencia de materiales, etc.). Las visitas a los laboratorios de investigación fueron diseñadas como sesiones interactivas orientadas principalmente a la participación activa, y teniendo en cuenta la edad del alumnado. En las demostraciones, se ha prestado especial atención en mostrar estudios y aplicaciones de investigaciones que tienen un impacto social positivo.

Dos empresas con sede en Madrid, Microsoft e Indra, han participado en varias ediciones. Para ello, pusieron a disposición del Girls' Day autobuses para que cincuenta alumnas de centros aragoneses pudieran ir a cada una de ellas y ver, in situ, el trabajo y la investigación que llevan a cabo, el entorno laboral, los grupos de trabajo y, especialmente, las mujeres que ocupan puestos de relevancia en dichas empresas.

En la primera edición, se organizó un stand en el cual ocho empresas de base tecnológica (seleccionadas entre treinta compañías que mostraron interés) pudieron exponer, de forma atractiva y participativa, la innovación y el desarrollo de cada una y sus políticas de inclusión de mujeres. Además de la presentación en el stand, varias de ellas se ofrecieron para organizar también visitas guiadas a sus propios establecimientos. 


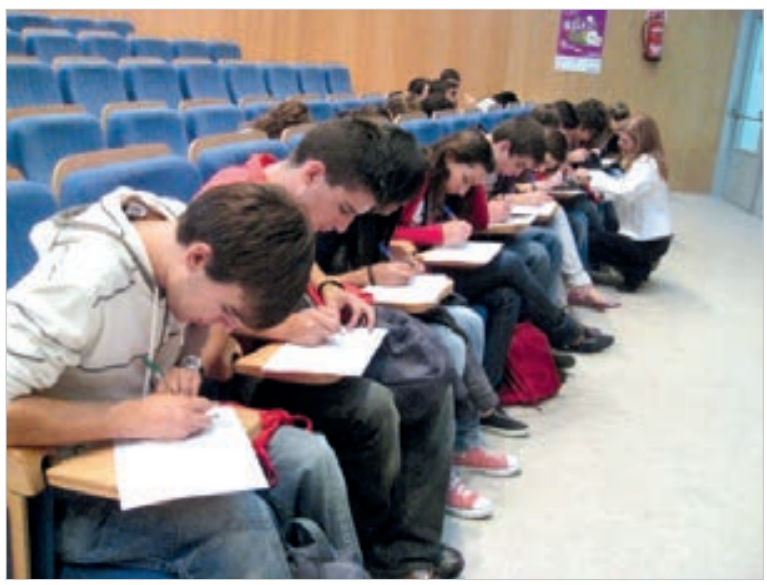

Estudiantes de secundaria realizando la encuesta al final de la visita del Girls’ Day 2009.

En la segunda edición, se suprimió el formato de participación de empresas en el stand y se decidió potenciar las visitas realizadas directamente a determinadas empresas, ubicadas en diversas localidades de la Comunidad Autónoma de Aragón, que abrieron sus puertas para recibir a grupos de alumnos en sus instalaciones, como General Motors, Telefónica, etc.

En la tercera edición, al igual que en la anterior, se visitaron empresas. Pero esta vez, no solo participaron departamentos y laboratorios de investigación en el Campus Río Ebro (Zaragoza) sino que se amplió el alcance a otros centros de la Comunidad Autónoma de Aragón, participando también el Centro Universitario de la Defensa, Campus de la Almunia, de Huesca y de Teruel, de la Universidad de Zaragoza.

En la cuarta edición, se realizaron visitas guidadas a diferentes laboratorios de investigación situados en el Campus Río Ebro y en el Campus de Teruel de la Universidad de Zaragoza y a empresas de ámbito técnico con sede en estos campus participantes.

La organización de la actividad resulta compleja debido a la cantidad de personas, instituciones y organismos implicados, así como a la diferente naturaleza de cada uno de ellos. Centralizar los datos de contactos, conocer las ubicaciones de cada laboratorio a visitar y las personas responsables, crear los grupos e itinerarios de las visitas supone un enorme esfuerzo organizativo. Para facilitar esta labor, se ha creado una aplicación informática, GAT, Girls' Day Application Tool 
que agiliza todos los procedimientos y nos permite tener toda la información actualizada y fácilmente accesible. Los detalles técnicos de la aplicación se presentan en el anexo $D$. 


\section{Experiencias del Girls' Day en Aragón}


La actividad del Girls' Day en Aragón ha sido coordinada por un grupo de profesoras e investigadoras de la Universidad de Zaragoza, la mayoría de ellas de la Escuela de Ingeniería y Arquitectura. Esta escuela (creada en 2012 como fusión del Centro Politécnico Superior y la Escuela Universitaria de Ingeniería Técnica Industrial) es el mayor centro de estudios técnicos de la Comunidad Autónoma. En esta escuela se pueden cursar estudios de Arquitectura, Ingeniería de Diseño Industrial y Desarrollo de Producto, Ingeniería Eléctrica, Ingeniería Mecánica, Ingeniería Electrónica y Automática, Ingeniería Química, Ingeniería de Tecnologías Industriales, Ingeniería Informática e Ingeniería de Tecnologías y Servicios de Telecomunicación. La gran variedad de titulaciones impartidas hace que durante las visitas se muestre una visión muy amplia de la ingeniería.

Participan también en distintas ediciones profesoras de otros centros con estudios técnicos de esta universidad: la Escuela Universitaria Politécnica de Teruel, la Escuela Politécnica de Huesca y los centros adscritos: la Escuela Universitaria Politécnica de la Almunia y el Centro Universitario de la Defensa. Los centros situados fuera de Zaragoza contaban con un equipo organizador propio.

\section{La experiencia del Girls' Day en Zaragoza \\ Mayte lozano Albalate, Ana Cris Murillo Arnal, RaQuel Trillo Lado}

En el transcurso de las diferentes ediciones del Girls' Day celebrado en Zaragoza, se han vivido diferentes experiencias y acumulado numerosas anécdotas. A continuación, se describen algunas de las actividades con mayor éxito entre el alumnado asistente al evento, a modo de ejemplo ilustrativo. Posteriormente, se citan algunas opiniones de voluntarias y visitantes. 


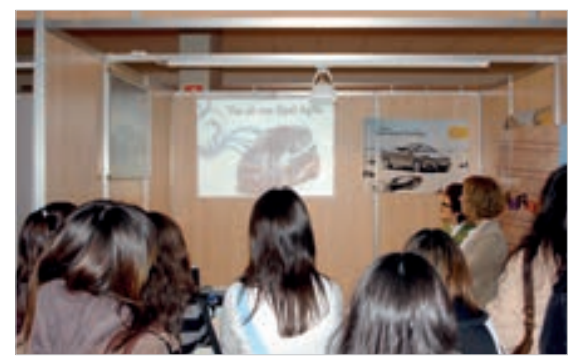

Estudiantes visitando el stand de la empresa General Motors en el Girls’ Day 2008.

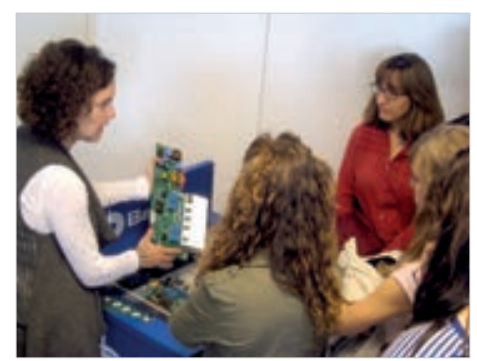

Alumnas visitando el laboratorio BSH. La profesora Pilar Molina muestra la circuitería electrónica de una cocina de inducción.

El conjunto de actividades ha sido muy variado, tanto como las diferentes formas que investigadoras y empresas tienen de comunicar la tecnología. En la primera edición, se contó con stands de empresas que de una u otra manera mostraban cómo la mujer ingeniera formaba parte de sus activos y, en algunos casos, cómo esto influía en su producto final. Por otro lado, algunas investigadoras mostraban sus laboratorios y explicaban su trabajo diario, el fin de sus investigaciones, el funcionamiento de la compleja maquinaria que manejan, o el funcionamiento de algo tan cotidiano como, por ejemplo, el aire acondicionado. Otras investigadoras apostaron por los talleres, donde los protagonistas eran los propios componentes de los grupos que nos visitaban. De modo que el alumnado pudo soldar conexiones en una placa o programar un robot, entre otros. En general, se observó que se despertaba mayor interés en el alumnado cuanta mayor implicación les exigía la actividad.

Todas las visitas a empresas y laboratorios han sido muy enriquecedoras y podrían formar parte de este libro. A continuación, a modo de ejemplo, se describen algunas de las actividades realizadas en colaboración: con BitBrain Technologies, Telefónica y Laboratorio RoPeRt de la Escuela de Ingeniería y Arquitectura de la Universidad de Zaragoza, así como la experiencia de visita a los laboratorios del Centro Universitario de la Defensa, adscrito a la citada universidad. 


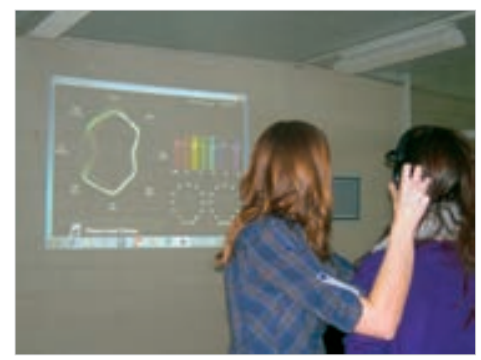

Viendo la señal cerebral y los niveles de atención y relajación de una voluntaria.

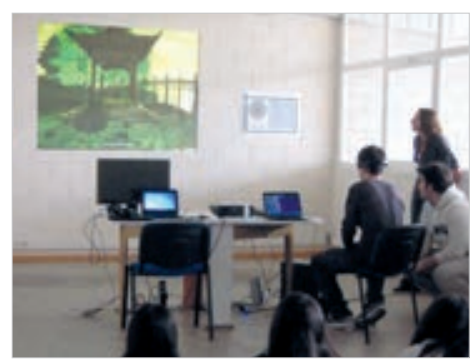

Un voluntario controlando un videojuego con la mente.

\section{Visita a una empresa tecnológica: BitBrain Technologies}

\section{María López VALDÉS}

BitBrain Technologies es una empresa spin-off de la Universidad de Zaragoza centrada en el desarrollo y comercialización de aplicaciones neurotecnológicas. Por ejemplo, BitBrain ha desarrollado herramientas que permiten mejorar las capacidades de nuestro cerebro. Para ello, BitBrain necesita realizar decodificaciones complejas de las señales cerebrales y esto es algo que se consigue gracias al trabajo de sus ingenieros e ingenieras. El personal de BitBrain es capaz de recoger la señal cerebral con unos sensores y detectar los procesos mentales que median en las capacidades cognitivas (como atención o memoria) o en las emociones.

El equipo de BitBrain está compuesto por gente joven, con una buena formación y muy alta motivación. La diversidad de su equipo es una clara ventaja competitiva, puesto que para trabajar con neurociencias es esencial la capacidad de enfocar de distintas formas un mismo problema. En este sentido, la plantilla de BitBrain está formada por personal de distintas titulaciones (principalmente ingeniería pero también matemáticas, psicología o comunicación), distintas nacionalidades y está perfectamente equilibrada en cuanto a número de hombres y mujeres.

BitBrain ha participado en el Girls' Day desde su primera edición, enseñando a chicos y chicas cómo se puede trabajar con información del cerebro e invitándoles a jugar con sus cerebros. Más concretamente, las visitas de treinta minutos en BitBrain consisten en una pequeña explicación sobre lo que se hace en la 
empresa, un trivial de preguntas sobre aspectos curiosos del cerebro, una demostración de las señales cerebrales de un voluntario o voluntaria con la decodificación en tiempo real de su nivel de atención y relajación y, por último, la oportunidad de poder jugar a un videojuego con la mente.

La participación de los chicos y chicas durante la visita ha sido siempre muy activa, la neurociencia es un tema que despierta mucho interés y les resultan tremendamente atractivas las demostraciones finales, por ejemplo, controlando videojuegos.

\section{Visita a una empresa multinacional tecnológica: Telefónica}

\section{Carmen Pellicer Lostao}

Telefónica es un operador integrado de telecomunicaciones líder a nivel mundial con presencia en 25 países y un promedio de 264000 empleados. Para Telefónica, las mujeres juegan un papel importante en la construcción de sus equipos de trabajo, especialmente en el ámbito técnico donde siempre se ha observado un desafortunado desequilibrio de género. Por ello, desde esta empresa se trabaja activamente para la no discriminación de género en el entorno de trabajo y la conciliación de la vida laboral y personal. La compañía valora y tiene gran interés en apoyar aquellas iniciativas que fomenten la participación profesional de la mujer en los campos tecnológicos.

La participación de Telefónica en el Girls' Day tiene como objetivo dar a las jóvenes la oportunidad de conocer la realidad de las telecomunicaciones: ¿cómo se hace posible que funcionen los dispositivos móviles desde cualquier lugar de España?, ¿cómo Internet nos conecta a 1,9 mil millones de usuarios y usuarias en todo el planeta?, ¿cómo cada día se mandan 250 mil millones de correos o se descargan 20 millones de aplicaciones?

La actividad que se propone es visitar las instalaciones de Telefónica en el Centro de Comunicaciones de Portillo en Zaragoza, donde convive una amplia gama de tecnologías (tecnologías de acceso: móvil, ADSL, Imagenio, etc.; tecnologías de transmisión: cobre, fibra y radio; tecnologías de conmutación: multiplexación por longitud de onda, conmutación telefónica tradicional, etc.). La visita está guiada por un grupo de diez ingenieras de Telefónica que trabajan en este centro y que dan a las alumnas una visión global del mundo de las telecomunicaciones, así como el testimonio de su experiencia profesional. Para 


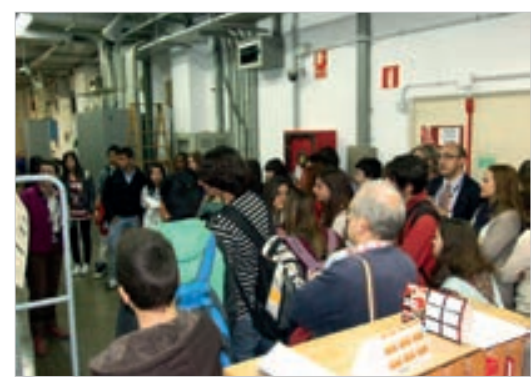

El grupo en el momento de llegada a las instalaciones de Telefónica.

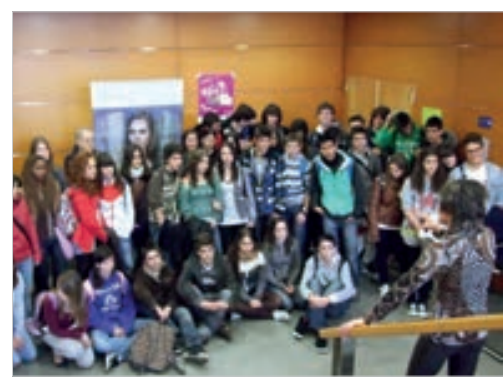

El grupo durante la visita al edificio.

Telefónica el objetivo de esta visita es destacar la importancia de que la mujer trabaje en esta profesión, animar a las estudiantes a que se conviertan en ingenieras y que sean no solo usuarias de las comunicaciones, sino las personas que las hacen posibles.

La visita se divide en dos partes. En primer lugar, se realiza una pequeña recepción y presentación en la que se da la bienvenida y se imparte una charla sobre el sector de las telecomunicaciones y el papel que Telefónica desempeña en este sector. Finalmente, se destaca el desempeño profesional de las ingenieras en Telefónica.

A continuación, se forman dos subgrupos de 25 estudiantes cada uno y se visitan las distintas partes de interés del edificio. Se ven tecnologías que intervienen en las comunicaciones y se explica el papel de la ingeniería en cada parte.

\section{Visita a un laboratorio de investigación: Laboratorio de Robótica, Percepción y Tiempo Real (RoPeRt)}

\section{Ana Cristina Murillo Arnal}

El grupo de investigación de Robótica, Percepción y Tiempo Real (RoPeRt) del Departamento de Informática e Ingeniería de Sistemas (DIIS) de la Universidad de Zaragoza desarrolla su actividad en el ámbito de la robótica y la inteligencia artificial, diseñando sistemas autónomos inteligentes. Por ejemplo, se han desarrollado sistemas de navegación autónoma y de reconocimiento de objetos de interés como pueden ser ciertos coches y matrículas en un aparcamiento. 


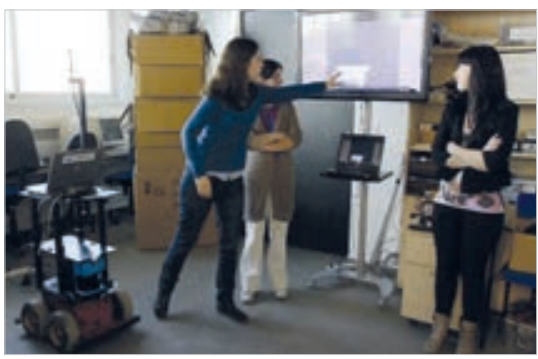

Investigadoras explicando el funcionamiento de los algoritmos de navegación autónoma en un robot Pioneer.

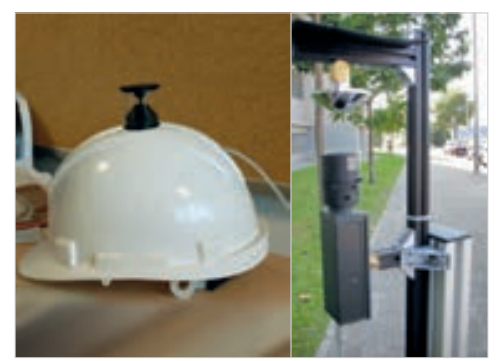

Algunos de los sistemas de cámaras que se observan en la visita.

En la visita al laboratorio de investigación del grupo, se explican conceptos avanzados relacionados con sistemas robóticos reales utilizados en tareas de investigación, como son los robots Pioneer, utilizados para monitorizar el estado de campos de cultivo, o sistemas comerciales como el robot-aspiradora Roomba. También se describe el funcionamiento de otro tipo de dispositivos utilizados como diferentes cámaras y sensores (sonar y láser) para medir distancias. Por otro lado, estas visitas permiten conocer el día a día de las investigadoras y estudiantes de doctorado.

\section{Preparación y desarrollo de un taller: Taller de Robótica}

En este laboratorio se ha llevado a cabo un taller basado en experiencias previas en asignaturas de robótica que se imparten en las carreras de ingeniería, adaptadas a la duración y a los conocimientos previos del alumnado que realiza la visita.

El taller se dirige a distintas edades, desde alumnado de primeros cursos de la ESO hasta Bachillerato, en grupos de veinte asistentes. Para la realización del taller se organizan distintas estaciones de trabajo en las que los y las participantes realizarán pequeñas tareas de programación de robots. En cada estación, se cuenta con un PC y un robot LEGO Mindstorm. También se les proporciona un guion de la actividad a realizar, como el que se muestra a continuación:

La realización del taller se divide en tres partes:

1. Una parte general para todas las personas participantes, donde se explica brevemente qué componentes tiene todo robot y cómo son, en particular, los robots que van a utilizar en el taller. 


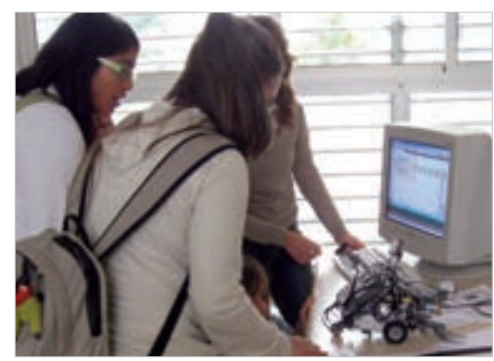

Alumnas familiarizándose con el entorno de programación.

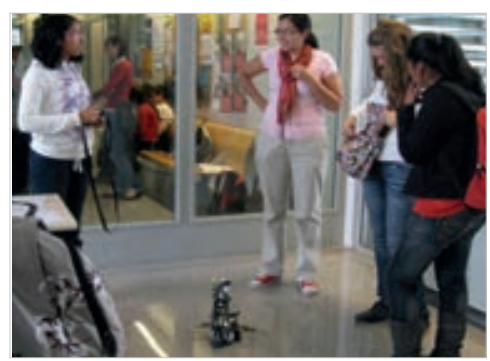

Ejecución de algunas de las tareas programadas sobre los robots.

2. A continuación, se reparten en grupos de entre tres y cinco participantes, y se les explica en mayor detalle cómo funciona el robot de su puesto de trabajo y el software que se va a utilizar para programar los robots (software incluido con los LEGO Mindstorms NXT, basado en el entorno LabView de National Instruments). Este software facilita la programación del robot con un lenguaje gráfico muy intuitivo.

3. Finalmente, se explica cómo conectar el robot al ordenador, las tareas a programar, y se reparten las tareas entre las personas que forman cada grupo. Con la continua supervisión de las organizadoras del taller, las y los estudiantes preparan y transfieren sus programas, los cuales probarán a continuación. Entre las tareas a programar se suele incluir un algoritmo para mover el robot en el entorno (siendo capaz de parar y cambiar su dirección de movimiento cuando encuentre algún obstáculo), programas que hagan que el robot pare o arranque cuando se da una palmada o apretamos un botón, o algoritmos para que se mueva siguiendo una línea negra pintada en el suelo.

El hecho de que el alumnado de colegios e institutos esté muy familiarizado con el uso de la tecnología (ordenador, móviles, videojuegos,...) facilita mucho la realización de este taller, tanto por la rápida comprensión de las actividades, como por el interés que despierta. El resultado del taller ha sido siempre muy positivo, ya que consiguen programar alguna pequeña tarea en los robots y jugar probando lo que han diseñado. 


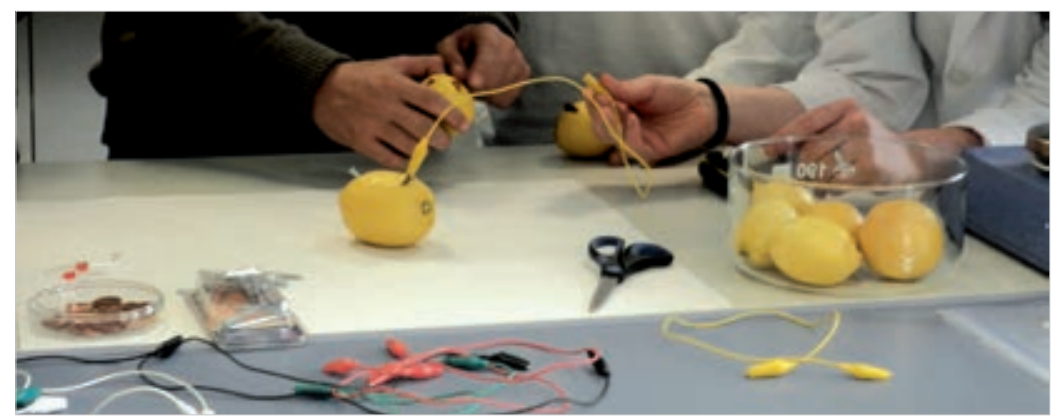

Práctica $1{ }^{a}$ : generación de corriente eléctrica con un limón, un clavo y un céntimo.

\section{Visita al Centro Universitario de la Defensa}

\section{Mayte Lozano}

Desde la instauración en el año 2010 del Grado en Ingeniería de Organización Industrial, perfil Defensa, el Centro Universitario de la Defensa (CUD, centro adscrito a la Universidad de Zaragoza) siempre ha colaborado de un modo u otro con el Girls' Day. El 23 de marzo de 2011, recibe la visita de un grupo de estudiantes de secundaria, enmarcada dentro de las actividades del Girls' Day en Zaragoza. A su llegada al centro, el grupo es recibido por una representación de la directiva y del profesorado investigador del CUD y del profesorado militar. De modo que de la mano de todas estas personas, conocen las distintas vertientes de estos estudios de ingeniería, enmarcados en la profesión militar. En primer lugar, se visita la maqueta de la Academia General Militar, donde se observa cada una de las localizaciones a visitar y se indica la planificación de la visita. En el edificio administrativo del CUD se presenta el centro y sus fines. Dando un paseo el grupo se desplaza, aprovechando la ocasión para aclarar dudas de un modo más cercano: desde curiosidades sobre el centro, hasta dudas sobre los nuevos grados, pasando por cuestiones generales de ingeniería.

Al llegar a los laboratorios, un grupo de profesoras investigadoras del centro acoge al alumnado, que es dividido en tres grupos, para poder realizar las distintas prácticas. En cada grupo, una profesora dirige la práctica que el propio alumnado va a realizar $\mathrm{y}$ da las explicaciones pertinentes de cada proceso $\mathrm{u}$ observación y de cómo se aplica a la vida diaria o en qué casos se puede encontrar.

A continuación, se indican tres prácticas, las cuales fueron preparadas y dirigidas por personal del CUD que, además, pertenece a los siguientes grupos de 


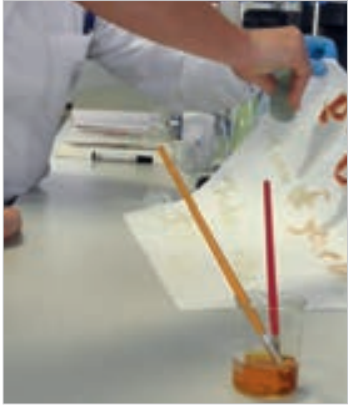

Práctica 2. ${ }^{a}$ : mensaje oculto.

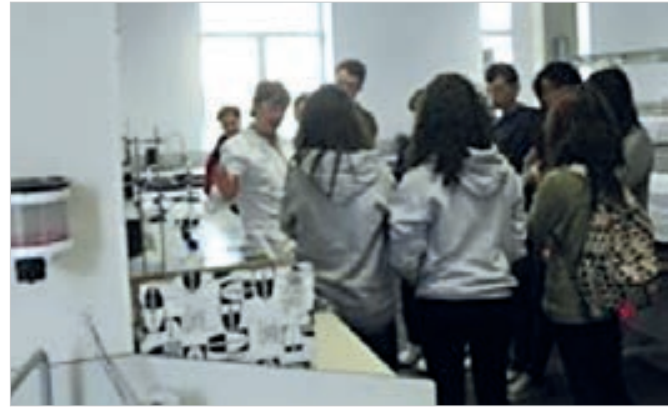

Práctica $3 .^{\mathrm{a}}$ : cristales líquidos.

investigación: Cristales Líquidos y Polímeros, Métodos de Análisis Rápidos mediante Técnicas Espectroscópicas, Catálisis Homogénea por Compuestos Organometálicos, Química del Oro y C-H ActivationProcessesthroughOrganometalliccomplexes.

En la primera práctica, el alumnado genera corriente eléctrica con un limón, un clavo y una moneda de céntimo de euro, haciendo un circuito con el que se enciende un led. En la segunda práctica, cada uno de los participantes escribe un mensaje oculto con tinta invisible (una disolución de Fe prácticamente incolora), de modo que, al pulverizar determinada sustancia sobre el papel, reacciona con el hierro y genera un compuesto coloreado que revela el mensaje oculto. $\mathrm{Y}$, en la tercera práctica, se observan unos cristales líquidos.

\section{Impresiones de visitantes, voluntarias y profesorado}

Los comentarios e impresiones de las investigadoras, las voluntarias y del alumnado participante nos han ayudado a mejorar distintos aspectos de las diferentes ediciones. Además, en la mayoría de los casos, nos animan a continuar con la realización de nuevas ediciones, pese al esfuerzo que supone su organización. En este apartado, se recogen algunas de sus opiniones.

En primer lugar, se incluye la opinión de estudiantes voluntarias e investigadoras que colaboraron en el desarrollo de las diferentes actividades.

Laura Fernando —ingeniera en Informática — ha sido voluntaria en las ediciones del Girls' Day celebradas en Zaragoza hasta la actualidad: 


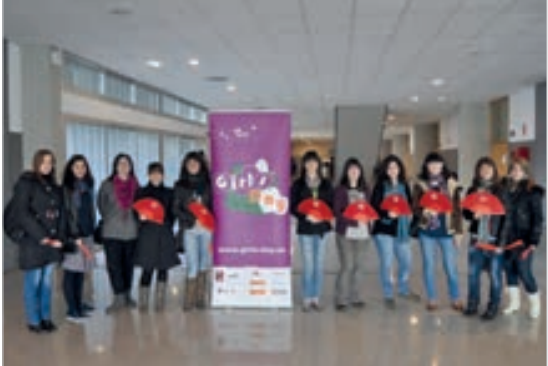

Estudiantes voluntarias en la organización del Girls' Day 2011, en la Escuela de Ingeniería y Arquitectura.

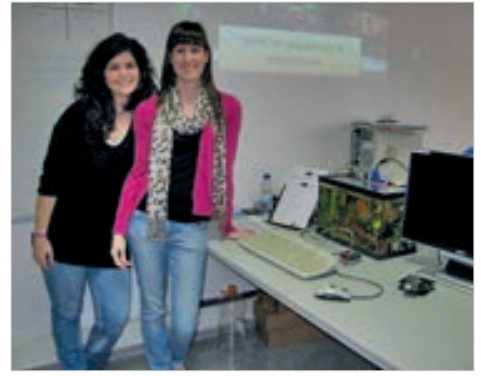

Experimento Un PC en una PCera, con Marta Ortín (dcha.) y Alexandra Ferrerón (izda.).

\begin{abstract}
Ser voluntarias nos ofrece tanto a nosotras como a los estudiantes una gran oportunidad para conocer empresas y grupos de investigación de la mano de mujeres que ocupan puestos relevantes en el sector. En la mayoría de las visitas, nos damos cuenta de que los estudiantes tienen, en general, una idea equivocada o incluso cierto desconocimiento del papel que podemos desempeñar las mujeres en el campo de la ciencia y la tecnología, por lo que les genera una gran expectación. La sensación, al terminar el día, es de una gran admiración e impresión tanto por todas las que nos involucramos como voluntarias como por las enseñanzas y experiencias que nos proporcionan todas las profesionales que participan.
\end{abstract}

Marta Ortín Obón -ingeniera informática e investigadora predoctoral en el Grupo de Arquitectura de Computadores de la Universidad de Zaragoza (GAZ) - ha sido voluntaria en las distintas ediciones. Además, en las dos últimas ocasiones, Marta ha mostrado como investigadora el laboratorio en el que trabaja actualmente:

A mí me gusta explicarles la PCera (sistema de refrigeración en aceite de girasol para la placa base de un ordenador), porque además les suele resultar curioso y yo creo que es entretenido. Ha habido muchos grupos que han ido muy bien, han estado atentos, han participado y han hecho preguntas. También hay casos en los que, a lo mejor yendo de un laboratorio a otro o en ratos un poquillo muertos, han hecho preguntas menos relacionadas con el laboratorio y más con la universidad: cómo eran las clases y los profesores, los horarios, la dificultad... El año pasado, que vinieron solo grupos pequeños de chicas que ya iban hacia carreras de ciencias fue muy bien, porque, además, como eran pocas, estuvimos hablando y se atrevían a participar más.

A continuación, se recogen diferentes opiniones de estudiantes participantes en la jornada. 
Paloma Clúa (estudiante de 3. ${ }^{\circ}$ de ESO en el curso 2011-2012):

Me pareció una oportunidad muy buena para acercarnos más al ambiente universitario, aprender nuevas ciencias y tecnologías y conocer los proyectos y estudios que estaban haciendo en ese momento. Me gustó mucho un proyecto de Ingeniería Informática y un edificio en el que estudiaban energías renovables y eficiencia energética. Me impresionaron todos los avances de la tecnología que nos enseñaron. Además, conocimos gente nueva y, a mí, la visita me sirvió de orientación para mis futuros estudios.

Teresa Carrasco (estudiante de 3. ${ }^{\circ}$ de ESO en el curso 2011-2012):

El curso pasado algunas alumnas de diferentes colegios tuvimos la fantástica oportunidad de conocer un poco más de cerca el mundo de la ingeniería asistiendo una tarde a la Escuela de Ingeniería en el Campus Río Ebro de la Universidad de Zaragoza. [...] Fue una experiencia muy interesante en la que disfrutamos averiguando nuevas cosas y conociendo un poco más las aplicaciones prácticas de la ingeniería. Pasamos una tarde muy instructiva rodeadas de un ambiente universitario que nos cautivó y numerosas actividades que nos daban a conocer el laborioso trabajo que realizan profesores y alumnos en esta escuela. A raíz de esto, ha surgido en nosotras un nuevo interés por algo que antes no conocíamos.

Como alumna de Secundaria, me gustaría dar las gracias a todas las personas que han hecho posible esta actividad $\mathrm{y}$, viendo la influencia positiva que ha tenido en $\mathrm{mi}$ ambiente, animarles a que continúen con ella.

\section{Bea Marín (estudiante de 3. ${ }^{\circ}$ de ESO en el curso 2011-2012):}

El Girls' Day del curso pasado resultó una agradable experiencia, en la que pude comprobar que hay más chicas de otros colegios de Zaragoza que, como yo, están interesadas en estudiar carreras técnicas. Si bien es cierto que no éramos un gran número, espero con ilusión que, año tras año, dicho número vaya en aumento. El esfuerzo e interés por parte de las profesoras era más que esperanzador.

\section{María Î́nigo (estudiante de 3. de ESO en el curso 2011-2012):}

Fue un día muy completo, ya que nos demostraron que ciertas profesiones técnicas, asociadas habitualmente a ser realizadas por hombres, son igualmente realizables por mujeres y, en mi opinión, son muy interesantes y con unas aplicaciones prácticas divertidas, inteligentes e ingeniosas, es decir, cosas con las que se trabaja y que resultan agradables e interesantes a la persona que trabaja con ellas. Nos mostraron su día a día en el trabajo y cómo lo adaptaban a las nuevas tecnologías, lo que es muy atractivo para los jóvenes. Además, hay muchos tipos distintos de ingenierías, enfocados a muchos temas como la química, industria, construcción, informática, medios de transporte, ciencia, ecología, investigación... Creo que las chicas se animarían a estudiar este tipo de carreras si antes de elegirla supieran realmente en qué consiste y cómo se desempeña el trabajo, así que creo que esta jornada es una muy buena oportunidad para adentrarse en el mundo de la ingeniería. A mí me gustó mucho porque se aprenden muchas cosas nuevas y te puede ayudar para concretar un poco más lo que en el futuro quieres estudiar profesionalmente. Espero volver este año de nuevo con mis compañeras y mi profesora.

Para finalizar este apartado de experiencias, se incluye la valoración de Concha Gaudó, profesora de Secundaria que participó en la primera edición: 
Como profesora de $3 .^{\circ}$ y $4 .^{\circ}$ de ESO del IES Goya de Zaragoza, tuve ocasión de acompañar en el curso 2009-2010 a un grupo de estudiantes que participaron en las actividades del Girls' Day, organizadas por la Asociación de Mujeres Investigadoras y Tecnólogas (AMIT) y la Asociación de Mujeres Científicas y Técnicas (MUCIT) en el Centro Politécnico Superior de la Universidad de Zaragoza. No fue fácil la empresa, pues yo impartía Geografía e Historia al alumnado de la Sección bilingüe (no a todo el grupo) y tutores y tutoras de estos grupos y algún profesor del Departamento de Física y Química tenían gran interés en esta actividad.

La valoración de esta visita fue altamente positiva, tanto por parte del alumnado como del profesorado (esta coincidencia ya es significativa). Por mi especialidad estoy acostumbrada a realizar visitas escolares a museos, exposiciones, monumentos, ... y no es fácil captar la atención y el interés del alumnado. La actividad del Girls' Day lo consiguió, tanto en chicas como en chicos. En primer lugar, por las innovadoras y prácticas experiencias que se presentaban, en segundo lugar, porque la presencia de mujeres científicas e investigadoras que mostraban su trabajo era, todavía, un elemento impactante para el alumnado. Una muestra más de que no todo está conseguido en temas de igualdad de género.

Gracias a las organizadoras y colaboradoras por el esfuerzo de realizar esta actividad educativa, de gran valor en la orientación personal y profesional, a la que, desde mi punto de vista, el sistema educativo no presta la atención suficiente, y una buena aportación en educación para la igualdad y empoderamiento de las mujeres, sobre todo entre adolescentes. Mis más sinceras felicitaciones por los resultados obtenidos y deseo que las dificultades que atravesamos no os hagan desistir de la organización de próximos Girls' Days.

\title{
La experiencia del Girls' Day en Teruel
}

\author{
La experiencia del Girls' Day en Teruel. \\ Primera edición: curso 2010-2011 \\ Piedad Garrido Picazo y Eva Hervás Puchalt
}

En los 19 años de historia de la Escuela Universitaria Politécnica de Teruel (EUPT), del alumnado que ha pasado por sus aulas, únicamente el $21,7 \%$ han sido mujeres. Una cifra que no solo no mejora sino que en la actualidad incluso, para algunas titulaciones del campus, roza la inexistencia. Sin ir más lejos, durante el curso académico 2010/2011, en el que se puso en marcha la jornada del Girls' Day en Teruel, en los dos nuevos grados de la EUPT: Grado en Ingeniería Informática y Grado en Ingeniería Electrónica y Automática, se matricularon 66 estudiantes y solo había tres mujeres. Con estas cifras tan significativas, se incorporaba el campus de Teruel a la tercera edición del Girls' Day. 


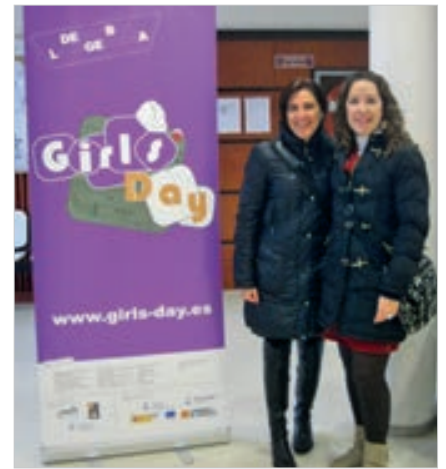

Organizadoras del Girls' Day en Teruel; a la izquierda, Piedad Garrido, a la derecha, Eva Hervás.

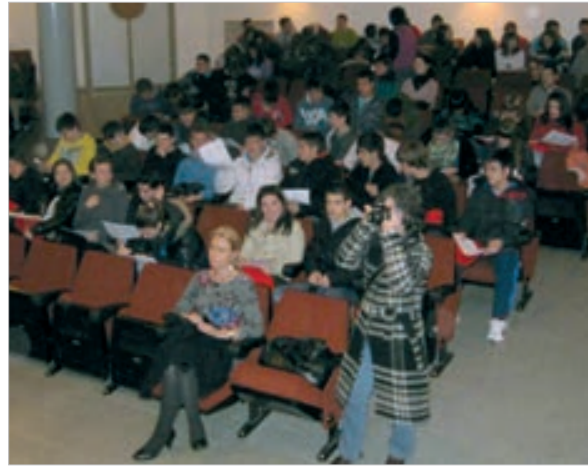

Asistentes a la primera edición del Girls' Day en Teruel, durante la recepción en el salón de actos.

El 23 de marzo de 2011, cerca de 225 estudiantes de cinco centros educativos (La Salle, Victoria Díez, Segundo de Chomón, Vega del Turia y Pedro Laín Entralgo) de la provincia, pudieron acercarse a la investigación que se desarrolla en el campus turolense y a las aplicaciones sociales de este tipo de formación, a través de las siguientes actividades:

- Visitar cuatro laboratorios de investigación: laboratorio del grupo gINIT (InteIligent Networks and InformationSystems), centrado en Redes Vehiculares y Sistemas Inteligentes de Transporte, laboratorio de calidad, del grupo EduQTech (Education-Quality-Technology), que aplica la calidad a actividades de I+D+i y a la docencia) laboratorio de IDentificación por RadioFrecuencia (RFID), cuyo trabajo en identificación arqueológica y museos es un claro ejemplo de transferencia tecnológica, y el laboratorio del Grupo GISED-Teruel (Ingeniería de Sistemas de Eventos Discretos), con investigación orientada al modelado y análisis de sistemas concurrentes y, aplicada en logística, manufactura y automatización.

- Disfrutar de una mesa redonda titulada «Mujer, ciencias e ingeniería en Teruel», moderada por la vicerrectora del campus Dra. Alexia Sanz, y que estuvo compuesta por jóvenes profesionales turolenses que desarrollan su labor en Teruel y se formaron en la Universidad de Zaragoza: María Cavero, ingeniera técnica en informática de gestión; Marisa Bayo, ingeniera química y directora de calidad de Agroquímica en TERVALIS, y Míriam Álvarez, ingeniera de telecomunicaciones, que desempeña su actividad laboral en la Cámara de 
Comercio de Teruel. Las tres compartieron sus trayectorias académicas y laborales, reconocieron que el campo de I + D es duro pero destacaron que, al mismo tiempo, es muy gratificante y aseguraron que no se han sentido discriminadas, a pesar de ejercer una profesión tan masculinizada.

- Conocer el Centro de Estudios de Física del Cosmos de Aragón (CEFCA), gracias a Luisa Valdivieso, licenciada en Físicas e investigadora responsable de proyección externa. En esta visita, los grupos de estudiantes pudieron conocer las instalaciones del centro y ser protagonistas de una charla-coloquio adaptada al público de esta edad, sobre la evolución de las galaxias y la cosmología.

Todas estas actividades pudieron llevarse a cabo gracias a la colaboración desinteresada de un total de 27 voluntarias y voluntarios que acompañaron a 225 estudiantes de los distintos centros de secundaria. Aprovecharon la jornada para animarles a elegir sus estudios centrándose en sus intereses, independientemente de su género y condición.

\section{La experiencia del Girls’ Day en Teruel: Segunda edición: curso 2011-2012 \\ Inmaculada Plaza García y Guillermo Azuara Guillén}

La segunda edición del Girls' Day contó con una barrera: la falta de financiación local para la actividad. Por ello, se integró como parte de la Jornada de Puertas Abiertas de la Escuela Universitaria Politécnica de Teruel. De esta forma, se unificaron esfuerzos y se involucró activamente a la dirección del centro.

La jornada constó de tres partes: Recepción y presentación del centro, a cargo de la Dirección; Visita a instalaciones y laboratorios; y la mesa redonda: «Trabajar en ingeniería. Diferentes experiencias con voz femenina».

Los laboratorios que se visitaron fueron los mismos que en la primera edición, añadiendo el laboratorio de Tecnologías Centradas en el Humano, donde se desarrolla software para la rehabilitación de lesiones cerebro vasculares y vestibulares.

La mesa redonda contó con la participación de representantes del entorno empresarial, investigación y servicios sociales-salud:

- Silvia Casas. Analista de INTERNOVA. Aportó la perspectiva empresarial: «el futuro pasa por la tecnología» y «los ingenieros pueden desarrollar una amplia variedad de funciones en la empresa». Explicó cómo INTERNOVA está mayoritariamente constituida por ingenieros que realizan tareas multi- 
disciplinares. Con su habitual espíritu entusiasta, animó a los presentes «a estudiar aquello que les apasione».

- Luisa Valdivielso. Responsable de Proyección Externa de CEFCA. Como física que trabaja en investigación, remarcó el importante papel de los ingenieros y la necesidad de la tecnología: «La ciencia sin la ingeniería no puede avanzar». Animó a las estudiantes, ya que estas titulaciones permiten colaborar activamente en grupos internacionales de trabajo, experimentar y desarrollar «un trabajo creativo en el que resulta imposible aburrirse».

- Mónica Rubira. Responsable informática de ATADI (Agrupación Turolense de Asociaciones de Personas con Discapacidad Intelectual), introdujo la dimensión social de la ingeniería, rompiendo estereotipos: «La ingeniería no solo tiene aplicaciones a nivel industrial. A nivel social, hay muchas adaptaciones técnicas que ayudan a personas con discapacidad».

- Inmaculada Plaza, Presidenta de la Sociedad de Educación del IEEE (Institute of Electrical and Electronics Engineers) en España, moderó la mesa, aportando una visión global del papel de organizaciones internacionales como MUCIT, AMIT o IEEE-Women in Engineering.

La valoración de las ponentes fue muy positiva, pero constataron que todavía queda mucho camino por recorrer. La actividad debía formar parte de un entramado de acciones en el que se fuera desarrollando el interés por la ciencia y la ingeniería. De esta forma, Girls' Day sería un acto que permitiera conocer las posibilidades profesionales y una ayuda a la toma de la decisión final sobre lo que les gusta estudiar. La reflexión sobre la igualdad de oportunidades debería llegar también a sus compañeros varones y al entorno familiar.

Al igual que sucedió con la edición anterior, los medios de comunicación locales se hicieron eco de la actividad. Además, este año la difusión fue mayor gracias al IEEE (Sociedad de Educación y Women in Engineering). Deseamos darles las gracias, al igual que al Vicerrectorado de Teruel por su constante apoyo.

Como la pasada edición, se mostró a las alumnas que ni ser mujer ni vivir en una ciudad pequeña está reñido con la ingeniería y la investigación. Al contrario, puede convertirse en una estupenda oportunidad para desarrollar una importante labor para la sociedad con proyección internacional. 


\title{
La experiencia del Girls' Day en la Escuela Politécnica de la Almunia (EUPLA)
}

\author{
M. a SAgrario Embid López
}

Cuando en septiembre de 2009 me proponen organizar en la EUPLA el Girls' Day (en nuestro caso, primera edición), una actividad enfocada principalmente a chicas, mi reacción fue de cierta sorpresa. Yo, que siempre he intentado evitar la diferencia de género en todos los ámbitos de mi vida, me encontraba ante la situación de ponerme al frente de su organización. Pero pensé: «Ante todo, ¿no perseguimos la igualdad de género?».

Recordando mis años de estudiante de ingeniería, se me presentaba la imagen de las aulas repletas de chicos, y una pocas chicas que representábamos la excepción. Si enfocaba en mi mente la fotografía de las aulas de ingeniería en la actualidad, constataba, a mi pesar, que la situación, después de casi veinte años, no había cambiado en absoluto. Las chicas seguíamos siendo una minoría en las carreras de ingeniería.

¿Qué mejor manera de colaborar en intentar cambiar esta situación, sino emprendiendo actividades que puedan ayudar a ello? Si para eso una de las opciones era desplazar al alumnado de los últimos cursos de ESO y Bachiller hasta los centros donde se imparten estas carreras, y mostrarles los trabajos y proyectos desarrollados en los diferentes departamentos y laboratorios, no iba a escatimar mi esfuerzo. De hecho, desde el principio asistieron estudiantes de ambos sexos, pues la educación en la igualdad debe estar dirigida a todas las personas.

Lo siguiente en que tenía que pensar era en cómo podíamos llamar la atención en estas jóvenes para que la visita les resultara enriquecedora y divertida y, a la vez, despertar el gusanillo en una parte de ellas y ellos para que, al menos, pensaran en la ingeniería como una opción para su futuro.

Pensé en mí misma a esa edad, e intenté recordar qué fue lo que me impulsó a mí a elegir la ingeniería como carrera de estudio. Lo que recuerdo de aquellos momentos es que me gustaban las asignaturas más técnicas. Lo cierto es que no me pregunté durante esa etapa cuáles eran las salidas profesionales de una ingeniería.

Así, consideramos que el primer acto de la jornada debía consistir en que varias ingenieras nos contaran su experiencia laboral, con el fin de mostrar las numerosas salidas profesionales de las ingenierías, mientras que el segundo acto de la jornada lo centramos en mostrar aquellos proyectos que ingenieras de diferentes ámbitos desarrollaban en la propia escuela. 


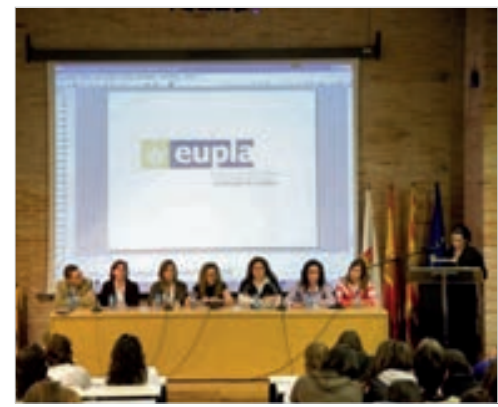

Presentación del Girls’ Day en 2009 en la EUPLA con ingenieras egresadas.

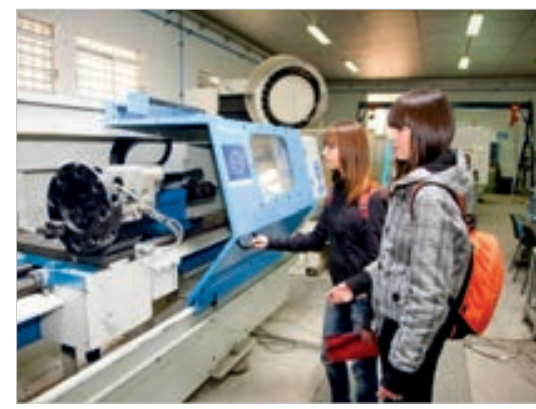

Estudiantes observando el funcionamiento del torno de control numérico.

Con todo esto, ¿habremos conseguido despertar en alguien el interés por las ingenierías? Lo desconozco, pero que, al menos, les hayamos hecho reflexionar sobre esta posibilidad me proporciona la energía suficiente para continuar en las próximas ediciones del Girls' Day.

Si alguien ha tomado la decisión de optar por una ingeniería espero que en ella haya encontrado la emoción, ilusión y encanto que a mí me ha producido durante estos años el desempeño de mi trabajo como ingeniera.

Por último, deseo que este evento tenga los días contados porque la presencia de mujeres en ingeniería deje de ser una excepción.

\section{La experiencia del Girls' Day en Huesca \\ María Villarroya Gaudó, M. Dolores Cepero, VANesa Bataller, Isabelle Hupont}

En el año 2011, los índices de participación en el Girls' Day iban creciendo; desde la Universidad de Zaragoza se hace un esfuerzo por llegar a todos los rincones de la comunidad autónoma, en particular, se trabaja por integrar en la acción a todos los centros que imparten docencia en alguna rama técnica, ingeniería o arquitectura, por ello, no podían quedarse fuera el Campus de Huesca y la Escuela Politécnica Superior. 
En esta edición, 120 estudiantes del IES Sierra de San Quílez, de Binéfar, participaron en la actividad en la provincia de Huesca. Este grupo de estudiantes, dividido en pequeños grupos, visitó las instalaciones de las empresas siempre de la mano de ingenieras y tecnólogas.

Se visita la empresa TAP Consultoría, responsable de proyectos de desarrollo y mejora industrial, ofertando soporte informático, con seguridad y TIC a otras empresas, así como proyectos de innovación. También, visitaron las instalaciones del grupo Gaypu, que ofrece servicios metalúrgicos integrales, mediante dos empresas cuyas actividades se complementan para dar un mejor servicio: GPCORTE y METÁLICAS GAYPU. La primera se dedica a trabajos de corte mediante láser, plasma de alta definición o mediante sopletes de oxigás. La actividad de Metálicas Gaypu está orientada a la fabricación, soldadura, montaje electro-hidráulico y pintura.

Se visitaron los laboratorios de investigación situados en el Parque Tecnológico Walqa, en particular el del grupo GTE de la Universidad de Zaragoza y el e-museum, proyecto de museo virtual desarrollado por el Instituto de Investigación en Ingeniería de Aragón (I3A). Allí se realizó una visita guiada a los laboratorios, observando el trabajo que allí desarrollaban los diferentes grupos de investigación del I3A. Se les mostró el funcionamiento del e-museum y experimentaron el funcionamiento del mismo, con el robot guía y con los diferentes cuadros instalados. Tras ello, se les realizó una presentación del trabajo del Grupo de Tecnologías en Entornos Hostiles, cuya labor se centra en desarrollar y mejorar las tecnologías de comunicación para lugares confinados donde las comunicaciones habituales no funcionan: cuevas, minas, túneles, nieve, etc. Pudieron observar prototipos y tecnología con la que trabaja el GTE y se les mostraron imágenes del trabajo realizado, donde se enfatizaba el nivel de experimentación y medidas de campo, así como la presencia de la mujer dentro de este grupo tecnológico. La respuesta a esta presentación fue muy positiva. Los asistentes se mostraron muy interesados en estas tecnologías.

Los grupos de estudiantes también tuvieron la oportunidad de visitar las instalaciones de la División de Tecnologías Multimedia del Instituto Tecnológico de Aragón, ubicadas en el Parque Tecnológico Walqa. Se hizo una presentación, desde un punto de vista didáctico y adecuado al nivel de los alumnos, de las principales tecnologías en las que trabaja el grupo: realidad virtual, realidad aumentada, interfaces gestuales, agentes virtuales inteligentes, televisión y ocio digital interactivo, y acceso multiplataforma a contenidos audiovisuales. Posteriormente, se permitió interactuar libremente con varias de esas tecnologías a través de aplicaciones demostradoras. Así, estudiantes pudieron comprobar en 

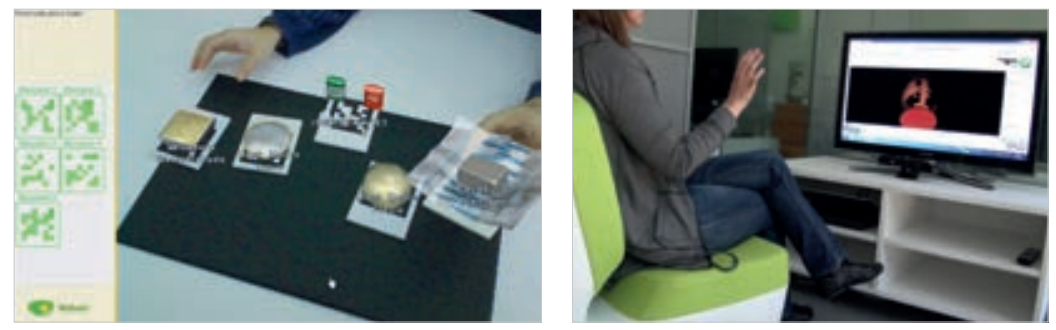

Aplicaciónes demostradoras de realidad aumentada (izquierda) e interfaces gestuales (derecha).

primera persona cómo se puede interactuar con una computadora usando el propio cuerpo como «comando» (interfaces gestuales) o cómo se puede superponer un objeto virtual sobre el mundo real capturado por una cámara de video (realidad aumentada).

La visita concluyó en la Escuela Politécnica Superior, donde fueron recibidos por la vicerrectora del Campus de Huesca, Dra. Pilar Bolea, y la dirección de la escuela; se les mostraron las instalaciones y se explicó qué tipo de estudios se pueden cursar en ese centro.

Se organizó un acto de bienvenida para el grupo de estudiantes, durante el cual se mostraron las características del campo de la investigación, así como las carreras científicas de diversas investigadoras. Después, participaron en un seminario sobre las trayectorias de algunas científicas célebres, Premios Nobel en Botánica, Medicina, Biología, Física o Química, siempre gracias a su esfuerzo, tesón y capacidad intelectual.

También, se les habló, como ejemplo de participación femenina en la investigación científica, de los proyectos de investigación en biología evolutiva y conservación de plantas desarrollados en la EPS de Huesca por el equipo Bioflora, del que forman parte diversas mujeres, desde investigadoras, a estudiantes de doctorado y máster y técnicas de laboratorio.

De primera mano, una becaria de un proyecto de investigación les describió el trabajo que estaba realizando en el Área de Ingeniería Mecánica y que constituía su Proyecto fin de carrera de Ingeniería Industrial.

Por último, visitaron el laboratorio de Biología molecular de plantas de Bioflora, donde pudieron formular preguntas a las investigadoras.

La experiencia fue de gran satisfacción para el alumnado participante, así como para ingenieras y profesoras investigadoras. 


\section{Percepción de la ingeniería por el alumnado de secundaria}

Pilar Molina Gaudó

SANDRA BALDASSARRI

María Villarioya 
En todas las ediciones del Girls' Day, se ha realizado un estudio sociológico, consistente en una o en varias encuestas a las y los asistentes al acto. En este capítulo analizaremos las conclusiones más importantes obtenidas en relación con la motivación hacia la ingeniería, el conocimiento de la profesión, la visión con perspectiva de género de la misma y las evaluaciones de la propia actividad. Dada la gran afluencia en algunas de las ediciones y los rangos de edad diferentes entre algunas de ellas, los resultados significativos se presentan a continuación.

Los objetivos planteados para la realización de estos estudios sociológicos eran tres. El primer objetivo consistía en encontrar las diferencias de entorno sociocultural y motivación entre las mujeres y los hombres con claro interés por estudiar ingeniería, para, posteriormente, poder usarlas en fomentar la matriculación de mujeres. En segundo lugar, profundizar en el grado de conocimiento de la profesión y en el posible sesgo de género que tenía sobre ella en el alumnado de secundaria. El tercer objetivo era poder evaluar el impacto de la actividad. Las preguntas concretas de cada una de las encuestas llevadas a cabo se pueden encontrar en la página web;' los resultados de las mismas han sido analizados por una empresa especializada bajo la supervisión y dirección de las editoras de este libro. Parte de los resultados aquí expuestos han sido presentados en varios foros y publicaciones internacionales ${ }^{2}$ y su obtención ha sido financiada por el Instituto de la Mujer y el Instituto Aragonés de la Mujer en las diversas ayudas concedidas a esta acción. La gráfica 1 muestra el volumen de encuestas realizadas en las diferentes ediciones del Girls' Day y el índice de error en cada uno de los casos; la fiabilidad de los resultados presentados es, por tanto, superior al $95 \%$. Como se puede ver, la primera columna (correspondiente a encuesta previa 2008) es notablemente superior a la segunda (encuesta posterior 2008),

1 http://www.girls-day.es.

2 Pilar Molina Gaudó, Sandra Baldassarri, María Villarroya Gaudó y Eva Cerezo, «Perception and intention in relation to engineering», IEEE Transactions on education, vol. 53, n. 1 , febrero de 2010, pp. 61-70. 
esto se debe a que se contestaron en los centros educativos donde las respondieron más estudiantes de los que posteriormente participaron en la visita. En el año 2008, el cuestionario preliminar tiene una proporción equilibrada de mujeres y hombres. En contraste, en el cuestionario final, el $62 \%$ de las encuestas fueron respondidas por chicas, como resultado de que la actividad estaba principalmente dirigida a mujeres y debido al límite de plazas en la asistencia, algunos centros decidieron que fuesen las chicas quienes participasen en la jornada.

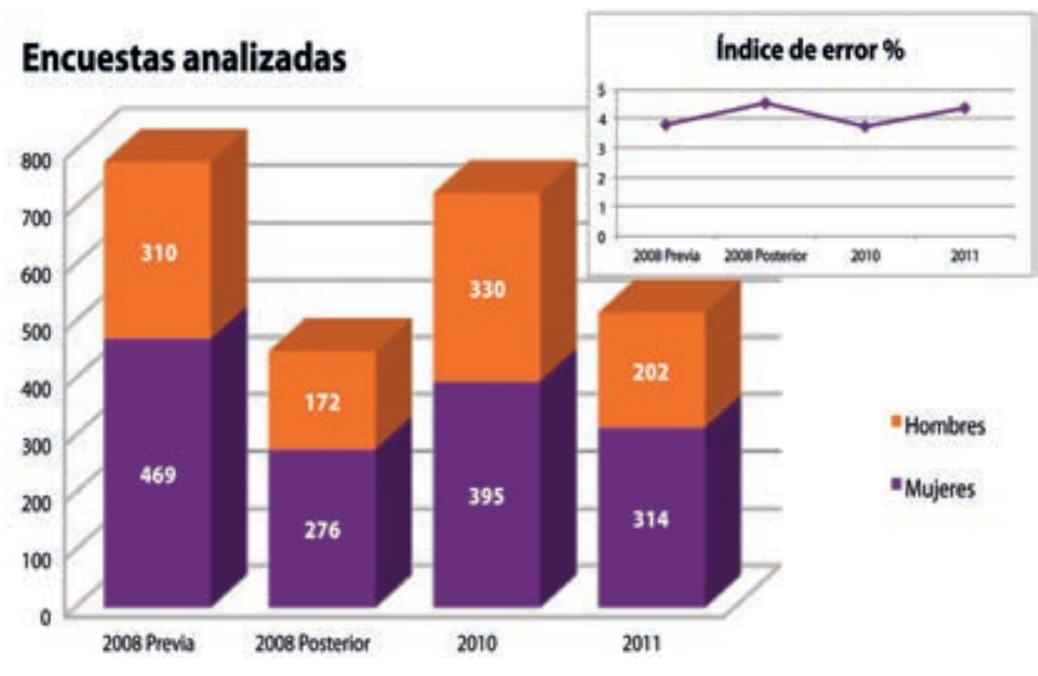

Gráfica 1. Resumen del número de encuestas e índice de error en cada una de las ediciones del Girls' Day.

En los resultados, se observa una temprana brecha existente entre chicas y chicos sobre su intención expresa de estudiar ingeniería, si bien, desgraciadamente, no son significativamente concluyentes apoyando la tesis de la compleja relación entre género y tecnología. ${ }^{3}$ Sin embargo, se observan ciertas tendencias de interés a tener en cuenta. En cualquier caso, los resultados obtenidos en cada edición han hecho que la actividad del Girls' Day haya evolucionado en sus 
sucesivas ediciones y han servido de realimentación para la misma y los posteriores estudios que se han llevado a cabo (por ejemplo, el estudio presentado en la siguiente sección, sobre las razones que han llevado a las y los estudiantes a elegir grados en ingeniería).

La primera edición del Girls' Day en el año 2008 fue orientada al alumnado aragonés de entre 15-16 años (4. ${ }^{\circ}$ curso de Enseñanza Secundaria Obligatoria, ESO). El número de asistentes se acercó a 800 (de ambos sexos), a los cuales se les realizaron dos encuestas:

- Un cuestionario preliminar: recogido antes de la actividad; iba dirigido a cualquier participante estudiante (chicas y chicos) de los centros de Secundaria.

- Un cuestionario final, realizado inmediatamente después de que la actividad finalizara, que iba dirigido a quienes asistieron al Girls' Day.

En este apartado, además de mostrar los resultados obtenidos en esta edición, se hace especial hincapié en la metodología de trabajo y de análisis, que se puede hacer extensiva a todas las demás ediciones.

Ambos cuestionarios contenían muy pocas preguntas abiertas. En la mayoría de los casos, tuvieron que elegir sus respuestas en base a una escala de 1-7 (Escala Likert) reflejando así su grado de conformidad con una afirmación dada. El anonimato de las encuestas se garantizó, y así ambos cuestionarios, el cuestionario preliminar y el cuestionario final, fueron independientes entre sí, lo que explica por qué algunas preguntas se repetían en el segundo formulario. Como ejemplo, en el anexo B de este libro aparece una encuesta.

Los cuestionarios abordaban asuntos que pueden ser clasificados dentro de las siguientes áreas de interés:

1. Entorno familiar y social

- Datos demográficos básicos, tales como edad, número de hermanos y ubicación geográfica.

- Nivel educativo y profesión de la madre y el padre, así como el grado de familiaridad con la tecnología y la ingeniería.

- Ingenieros en la familia.

- Apoyo familiar.

2. Auto-percepción de la personalidad de la / del estudiante

3. Información académica

- Cómo de buena/bueno te consideras en temas relacionados con la tecnología (matemáticas, física, etc.).

- Percepción de la dificultad de los estudios de ingeniería. 
4. Interés en la ingeniería

- Interés en realizar estudios de ingeniería.

5. Percepción de la Ingeniería

- Conocimiento de la profesión de la ingeniería.

- Percepción cualitativa y valores altruistas de la ingeniería.

- Sesgos de género en la ingeniería.

6. Evaluación del alcance de la actividad

- Cuestiones directas acerca del desarrollo y evaluación del alcance o impacto de la actividad (solo en el cuestionario final).

Los datos demográficos de la muestra, limitada a la región española de Aragón, estuvieron igualmente distribuidos entre áreas urbanas y rurales. Analizando la muestra, el nivel educativo de los progenitores, así como el número de hermanas y hermanos, refleja la composición de la sociedad española, en general, de acuerdo con los datos del Instituto Nacional de Estadística.

Una de las metas de investigación fue incrementar el conocimiento sobre las razones por las cuales alumnas y alumnos eligen estudiar ingeniería, así como sus perfiles. El objetivo final consistía en detectar los motivos de la obvia diferencia entre chicos y chicas estudiantes en lo que atañe a los estudios universitarios.

Para hacer esto, el estudio clasifica al alumnado de instituto en seis diferentes grupos: hombres $(\mathrm{H})$ y mujeres $(\mathrm{M})$ fueron divididos en tres categorías en base a su grado de acuerdo con la afirmación siguiente del cuestionario preliminar («Estoy interesado en estudiar ingeniería»). Aquellos con bajo grado de acuerdo (1-2 en la escala Likert) son clasificados dentro de los grupos de Bajo Interés ( $\mathrm{M} 1$ y $\mathrm{H} 1$ ) en contraste con los grupos de Alto Interés (6-7 en la escala de Likert) que se designaron $\mathrm{M} 3$ y H3; quienes respondieron con interés medio se agrupan

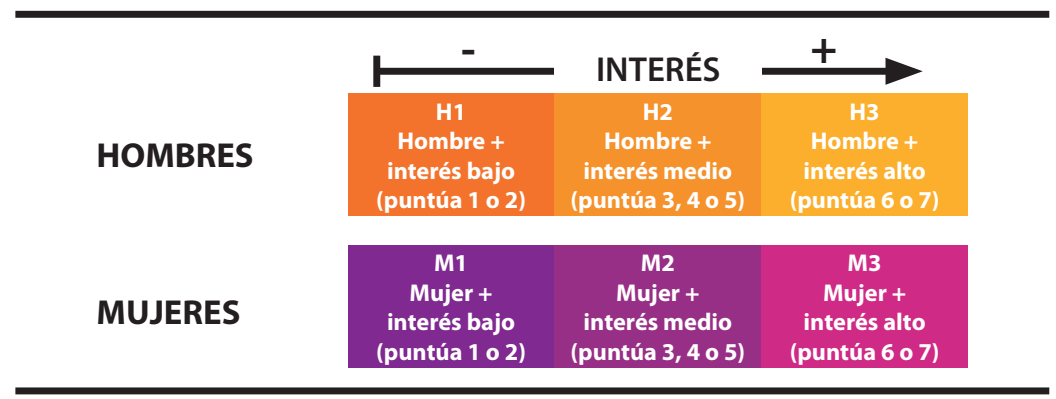

Gráfica 2. Clasificación de los encuestados en grupos de interés para estudiar ingeniería por género. 
en $\mathrm{M} 2$ y H2. Estas categorías son importantes, de modo que a partir de ahora los resultados del estudio serán correlacionados con estos grupos M1-3 y H1-3, como muestra la gráfica 2.

Incluso a tan temprana edad, se detecta una gran brecha de género, como se evidencia en la gráfica 3. El porcentaje de mujeres altamente interesadas en estudiar ingeniería (M3) es solo de un 8,3\% en comparación con el 22,5\% de hombres (H3). Esta diferencia es incluso más acusada en aquellos sujetos que claramente muestran un bajo interés en esta área, el $60 \%$ de los cuales fueron mujeres (M1) en contraposición con el $35 \%$ de hombres $(\mathrm{H} 1)$. Estas cifras fueron extraídas de los datos del cuestionario preliminar. El número absoluto de mujeres en el grupo M3 es relativamente bajo, y, por tanto, su significancia estadística puede ser más baja y el margen relativo de error puede ser más alto (hasta un $15 \%$ en comparación con el $5 \%$ para el mejor caso). Los márgenes de error fueron calculados para todas las variables y están disponibles bajo petición. Como se discutirá posteriormente, los ligeros incrementos en el grado de interés se midieron en el cuestionario final: el interés promedio de las chicas incrementó de 2,49 a 3,01, mientras que el de los chicos subió de 3,7 a 3,93.

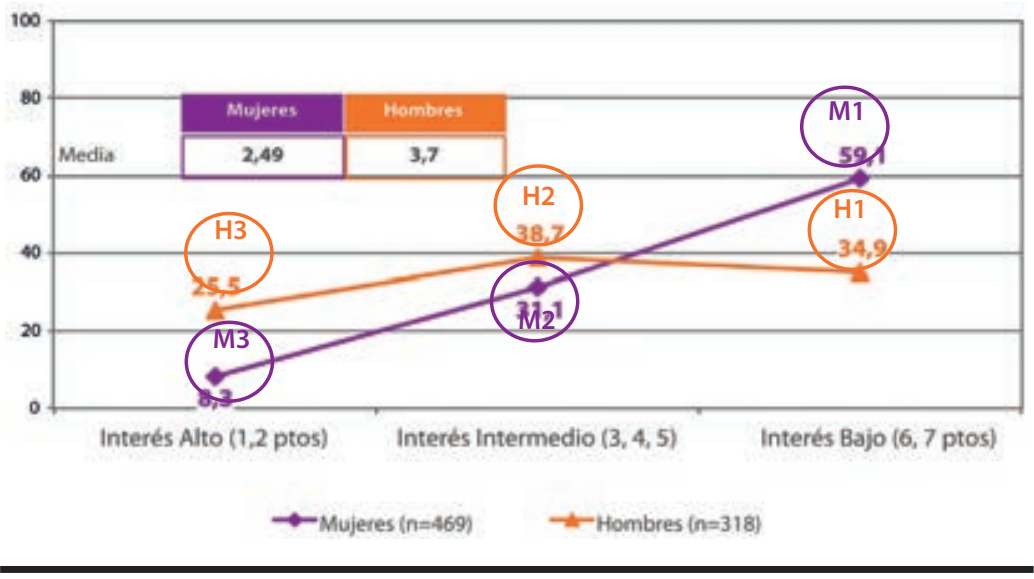

Gráfica 3. La brecha de género detectada en los grupos de interés expresada en porcentajes (n: número de cuestionarios preliminares).

Otro punto en el cuestionario preliminar fue específicamente dirigido hacia los estudios de ingeniería ofrecidos por la Universidad de Zaragoza, que abarcan casi todos los campos de la ingeniería. La pregunta demandaba una respuesta 
muy clara sobre cada disciplina separada de la ingeniería, incluyendo: «Seguro que la estudiaré» y «Nunca la estudiaré». Debe subrayarse que el 12,8\% de las chicas respondió «Nunca la estudiaré», en todos los posibles casos, mientras que solo el 3,2\% respondió «Seguro que la estudiaré» a una o más de una. Para los chicos, las cifras son prácticamente polos opuestos: el 6,6\% no estudiarían ninguna ingeniería y el 13,2\% sí quería estudiar una de las disciplinas de la ingeniería. Los grupos de interés fueron, de nuevo, redefinidos en base a las respuestas a esta afirmación con propósitos de verificación. Como se podía esperar, resultados más sesgados se obtuvieron con un grupo intermedio mucho mayor, pero que también generaban tendencias similares.

Correlaciones exhaustivas entre los grupos de interés y el resto de parámetros estudiados se realizaron para reflejar diferencias y tendencias significativas. Las siguientes secciones presentan los resultados más relevantes. En particular, para estos seis grupos se analiza: entorno social y familiar, auto-percepción de la personalidad del estudiante y el rendimiento académico y la percepción de la ingeniería. Finalmente, también se evaluó el impacto de la propia actividad.

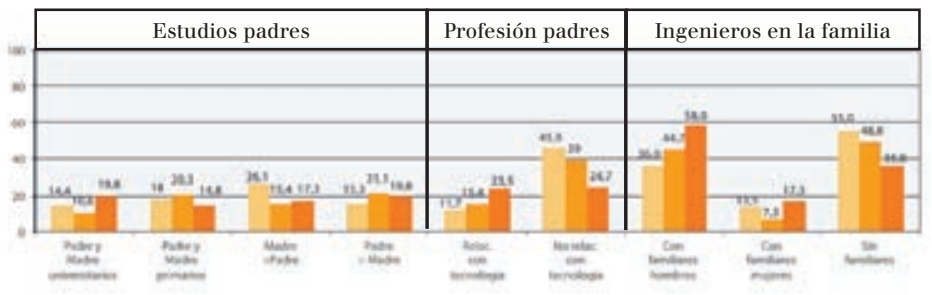

\section{PERFIL ALUMNA}

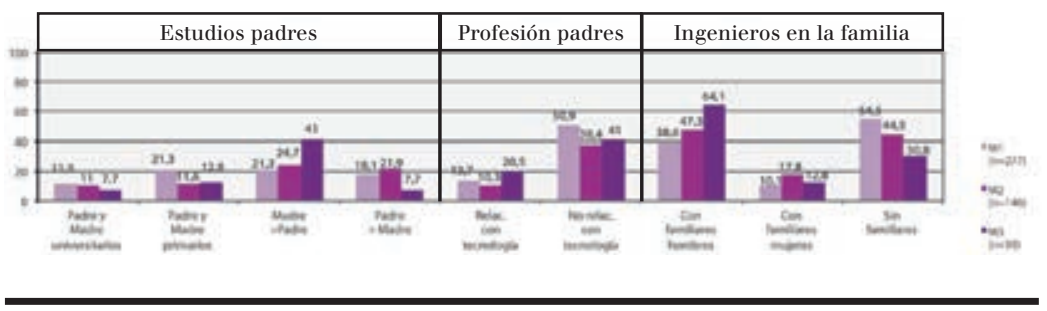

Gráfica 4. Nivel educativo y profesión de madres y padres, así como su relación con la tecnología para grupos de interés femenino (superior) y masculino (inferior). Resultados de los cuestionarios preliminares. 
Del primer grupo de cuestiones se extrajo información significativa del entorno social y familiar. Un hecho interesante es el creciente interés en la ingeniería en parte del grupo de áreas rurales, tanto en hombres, como mujeres. Esta tendencia es incluso más acusada en el cuestionario final, particularmente para las chicas, con más de un $65 \%$ de chicas en M3 provenientes de zonas rurales.

La gráfica 4 muestra información acerca del nivel educativo y profesión de los progenitores y su relación con la tecnología en los grupos de interés. Un dato significativo es que, dentro del grupo M3, hay un alto porcentaje cuyas madres tienen niveles educativos superiores a los padres. Adicionalmente, los miembros de M3 tienen más probabilidad de contar con miembros de su familia que son ingenieros, una tendencia confirmada en el cuestionario final.

Una de las conclusiones más significativas de este estudio ha sido subrayar cómo se percibe que el apoyo familiar en la elección e inicio de una carrera de ingeniería tiene un impacto enorme en los grupos de interés, independientemente del género. La gráfica 5 muestra el apoyo familiar (nivel de acuerdo con la afirmación: «Mi familia me anima a estudiar ingeniería») para los seis grupos de interés. A pesar del hecho de que el alcance de las cartas de actividad de 2008 fue enviado a padres y familias informándoles de la actividad, una de las conclusiones extraídas es que se necesita establecer un contacto más estrecho con padres y tutores y extender el alcance a las familias y no solo a las y a los estudiantes. Esta será una directriz para futuras mejoras.

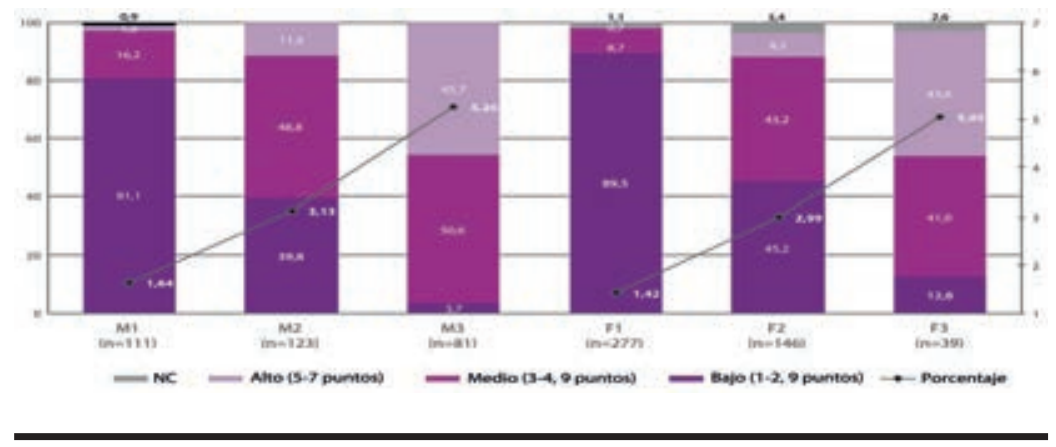

Gráfica 5. El apoyo familiar para los diferentes grupos de interés. Grado de acuerdo con la afirmación: «Mi familia me anima a estudiar ingeniería». Se muestran promedios para cada grupo. La línea une los puntos promedios de los participantes de cada grupo en la escala de 1-7.

Ambos cuestionarios incluyeron una pregunta dirigida a asignarse adjetivos para describir su personalidad. Las diferencias de género son obvias. Hay dife- 
rencias mayores en la percepción atlética, claramente inclinada hacia los chicos, así como en «competitivo» y «auto-confiado». Las chicas se identifican a sí mismas como más «afectuosas», «discretas» y «tímidas» que los chicos. Cuando el análisis es llevado a cabo en base a los grupos de interés, las diferencias persisten o incluso aumentan. Hay una clara diferenciación entre áreas masculinas y femeninas, como en el caso general, y también emergen interesantes diferencias. Los chicos en $\mathrm{H} 3$ se consideran a sí mismos como más analíticos que aquellos en $\mathrm{H} 2$ y $\mathrm{H} 1$, pero esto no se traslada a los grupos de chicas. Los chicos son más competitivos que las chicas en general, pero aquellos en el grupo $\mathrm{H} 3$ lo son todavía más, una tendencia que tampoco se transfiere al grupo M3. En lugar de ello, cuanto mayor era el interés de las chicas hacia la ingeniería, menos atléticas se consideraban ellas mismas, lo cual no era el caso de los chicos (7,7\% del grupo M3 se consideraban atléticas frente a un 67,7\% del grupo H3).

Para analizar el rendimiento académico, se preguntaba cómo de buenas o buenos eran en temas científicos y técnicos. Como cabía esperar por conclusiones de estudios similares, ${ }^{4}$ las chicas tendían a considerarse peores, o no tan buenas como los chicos en todos los campos. Esto se refleja en la gráfica 6 (a). Las diferencias se hicieron más acusadas en el apartado de Tecnología, con un 3,9 de promedio para las chicas frente a un 4.9 para los chicos en autoevaluación para este tema particular. Se analiza en detalle la opinión sobre las matemáticas para los 6 grupos de interés, gráfica 6 (b), las chicas en el grupo F3 se calificaban a ellas mismas más alto que los chicos. Esto también ocurre en física y en los campos restantes (química, tecnología y dibujo técnico), donde aunque las chicas se daban calificaciones inferiores a las de los chicos, las diferencias globales son mucho menores. Considerando la tendencia general de las chicas a ser más modestas o subestimar su conocimiento, el hecho de que F3 tenga una muy alta autoevaluación en matemáticas y física demuestra que ellas son mucho mejores o, al menos, que tienen una más alta autoestima en estas áreas.

Otro punto interesante es el nivel de acuerdo con la afirmación «Considero la ingeniería como un campo difícil»; el $52 \%$ del grupo M1 la considera como muy difícil, en contraposición de solo un 37,8\% del grupo H1. Esta diferencia prevalece en $\mathrm{H} 3$ y M3, donde solo el $19 \%$ de H3 la considera difícil, frente al $30 \%$ del grupo M3.

4 O. Hazzan, D. Levy, A. Tal, «Electricity in the Palms of Her Hands. The Perception of Electrical Engineering by Outstanding Female High School Pupils», IEEE Trans. Education, 2005, vol. 46, n. ${ }^{\circ}$, pp. 402-412. 


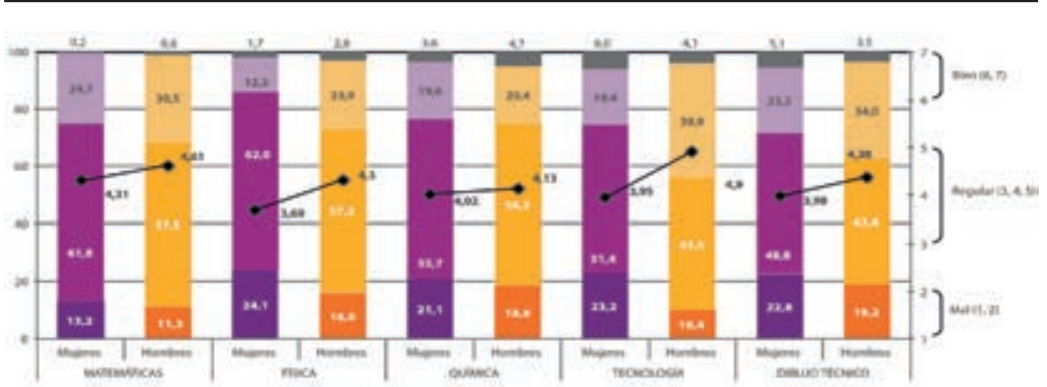

(a)

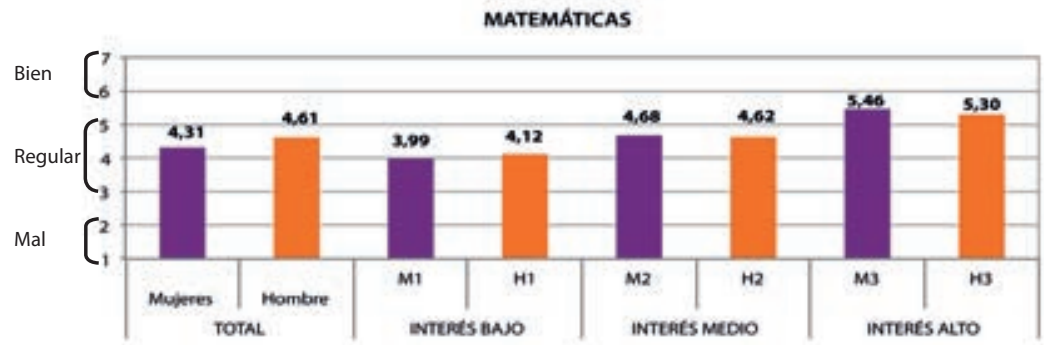

(b)

Gráfica 6. Autoevaluación de mujeres y hombres por grupos de interés (a) en temas relacionados con la ciencia y tecnología, (b) en matemáticas.

La percepción de la ingeniería fue evaluada en el estudio preliminar en base al grado de acuerdo con las siguientes afirmaciones:

1. La ingeniería es considerada una profesión de prestigio.

2. La ingeniería es una profesión creativa.

3. La ingeniería es una buena opción porque uno puede ganar mucho dinero.

4. Me gusta lo que hacen los ingenieros.

5. Estudiando ingeniería seré capaz de ayudar a la gente.

6. La ingeniería hace posible el avance de la Humanidad.

7. La razón por la que menos chicas que chicos estudian ingeniería es porque no contribuye al bienestar de la Humanidad.

La comparación de los resultados de los seis grupos de interés muestra que el único resultado interesante es que M1 tiene una percepción ligeramente mejor de la ingeniería que H1. No hay diferencias significativas entre H3 y M3. Naturalmente, a mayor interés, mejor percepción. La única diferencia es que el $60 \%$ 
de H3 cree que la profesión de la ingeniería conduce a retribuciones más altas, frente a solo el $48 \%$ de $\mathrm{M} 3$, demostrando que las chicas se rigen menos por criterios económicos.

Las afirmaciones 5, 6 y 7 están relacionadas con los valores altruistas de la ingeniería. Ciertos estudios, entre ellos el informe PISA, ${ }^{5}$ parecen conectar la preferencia femenina por ciertas profesiones con la naturaleza altruista y los valores de esos campos. Para investigar este aspecto en profundidad, se añadieron preguntas al cuestionario preliminar. Para simplificar el análisis, como en las anteriores variables, un grupo de tres (cambiando la última afirmación, que está en su forma negativa) fue computado y etiquetado como percepción altruista. La gráfica 7 refleja que cuanto más altruista es la percepción de la ingeniería, mayor es el interés suscitado; este es incluso más así para las chicas, reflejando de este modo que este es un importante punto a abordar en las actividades de sensibilización. De hecho, a los laboratorios seleccionados para participar en el Girls' Day se les solicitó presentar sus proyectos de ingeniería o experiencias de investigación que fueran lo más cercanas posibles a las perspectivas altruista y humanitaria.

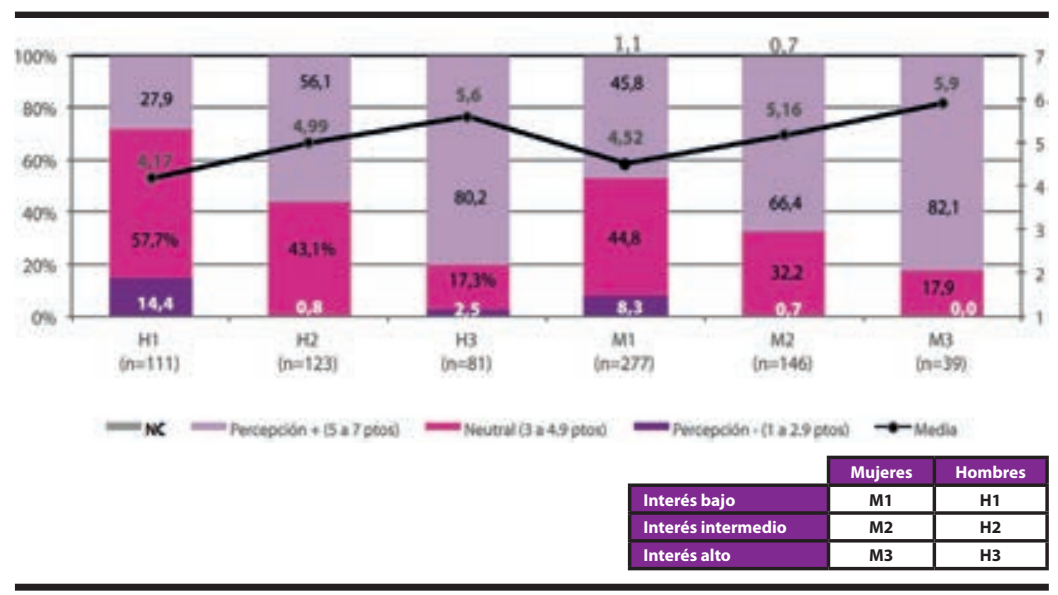

Gráfica 7. Grado de acuerdo con la variable de percepción altruista para diferentes grupos de interés. Resultados globales del nivel de acuerdo con los tres últimos de la tabla. Se muestran los valores promedios de las respuestas (en escala 1-7) para cada grupo.

5 Organisation for Economic Co-operation and Development (OECD), «Programme for International Student Assessment 2003»; http://www.oecd.org/pisa. Último acceso: mayo de 2013. 
Para analizar sesgos de género se pedía valorar las siguientes afirmaciones:

1. La ingeniería es más adecuada para los hombres.

2. A los chicos les gusta más la tecnología que a las chicas.

3. La razón por la que hay menos chicas que chicos en la ingeniería es porque la ingeniería no es para chicas.

4. La razón por la que hay menos chicas que chicos en ingeniería es porque las chicas no son tan buenas en tecnología.

Un agregado (simplemente una suma) de las respuestas a esos puntos fue computada para valorar cómo de masculina se consideraba a la ingeniería. En general, las chicas encontraban la profesión menos masculina de lo que la encontraron los chicos, y las chicas más interesadas en la ingeniería fueron aquellas que la encontraron menos masculina, como muestra la gráfica 8. El último patrón no aparece en el caso de los chicos. Claramente, hay una fuerte oposición general a la afirmación: «La ingeniería es más adecuada para los hombres». M3 es el grupo más en contra esta afirmación (82 \% respondieron 1-2); $\mathrm{H} 1$ también se opuso aunque no tan fuertemente (60\% respondieron 1-2). Los mismos porcentajes aparecen en relación con la afirmación 4: «La ingeniería es para chicas»; esta afirmación es simplemente una reformulación de la afirmación anterior, verificando así estas conclusiones.

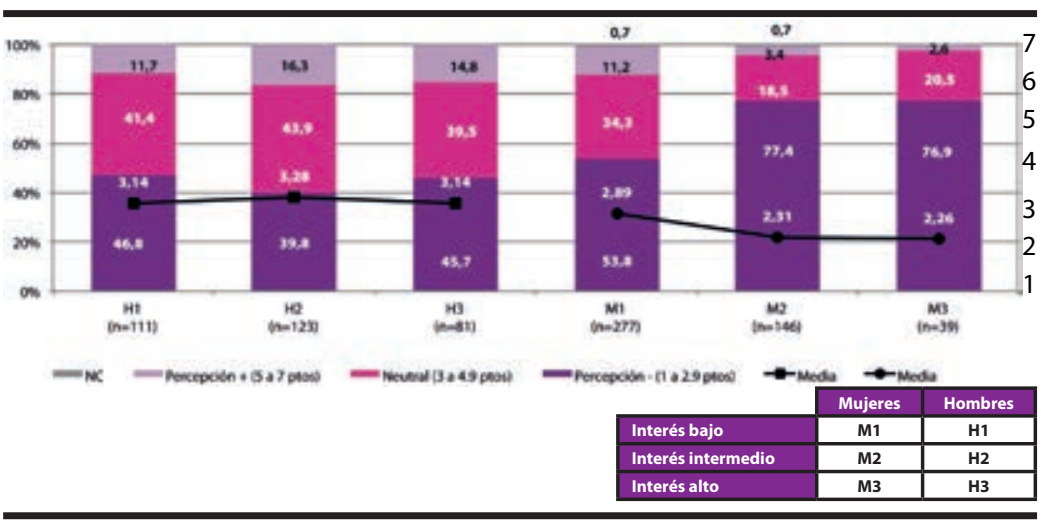

Gráfica 8. Sesgo de género y grupos de interés: bajo, medio y fuerte grado de acuerdo con la afirmación de que la ingeniería es una profesión masculina (agregado). Se muestra el nivel promedio de acuerdo (escala 1-7).

No obstante, para la afirmación: «A los chicos les gusta más la tecnología que a las chicas», no hay prácticamente diferencias en los grupos de interés masculino. En los grupos de chicas, solo M3 está más claramente en contra (59\%) que 
a favor (15\%) de esta afirmación. Hay muchos hallazgos interesantes relacionados con la percepción de la ingeniería que será objeto de un futuro estudio. En cualquier caso, la mejora de la percepción de género de la ingeniería, sobre todo en lo que respecta a los chicos, es una importante tarea que cumplir.

Al final del cuestionario se evaluó el impacto del Girls' Day. Como ya se ha mencionado, el interés en comenzar un grado de ingeniería se ha incrementado gracias al Girls' Day. La siguiente tabla compara la distribución de los grupos de interés antes y después de la actividad: el interés incrementó en los seis grupos. Es cierto que quienes respondieron al cuestionario final pudieran tener una inclinación más marcada a comenzar estudios de ingeniería, incluso antes de que la actividad de sensibilización tuviera lugar, pero no es viable estudiar este aspecto con cuestionarios independientes. Sin embargo, el método por el cual las diferentes instituciones eligieron a los asistentes no se restringió a estudiantes con interés en ingeniería, en general, asistieron clases enteras, independientemente de las inclinaciones o interés previos.

\section{GRUPOS DE INTERÉS ANTES Y DESPUÉS DEL GIRLS' DAY}

\begin{tabular}{|l|c|c|}
\hline & \%en cuestionario previo & \% en cuestionario posterior \\
\hline M1 & 59,1 & 45,3 \\
M2 & 31,1 & 43,1 \\
M3 & 8,3 & 10,5 \\
H1 & 34,9 & 27,9 \\
H2 & 38,7 & 40,1 \\
H3 & 25,5 & 28,5 \\
\hline
\end{tabular}

La gráfica 9 presenta una evaluación directa de la utilidad del Girls' Day, tras participar en la jornada, en relación con la intención de comenzar estudios de ingeniería. El bajo nivel promedio, de acuerdo con este punto acerca de la motivación para estudiar ingeniería (especialmente en el caso de las chicas) y con la afirmación «La actividad de sensibilización me ha llevado a reconsiderar mi elección de estudios», es un indicio de la necesidad de bajar la edad de los futuros asistentes.

La percepción positiva de la ingeniería incrementó en todas las respuestas individuales por, al menos, un promedio de 0,2 puntos (excepto para la pregunta con respecto a los ingresos económicos de los ingenieros, que muestra un descenso muy pequeño). Los mayores incrementos (de hasta 0,5 puntos) se dan en aquellas afirmaciones referidas a valores altruistas, resultado muy satisfactorio para las organizadoras. 


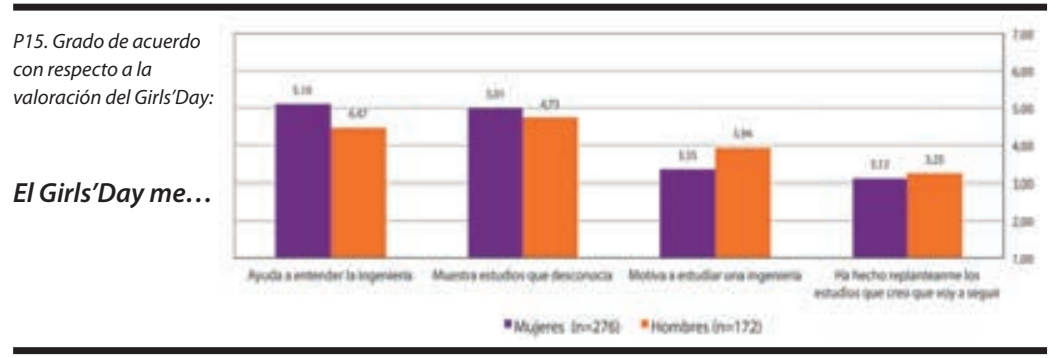

Gráfica 9. Evaluación directa final de la utilidad del Girls' Day. Nivel de acuerdo con las afirmaciones promediadas por género.

Las afirmaciones que se referían al sesgo de género fueron formuladas de una manera ligeramente diferente en el cuestionario final. La razón detrás de este cambio fue mejorar la compresión de las afirmaciones y evitar sesgos. Por ejemplo, la comparación de los resultados de la afirmación: «La ingeniería no es para chicas» del segundo cuestionario con la afirmación: «La ingeniería es más adecuada para hombres», en el cuestionario preliminar, reveló que el desacuerdo aumentó tanto en promedio como para cada grupo de interés. Esta tendencia prevaleció en todas las afirmaciones sujetas a comparación directa.

La gráfica 10 muestra la evaluación directa de la actividad realizada. En general, esta edición del Girls' Day recibió una evaluación muy positiva, más por chicas que por chicos, con una clara preferencia por un evento más largo y más centrado en demostraciones de laboratorios. Un dato reseñable es que en las respuestas no se observa convencimiento del beneficio de restringir la actividad a las chicas. Ellos fueron relativamente más favorables que ellas a que fuera un evento únicamente de chicas.

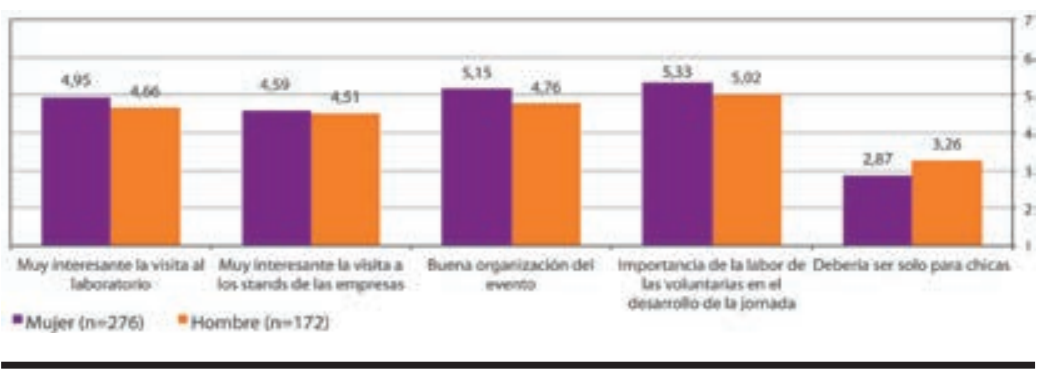

Gráfica 10. Evaluación del Girls' Day mostrando las diferencias de mujeres y hombres. 
A partir de los resultados de este estudio y sobre todo al ver la brecha de género existente en la intencionalidad de estudiar ingeniería en esta edad, las organizadoras del Girls' Day decidimos que debíamos bajar la edad de realización de la actividad y «atacar» el problema con anterioridad. Por este motivo, se planteó la segunda edición del Girls' Day orientada a alumnos de $3 .^{\circ}$ y $4 .^{\circ}$ de la ESO. Otra decisión tomada fue eliminar las encuestas previas ya que, al ser anónimas, no se podían asociar los resultados con los posteriores y, en general, los resultados eran bastante similares. La gran ventaja de haber hecho dos encuestas, con el volumen de datos que esto supuso, fue haber podido constatar los datos positivos de la acción que se muestran en la tabla 3, con un cierto aumento de las vocaciones femeninas.

También, el largo proceso de los datos y la falta de resultados concretos de algunas preguntas nos llevaron a mejorar sustancialmente las cuestiones de la encuesta, corrigiendo algunas o incluso eliminándolas y añadiendo algunas otras.

La segunda edición del Girls' Day tuvo un gran éxito de acogida y pudimos llevar a cabo 728 encuestas tras la participación en el evento. Al igual que en la edición anterior, el estudio de nuevo fue realizado por una empresa profesional de estudios de marketing, opinión y socioeconómicos. La brecha entre hombres y mujeres interesados en estudiar ingeniería sigue existiendo aun cuando la edad media era inferior. La gráfica muestra los porcentajes correspondientes a la encuesta de este año, igualmente clasificados en $\mathrm{H1}, \mathrm{H} 2, \mathrm{H} 3, \mathrm{M} 1, \mathrm{M} 2, \mathrm{M} 3$, en función de su interés en estudiar ingeniería. Se observa un grupo de indecisos mayor que en la encuesta anterior.

Sin embargo, los resultados con respecto a las potenciales variables motivadoras hacia la ingeniería son descorazonadores. No se observa ningún tipo de cambio entre M1, M2 y M3 en casi todas las variables de estudio analizadas. Curiosamente, los hombres parecen tener motivaciones claras entre los que sí que desean estudiar ingeniería, los H3. La gráfica 12 muestra una tabla resumen de los resultados que se obtuvieron con las variables (resultados agregados de varias preguntas de la encuesta). En el caso de los hombres (en azul) las medias, en general, se incrementan proporcionalmente al interés. En el caso de las mujeres, prácticamente nada.

Otro resultado, consecuente de bajar la media de edad de las y los participantes en esta edición, fue que no se refleja la percepción de las M3 de ser buenas en matemáticas o física, por encima de lo que piensan los pertenecientes al grupo $\mathrm{H} 3$ y, por supuesto, las mujeres en general. Resultó difícil preguntar acerca de materias concretas como física o tecnología, ya que apenas habían 
comenzado a tener estas materias como asignaturas en los planes de estudio. La única prevalencia con respecto al año anterior parece ser el apoyo de la familia como factor de apoyo de estudiar ingeniería.

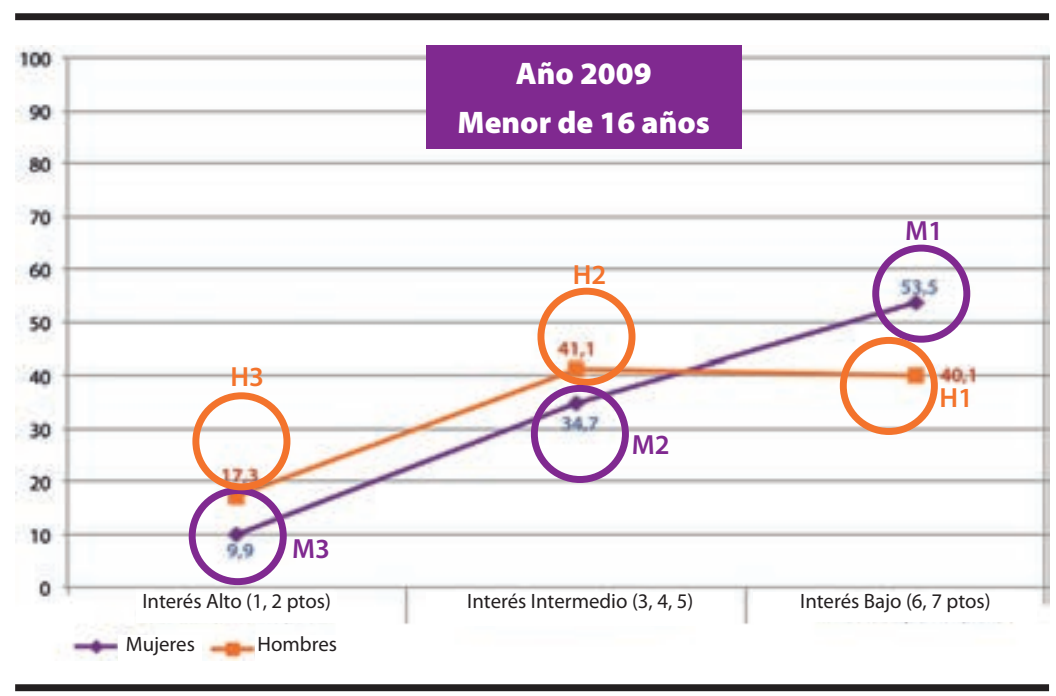

Gráfica 11. Porcentajes de hombres y mujeres en función del interés hacia la ingeniería.

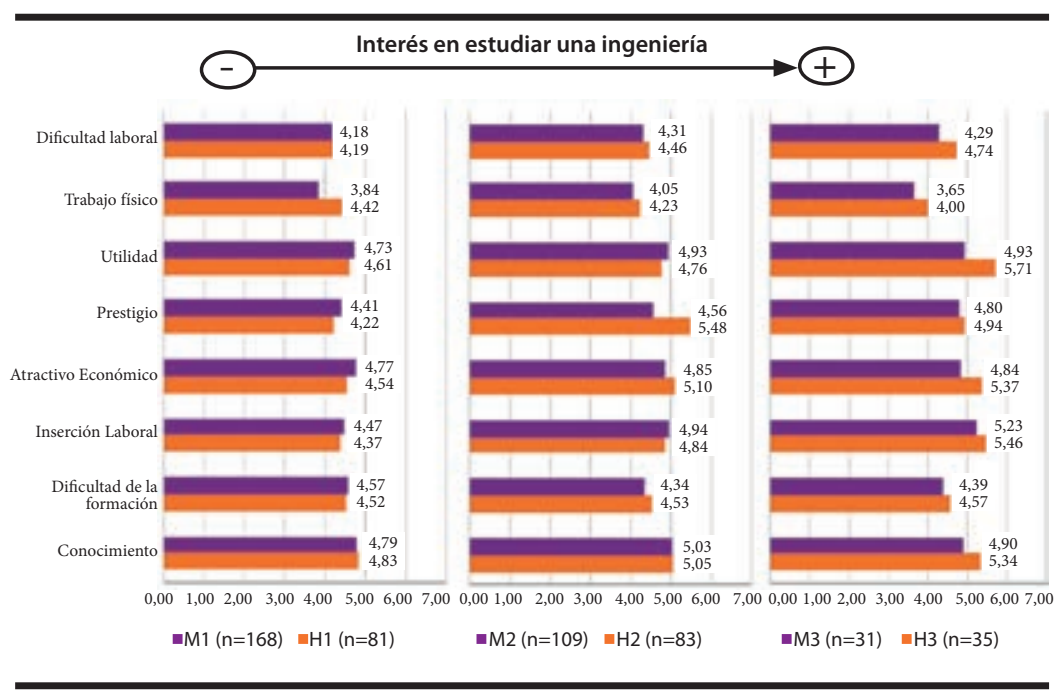

Gráfica 12. Variables de interés motivadoras hacia la ingeniería bajo análisis en función de género y el interés manifiesto hacia la ingeniería. 
La conclusión fundamental que obtuvimos con el estudio de la segunda edición del Girls' Day fue el error en rebajar la media de edad. De hecho, y esto se puede apreciar en el capítulo siguiente, la inmensa mayoría del alumnado toma su decisión más tarde (en Bachillerato); resulta, por tanto, más oportuno concentrarnos en los indecisos y esperar a llevar a cabo la experiencia a que estén en Bachillerato, independientemente de la existencia ya, incluso a esta edad, de la brecha de género en el interés por estudiar ingeniería. Se detectó, no solo por los resultados del estudio, sino por las impresiones de las voluntarias, una cierta falta de madurez hacia una iniciativa de este estilo. De nuevo, y de cara al siguiente Girls' Day que tuvo lugar unos meses después de obtener los resultados de este estudio, se decidió aumentar la edad media de los participantes y dirigirlo a Bachillerato o cuarto de la ESO.

La encuesta realizada en el Girls' Day 2011 a un total de 521 estudiantes es la versión que se ha decidido incorporar en el anexo B de este libro, ya que, tras las diversas iteraciones y mejoras entre ediciones, es la que las autoras de este libro consideramos definitiva. Se corrigieron diversas preguntas que podían dar lugar a equívocos y se afinó la forma de preguntar ciertas cuestiones para clarificar mejor las respuestas obtenidas.

La gráfica 13 muestra los porcentajes de interesados hacia estudiar una ingeniería por sexo en este año.

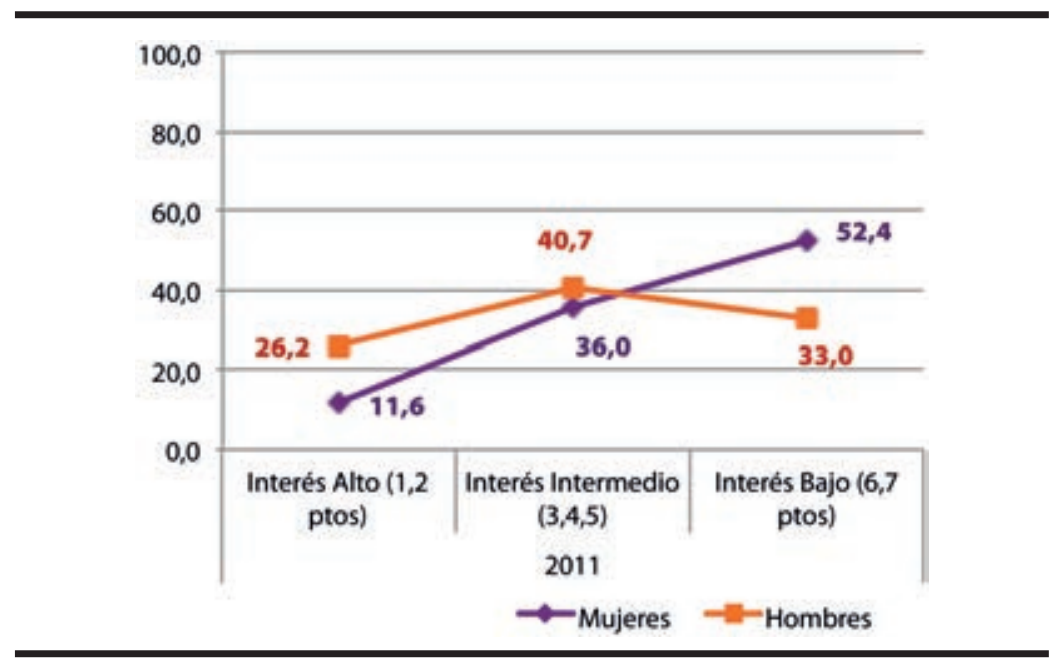

Gráfica 13. Porcentajes de hombres y mujeres en función del interés hacia la ingeniería en el tercer año de estudio. 
En esta edición reaparece la mejor percepción de las M3 de sus capacidades en matemáticas y física. Mejores que los varones, incluso los propios H3. Y, también, resulta significativo el apoyo de la familia como se muestra en la gráfica 14.

P12. Hay personas que desaconsejan a las chicas estudiar ingeniería utilizando distintos argumentos. Indica el grado de acuerdo o desacuerdo con los distintos argumentos... 1 (Nada de acuerdo) al 7 (Totalmente de acuerdo).

Mi familia me anima a que estudie ingeniería

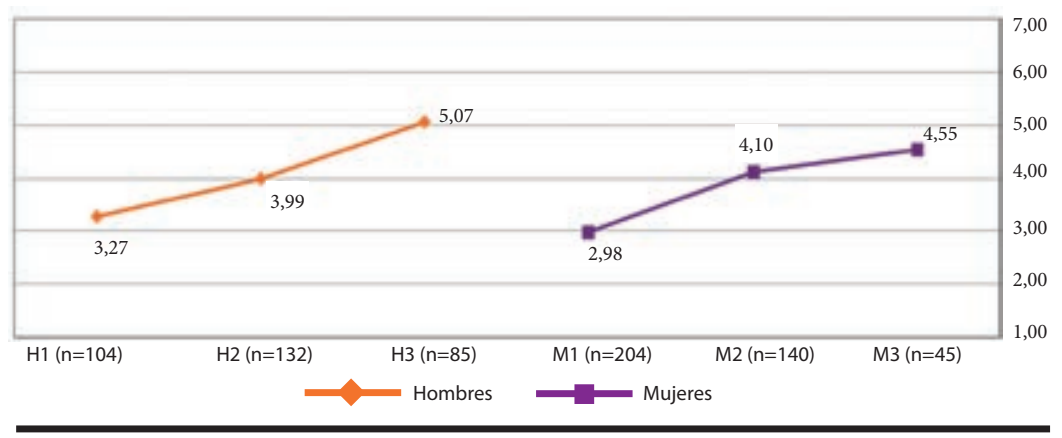

Gráfica 14. Apoyo de la familia percibido por sexo y grupo de interés.

La gráfica 15 presenta resultados interesantes, repetidos, en general, a través de las tres ediciones, acerca de la visión de la profesión en relación con el género. Como se puede observar, las mujeres, en general, las M3 aún más, son muy contrarias a una visión sesgada de las profesiones en general y la ingeniería en particular. En todos los casos, las respuestas de los hombres son sustancialmente más suaves, más cercanas a la masculinización de la profesión. Esto es una tendencia, no solo presente en este estudio, que se pone de manifiesto en otros estudios sociológicos llevados a cabo con jóvenes. ${ }^{6}$

La gráfica 16 muestra los resultados de la evolución de la valoración de la experiencia del Girls' Day (sobre una escala de 1-7) para las chicas. En la parte derecha, se muestran desagregadas las respuestas de chicas y chicos. Como se puede observar, la experiencia está bien valorada y se ha ido mejorando en todos los aspectos a lo largo de las tres ediciones. Resulta, no obstante, curioso que ante la pregunta de si la experiencia motiva a realizar estudios de ingeniería, la respuesta en media sea de 3,55 (sobre 7), es decir, un valor muy templado 
P11. Indica tu grado de acuerdo con las siguientes afirmaciones....1 (Nada de acuerdo) al 7 (Totalmente de acuerdo).

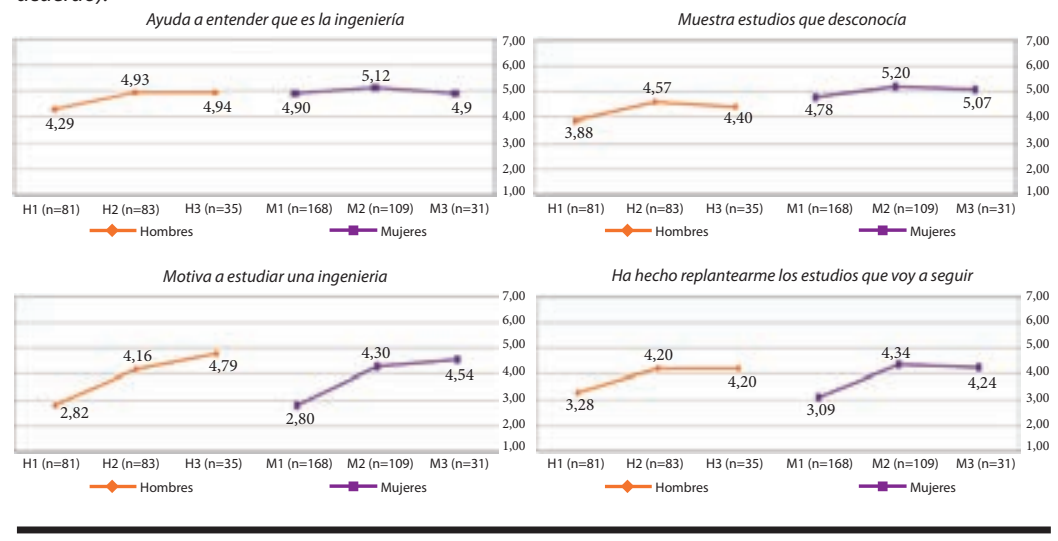

Gráfica 15. Relación entre ingeniería y género por sexo y grupo de interés.

P13. Grado de acuerdo con las siguientes afirmaciones con respecto a tu valoración del Girls'Day... 1 (Nada de acuerdo) al 7 (Totalmente de acuerdo).

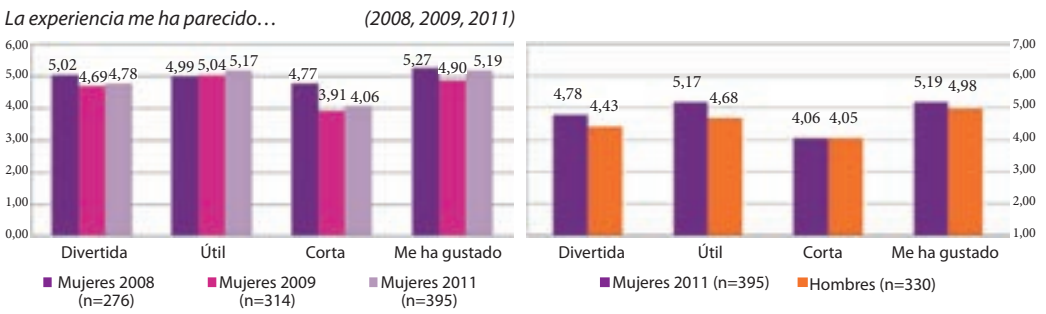

P15. Grado de acuerdo con respecto a la valoración del Girls'Day... 1 (Nada de acuerdo) al 7 (Totalmente de acuerdo).

El Girls'Day me...

$(2008,2009,2011)$

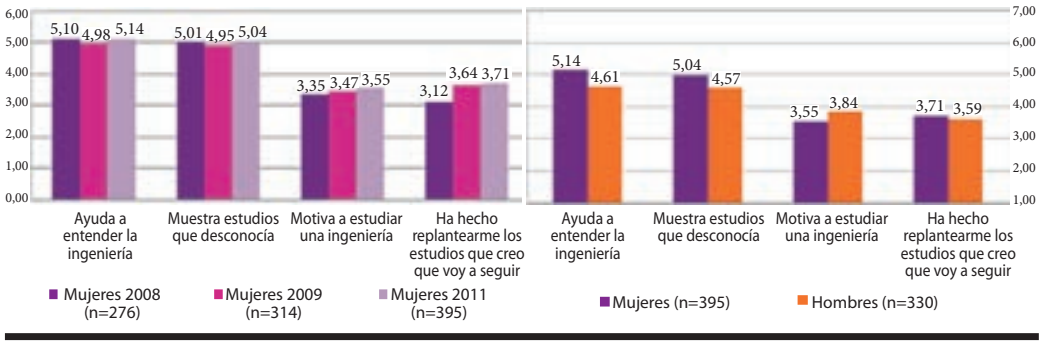

Gráfica 16. Valoración de diversos aspectos del Girls’ Day a lo largo de las ediciones y para la tercera de ellas, la de 2011, por sexo. 
para el esfuerzo que supone la realización de una actividad de estas características. Es más, se presenta ligeramente más motivadora para hombres que para mujeres $(3,89$ en media frente a 3,55$)$. Este ha sido uno de los factores que nos hace replantearnos el desarrollo de la actividad, $y$, junto con la reducción general de ayudas financieras a la misma, la cuarta de las ediciones fue únicamente para chicas, y únicamente para aquellas que tenían un interés manifiesto en aprender lo que se lleva a cabo y, en todo caso, principalmente alumnas de Bachillerato. No se cierra la presencia de chicos en el evento; pero se dirige a los institutos y colegios a otros eventos de divulgación de la tecnología si lo que pretenden es asistir con todo el alumnado de forma generalizada a un evento de este tipo.

En la cuarta edición del Girls' Day, no se llevaron a cabo encuestas a las participantes, en parte, porque por la falta de hombres y lo sesgado de la asistencia los resultados, desde un punto de vista sociológico, no podrían tenerse en cuenta para estudios de estas características. No obstante, la realimentación obtenida por las asistentes y las voluntarias fue excelente, verificando que la calidad es mejor en muchos casos que la cantidad.

\section{Conclusiones de los estudios sociológicos}

El resultado más claro de los cuatro estudios realizados, su exhaustivo análisis y un gran número de horas cruzando datos para tratar de obtener tendencias nos permiten únicamente concluir en la enorme complejidad de las relaciones entre tecnología y sociedad, percepción de la ingeniería por los jóvenes e interés por la misma. También podemos confirmar que la brecha de género para estudiar tecnología es manifiesta y muy temprana (aparece claramente antes de los 16 años) pero que, manejando convenientemente el gran número de indecisos ante la ingeniería (especialmente a tan temprana edad), se podría llegar a revertir la tendencia. Cuando hemos podido analizarlo, hemos constatado que una acción de estas características influye y mejora su visión de la ingeniería. En general, los aspectos motivadores hacia una carrera técnica son los mismos para mujeres que para hombres, algo más el sueldo y el prestigio social para los hombres y para las mujeres un poco más la visión más altruista de la utilidad de la ingeniería con la sociedad, pero no significativamente. En general, los hombres que quieren estudiar ingeniería tienen algo más claro el porqué y las mujeres no tanto. En todos los casos aparece que el apoyo de la familia resulta decisivo. Con esta única variable segura en mente, el apoyo de la familia y también 
de los orientadores o profesores, nos hemos llegado a plantear la organización de un Girls' Day o bien otras acciones específicas, orientadas a progenitores y orientadores. Estamos estudiando las posibles fórmulas para hacerlo.

Para finalizar, la conclusión es que no hay conclusión. Que las diferencias, aunque existentes, no son lo suficientemente significativas como para poder centrarnos en puntos muy concretos. Es obvio que el conocimiento de la profesión, la visión de utilidad y altruismo de la misma, el prestigio social son factores de apoyo, pero tanto para hombres como para mujeres, incluso más para hombres. Lo único que vemos determinante es el apoyo de la familia como clave del interés. Se pone de manifiesto la compleja imbricación entre tecnología, sociedad y género. Motivadas por esta falta de resultados que nos pudieran ser de ayuda en las siguientes ediciones del Girls' Day para aumentar las vocaciones femeninas, en MUCIT nos plantemos realizar encuestas a todos los estudiantes de las titulaciones de grado para poder evaluar cuáles habían sido los factores determinantes para su elección. Este fue el origen del estudio que se presenta a continuación. 


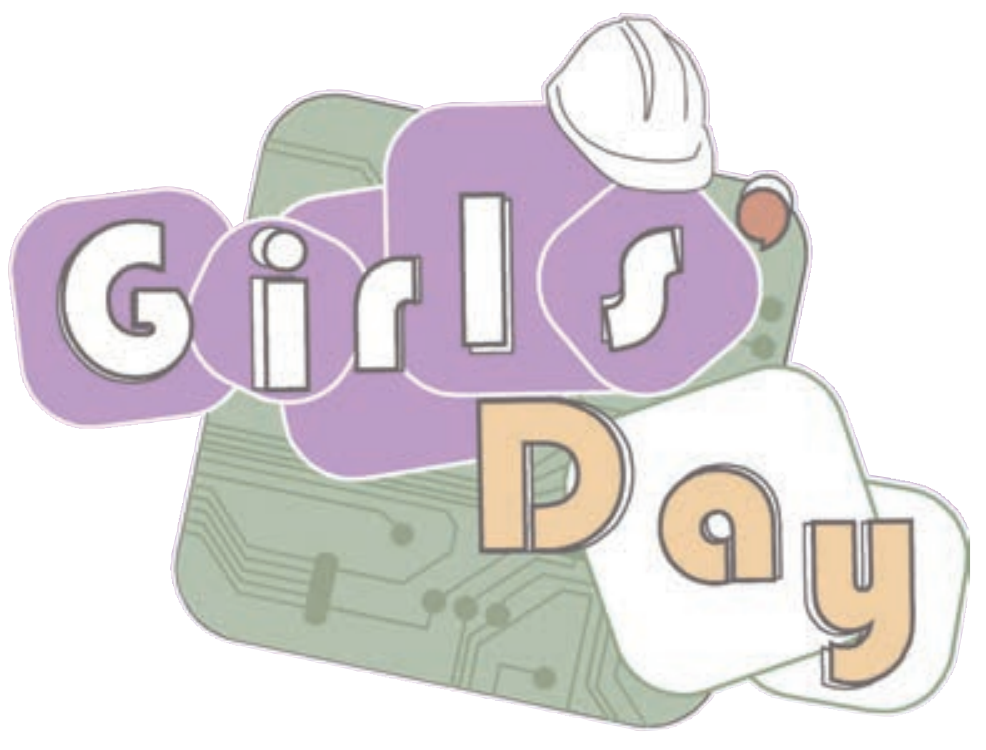




\section{Estudiantes de ingeniería: procedencias y perfiles}

María Villarroya Gaudó

Pilar Molina Gaudó

SANDRA BALDASSARRI 
En nuestro objetivo de tomar medidas para fomentar la existencia de ingenieras y tecnólogas, decidimos analizar las diferencias de los perfiles de las y los estudiantes que ingresaban en las carreras de grado en ingeniería.

Para ello realizamos una encuesta en la Escuela de Ingeniería y Arquitectura de la Universidad de Zaragoza, en abril de 2011, curso en el que se implantaron las titulaciones de grado.

Al realizar este estudio, se pretendía conocer las razones que llevan a las alumnas de ingeniería a elegir esta opción de futuro y tratar de usarlas como motivación en otras alumnas de Secundaria y Bachillerato. Aunque esperábamos obtener alguna tendencia muy clara de estas razones, en realidad, solo hemos apreciado algunas pequeñas diferencias. Sin embargo, confiamos que este estudio sirva para tomar más medidas en el futuro y, sobre todo, para conocer si existen condicionantes sociales y educativos que llevan solo a una muy pequeña proporción de las universitarias a elegir carreras técnicas.

En este apartado, se ponen en valor los resultados más significativos del estudio realizado al alumnado de primer curso de los grados en Ingeniería de Tecnologías Industriales, Ingeniería de Tecnologías y Servicios de Telecomunicación, en Ingeniería Informática, en Ingeniería Química, en Ingeniero en Diseño Industrial y Desarrollo de Producto, en Ingeniería Electrónica y Automática, en Ingeniería Mecánica y en Ingeniería Eléctrica. Los datos cuantitativos completos aparecen en el anexo $C$.

Comenzamos el análisis por los perfiles del alumnado encuestado y su entorno social y familiar. La primera diferencia notable que encontramos es que, del total del alumnado masculino, un $56,8 \%$ tiene su residencia habitual en capital de provincia, mientras que de las mujeres son un $65,8 \%$. Hay prácticamente diez puntos de diferencia, esto indica que es precisa una labor de acercamiento de las mujeres a la ingeniería en las poblaciones con menos de 10000 habitantes. Dicho de otro modo, en el mundo rural, los roles de género tradicionales conservan aún más peso y hacen que la proporción de ingenieras siga siendo menor. En relación con los estudios de los progenitores, parece que su mayor formación y en particular la de las madres favorece ligeramente el hecho de que ellas 
estudien ingenierías. Observamos que los casos en que el padre tiene estudios primarios son diez puntos por encima en el caso de los chicos que de las chicas, y que ellas tienen más madres con titulación universitaria superior $(22,8 \%$, frente a un 15,4\%). Parece que la existencia de referentes familiares que se dedican a la ingeniería influye notablemente (más del $50 \%$ de ellos tienen algún familiar y el $55 \%$ en el caso de ellas). La situación laboral, sobre todo de las madres, es también un dato a considerar; las madres que trabajan actualmente son un $74,7 \%$ en el caso de ellas y un $65,6 \%$ en el caso de ellos. Por tanto, comprobamos con estos datos que se repiten los resultados de otros estudios, donde la formación y la dedicación de las madres es determinante para que las chicas estudien ingeniería (no se observa esta vinculación tan clara en el caso de los chicos). Así mismo hay una leve diferencia de la existencia de referentes próximos en la familia que sean ingenieras o ingenieros.

Más del $80 \%$ del alumnado estudia la titulación que había elegido en primera opción y un alto porcentaje del resto la segunda opción. La decisión de qué estudios cursar la han realizado fundamentalmente en el Bachillerato, de ahí que sea en ese momento cuando se deben realizar acciones para acercar la ingeniería al alumnado, si bien, hay decisiones de itinerarios que se toman con anterioridad y pueden determinar la formación a seguir.

Con respecto a la información utilizada para tomar la decisión, la recogen de Internet en la mayoría de los casos, seguido por el profesorado de secundaria y charlas en los centros educativos. Las alumnas, en particular, manifiestan que no fue excesivamente buena la información del profesorado de su centro; esta situación hace que nos replanteemos dirigir acciones hacia este colectivo. Un dato importante, sobre todo para las organizadoras del Girls' Day, es que el $7 \%$ del alumnado encuestado, tanto masculino como femenino, había recibido información a través del Girls' Day de ediciones anteriores, por tanto, la actividad cumple sus objetivos. El objetivo de la siguiente parte del estudio consistía en detectar diferencias en la valoración de la ingeniería por ellas y ellos y si tienen razones para ver en la profesión sesgos de género. Los resultados significativos se muestran en las siguientes tablas y diagramas, la valoración debía ser entre 1 y 4 (1, nada de acuerdo; 2, poco de acuerdo; 3, bastante de acuerdo; 4, totalmente de acuerdo). La siguiente gráfica muestra la valoración de la ingeniería; observamos que tienen una percepción similar de la ingeniería tanto ellas como ellos, en relación con el esfuerzo que supone y no observamos diferencias significativas según el sexo de quienes respondieron la encuesta. Las estudiantes son más cautas a la hora de valorar que el título de ingeniería facilita encontrar trabajo y, además, ven la profesión más absorbente. 


\begin{tabular}{|l|l|ccc|}
\hline \multicolumn{3}{|c|}{ VALORACION DE LA INGENIERIA } & TOTAL & $\mathbf{7 9}$ \\
\hline \\
\hline 1
\end{tabular}

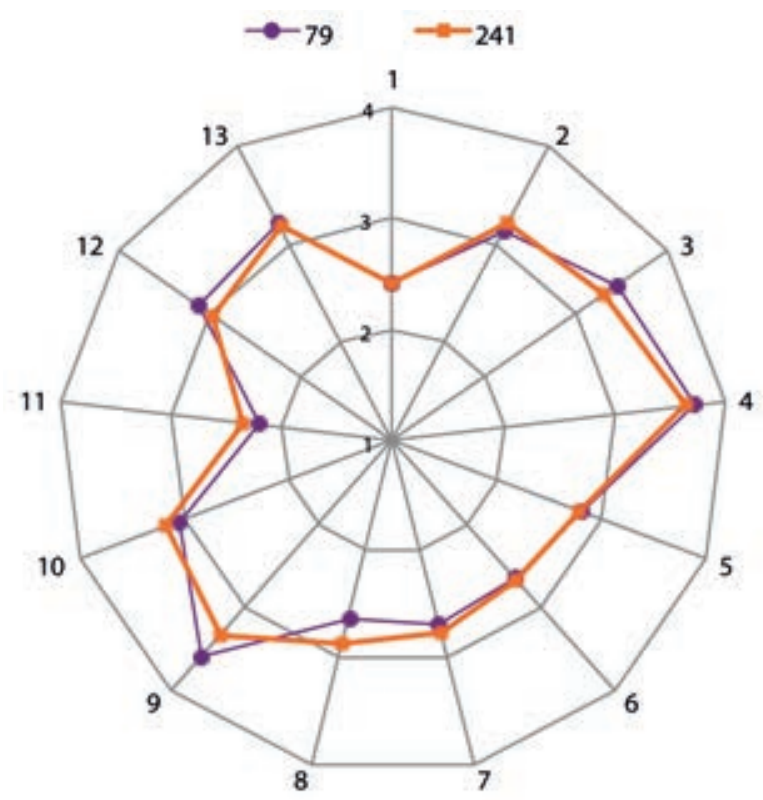

Valoración de la ingeniería del alumnado de la Escuela de Ingeniería y Arquitectura. 


\begin{tabular}{|c|c|c|c|c|c|}
\hline \multirow[b]{2}{*}{1} & \multicolumn{2}{|r|}{ VALORACION DE LA INGENIERIA } & TOTAL & mujeres & hombres \\
\hline & \multirow{4}{*}{ 迩 } & El trabajo de ingeniería es más femenino que masculino & 1,45 & 1,45 & 1,46 \\
\hline 2 & & El trabajo de ingeniería es más masculino que femenino & 2,43 & 2,43 & 2,43 \\
\hline 3 & & $\begin{array}{l}\text { Las carreras universitarias no son ni femeninas ni } \\
\text { masculinas }\end{array}$ & 3,37 & 3,68 & 3,27 \\
\hline 4 & & El trabajo de ingeniería no es ni masculino ni femenino & 3,43 & 3,60 & 3,37 \\
\hline \multirow{2}{*}{5} & \multirow{2}{*}{ 㟧 } & $\begin{array}{l}\text { Ciertas capacidades mentales asociadas con la ingeniería } \\
\text { están más desarrolladas en general en los hombres que } \\
\text { en las mujeres }\end{array}$ & 1,90 & 1,60 & 2,00 \\
\hline & & $\begin{array}{l}\text { Lios hombres tienen más capacidad técnica que las } \\
\text { mujeres en general }\end{array}$ & 1,88 & 1,51 & 2,00 \\
\hline 7 & $\frac{\alpha}{8}$ & $\begin{array}{l}\text { Los hombres tienen más apoyos que las mujeres a la hora } \\
\text { de escoger una carrera de ingeniería }\end{array}$ & 2,23 & 2,31 & 2,20 \\
\hline \multirow{3}{*}{8} & \multirow{3}{*}{ 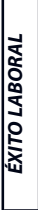 } & $\begin{array}{l}\text { Una mujer ingeniera tiene más fácil encontrar trabajo que } \\
\text { un hombre ingeniero }\end{array}$ & 1,74 & 1,68 & 1,76 \\
\hline & & $\begin{array}{l}\text { Ün hombre ingeniero tiene más posibilidades de } \\
\text { promocionar laboralmente que una mujer ingeniera }\end{array}$ & 1,98 & 2,07 & 1,95 \\
\hline & & $\begin{array}{l}\text { Mis posibilidades de éxito en una carrera universitaria y } \\
\text { profesional no están relacionadas en absoluto con que yo } \\
\text { sea hombre o mujer }\end{array}$ & 3,42 & 3,47 & 3,40 \\
\hline 11 & 高 & $\begin{array}{l}\text { Está mejor visto socialmente que un hombre estudie } \\
\text { ingeniería que que lo haga una mujer }\end{array}$ & 2,05 & 2,13 & 2,02 \\
\hline
\end{tabular}

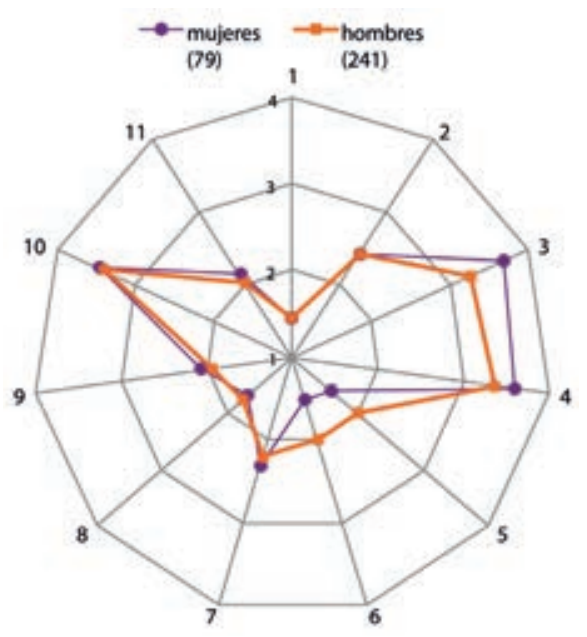

Percepción de género en la ingeniería por el alumnado de primer curso de los grados en Ingeniería. 
Las últimas preguntas iban dirigidas a analizar sesgos de género en la percepción tanto de los estudios de ingeniería, como en la profesión. La siguiente tabla y el diagrama muestran las respuestas de las y los estudiantes. Observamos contradicción en algunas preguntas, ya que la mayor parte de las respuestas dicen estar de acuerdo con: «el trabajo de ingeniería no es ni masculino ni femenino» y, por otro lado, un porcentaje no despreciable dice estar de acuerdo con «el trabajo de ingeniería es más masculino que femenino». Otro factor significativo es que ellos se ven más capaces y con más aptitudes que ellas para estudiar ingeniería. Afortunada o desgraciadamente, ellas manifiestan que el éxito profesional no está relacionado con su sexo. Es una buena señal en el sentido de que ven la igualdad real, pero, por otro lado, choca con los datos estadísticos que constatan que aún hoy el progreso en la escala profesional de las mujeres es más lento, en todos los campos en general y también en ingeniería.

Este estudio ha cumplido su objetivo puesto que aporta líneas para seguir trabajando, razones por las que seguir realizando actividades como el Girls' Day. Si bien no es completamente concluyente sobre los perfiles y las razones que llevan a las chicas a elegir la ingeniería como su salida profesional.

En la recogida de datos, contamos con la colaboración de una estudiante del Máster de Relaciones de Género y con el apoyo de la dirección de la Escuela de Ingeniería y Arquitectura para coordinar la realización de las encuestas en las aulas, a quienes agradecemos su colaboración y, por supuesto, al alumnado que, de forma voluntaria, contestó a los cuestionarios. 


\section{Reflexiones finales a modo de conclusión}

SANDRA BALDASSARRI

Pilar Molina Gaudó

María Villarroya Gaudó 
En los últimos treinta años, las mujeres componen en proporciones similares o incluso superiores a los hombres el alumnado universitario de España, pero en los campos tecnológicos todavía son una minoría. Su presencia en las escuelas de ingeniería se incrementó durante unas décadas, pero en los últimos lustros se ha estancado y en algunas disciplinas incluso está descendiendo.

Los testimonios de nuestras pioneras, las primeras ingenieras, las primeras tecnólogas, muestran que sus vidas no han sido fáciles, que han sido mujeres privilegiadas y que han contado con cualidades y capacidades intelectuales extraordinarias. Además, han tenido apoyos en sus círculos profesionales $y_{\text {, }}$ sobre todo, personales que les han permitido introducirse en áreas altamente masculinizadas. Desgraciadamente, también han sufrido situaciones difíciles, de hostilidad con algún compañero, de minusvaloración de su labor, de falta de reconocimiento de todos sus méritos.

Durante estos años, analizando los datos de distintos trabajos científicos y estudios sociológicos (propios o de otras compañeras) hemos constatado que nuestra situación tanto personal como estadística, en la Universidad de Zaragoza, no es un caso particular, sino que es solo un reflejo más de lo que ocurre en nuestro país, pero también en Europa y en otros muchos países.

La situación no va a cambiar por sí sola. Debemos ser conscientes de la realidad en la que vivimos, donde el acceso a la tecnología y a la ingeniería no es igual para mujeres y para hombres. Como se ha visto en los resultados publicados en este libro, las familias de origen de las y los estudiantes de ingeniería corresponden a patrones sociales distintos $y$, por ende, la igualdad en el acceso a la formación, teóricamente alcanzada, está lejos de la realidad.

La libertad de elección está condicionada por el ambiente, es decir, no se trata de una libertad completa que muchas jóvenes creen tener en sus manos. Esta falsa libertad, esta falsa igualdad, resulta una traba en el progreso de las mujeres en todos los campos del conocimiento y profesionales, en particular en la ingeniería.

Entendemos que para las niñas y jóvenes siguen faltando modelos de referencia de ingenieras y tecnólogas. Afortunadamente, cada vez más medios de 
comunicación comienzan a ser sensibles con esta situación y empiezan a mostrar el perfil más humano de la tecnología, mostrando las contribuciones de mujeres que han comenzado y siguen participando en esta «revolución tecnológica» que estamos viviendo.

Hoy, tras cuatro ediciones exitosas de la actividad, tras numerosas conferencias y charlas en distintos foros académicos y no tan técnicos contando la iniciativa, podemos sentirnos satisfechas por el esfuerzo y el camino recorrido. Si bien, son solo los primeros pasos, porque todavía nos queda un trecho hasta que la igualdad entre mujeres y hombres en el ámbito de la tecnología, la ingeniería y la arquitectura sea una realidad.

A pesar de que la incorporación de mujeres en los estudios técnicos en los últimos años ha sido importante, siguen existiendo considerables barreras especialmente cuando tienen que salir al mundo laboral. Al problema inicial de mayor dificultad a la hora de ser contratadas, se le une la cuestión de poder promocionar en igualdad real de condiciones.

Asociarnos, conocernos, relacionarnos nos ayuda a continuar trabajando en nuestro campo, a que la sociedad nos visibilice, a darnos apoyo mutuo, a que sigamos confiando en nosotras mismas, a que valoremos cada vez más nuestros logros y nuestras contribuciones a la técnica. En definitiva, a que seamos conscientes de que la existencia de ingenieras es tan necesaria, como lo es la de los ingenieros.

Por ello, continuaremos trabajando, seguiremos aportando nuestro pequeño granito de arena, para que nuestras hijas no sufran las barreras que sufrieron nuestras abuelas, cuando les daban los puestos a sus compañeros solo por el hecho de ser hombres, para que vean que ellas pueden y que, de verdad, cuenten con los apoyos, de toda la sociedad, para conseguir lo que por méritos propios merecen.

Querríamos que este libro sirva de homenaje a todas las mujeres que han abierto puertas y ventanas, para que nosotras ahora podamos pasar a nuevos territorios y contribuir, desde otras perspectivas, a que la ingeniería sea más humana. 


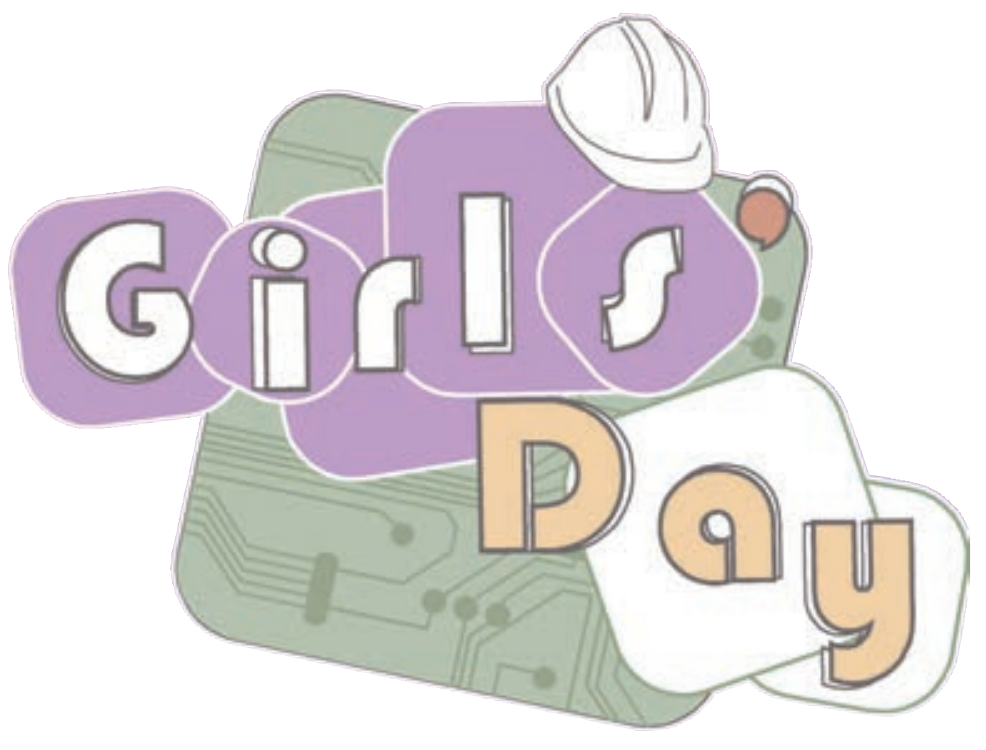




\section{Anexo A: \\ Los Girls' Days en cifras}

Carmen Mayoral Gastón

SANDRA BALDASSARri

María Villarroya Gaudó 
Este anexo recoge los detalles de participación de las distintas ediciones del Girls' Day en Aragón, desde la primera edición en 2008 hasta la cuarta edición en 2012. En primer lugar, con un cuadro resumen de los datos valorados cuantitativamente, seguido de las entidades que han financiado los eventos $y$, a continuación, de los listados de centros, laboratorios y empresas participantes.

RESUMEN DE DATOS DE PARTICIPACIÓN

\begin{tabular}{|l|c|c|c|c|}
\hline Edición & I & II & III & IV \\
\hline Fecha & 11 nov. 2009 & 28 oct. 2009 & 23 mar. 2011 & 28 mar. 2012 \\
\hline Campus & Río Ebro & Río Ebro, EUPLA & $\begin{array}{c}\text { CUD, Río Ebro, } \\
\text { Huesca, Teruel, } \\
\text { EUPLA }\end{array}$ & Río Ebro, Teruel \\
\hline Empresas & 8 & 5 & 13 & 2 \\
\hline Laboratorios & 15 & 19 & 40 & 22 \\
\hline Voluntarias & 30 & 38 & 50 & 10 \\
\hline Investigadoras & 25 & 30 & 50 & 50 \\
\hline Centros & 14 & 17 & 17 & 5 \\
\hline Asistentes & 500 & 700 & 1200 & 70 \\
\hline
\end{tabular}

\section{Financiación (en una o varias ediciones)}

- Instituto de la Mujer (Ant. Ministerio de Igualdad; actualmente, Ministerio de Sanidad, Política Social e Igualdad).

- Fundación Española para la Ciencia y la Tecnología (Ant. Ministerio de Ciencia e Innovación; actualmente, Ministerio de Economía y Competitividad).

- Instituto Aragonés de la Mujer (Gobierno de Aragón).

- Fundación Zaragoza Ciudad del Conocimiento.

- Casa de la Mujer (Ayuntamiento de Zaragoza).

\section{Listado de empresas participantes en una o varias ediciones}

- Balay

- BSH-Electrodomésticos

- Finestra Estudio
- BitBrain

- Cisco

- General Motors España 
92 El mundo necesita ingenieras. ¿Quieres ser una?

- Grupo GAYPU

- Indra

- Inycom

- Libelium

- Pikolin

- TAP consultoría tecnológica

- Tervalis
- Idom

- Inprox

- Johnson Controls

- Microsoft lbérica RSL

- Sicilia y asociados

- Telefónica

\section{Listado de laboratorios participantes en una o varias ediciones}

Universidad de Zaragoza

Laboratorios del Campus Río Ebro pertenecientes a la Escuela de Ingeniería y Arquitectura y a los Institutos Universitarios de Investigación de Ingeniería de Aragón (I3A), de Biocomputación y Física de Sistemas Complejos (BIFI), en Nanociencia de Aragón (INA).

- GIGA Grupo de Informática Gráfica Avanzada

- Interfaz Cerebro-Computador-Bit\&BrainTechnologl.E.S.

- Laboratorio de Materiales nanoestructurados y membranas

- Laboratorio BSH Electrodomésticos-Electrónica de Potencia

- Laboratorio de Arquitectura de Computadores

- Laboratorio de Caracterización Magnética

- Laboratorio de Cristalografía

- Laboratorio de Estructuras

Laboratorio del Grupo de Tecnologías en Entornos Hostiles (GTE)

- Laboratorio de Ingeniería de tejidos y Mecanobiología

- Laboratorio de Microscopia de Sonda Local (INA)

- Laboratorio de Robótica

- Laboratorio de Síntesis y Laboratorio de Hipertermia Magnética

- Laboratorio de Sistemas de Registro Biomédico

- Laboratorio de Telemática

- Laboratorio Reacciones en combustión

Laboratorio de High ThroughputScreening (HTS)

Laboratorio de Supercomputación

Laboratorio Group of AppliedThermodynamics and Surfaces (GATHERS)

Laboratorios del Centro Universitario de la Defensa

Laboratorios de la Escuela Politécnica de Teruel 
Laboratorios de la Escuela Universitaria Politécnica de La Almunia

CSIC (Consejo Superior de Investigaciones Científicas)

- Instituto de Carboquímica

CIRCE (Centro de Investigación de Recursos y Consumos Energéticos)

- Edificio Circe

Laboratorios de Biomasa y Oxicombustión

ITA (Instituto Tecnológico de Aragón)

- Laboratorio Químico

- Laboratorio Eléctrico

- Laboratorio Mecánico

- Laboratorio Seguridad Eléctrica

- Laboratorio Prototipado Rápido

\section{Listado de centros educativos participantes en una o varias ediciones}

Provincia de Huesca

- IES Castejón de Sos (Castejón de Sos)

- IES Sierra de Guara (Huesca)

- IES Sierra de San Quílez (Binéfar)

- IES San Vicente de Paúl (Barbastro)

Provincia de Teruel

- Colegio La Salle de Teruel

- Colegio Victoria Díez de Teruel

- IES Damián Forment (Alcorisa)

- IES Francés de Aranda (Teruel)

- IES Pedro Laín Entralgo (Híjar)

- IES Segundo de Chomón (Teruel)

- IES Vega del Turia (Teruel)

Zaragoza, capital

- Colegio Cardenal Xavierre (PP. Dominicos)

- Colegio del Buen Pastor

- Colegio EE.PP. Santa Engracia

- Colegio Montessori

- Colegio Ntra. Sra. del Carmen de San José

- Colegio San Agustín 
94 El mundo necesita ingenieras. ¿Quieres ser una?

- Colegio Sansueña

- Colegio Santa Ana

- Colegio Santa Rosa

- IES Andalán

- IES Avempace

- IES José Manuel Blecua

- IES El Portillo

- IES Elaios

- IES Francisco Grande Covián

- IES Goya

- IES La Azucarera

- IES Luis Buñuel

- IES Medina Albaida

- IES Miguel Catalán

- IES Pablo Gargallo

- IES Pablo Serrano

- IES Río Gállego

- IES Tiempos Modernos

Provincia de Zaragoza

- Colegio Salesianos (La Almunia)

- Colegio Santa Ana (Calatayud)

- Colegio Sta. Ana (Caspe)

- IES Benjamín Jarnés (Belchite)

- IES Cabañas (La Almunia de Doña Godina)

- IES Joaquín Costa (Cariñena)

- IES Mar de Aragón (Caspe)

- IES Río Arba (Tauste)

- IES Siglo XXI (Pedrola) 


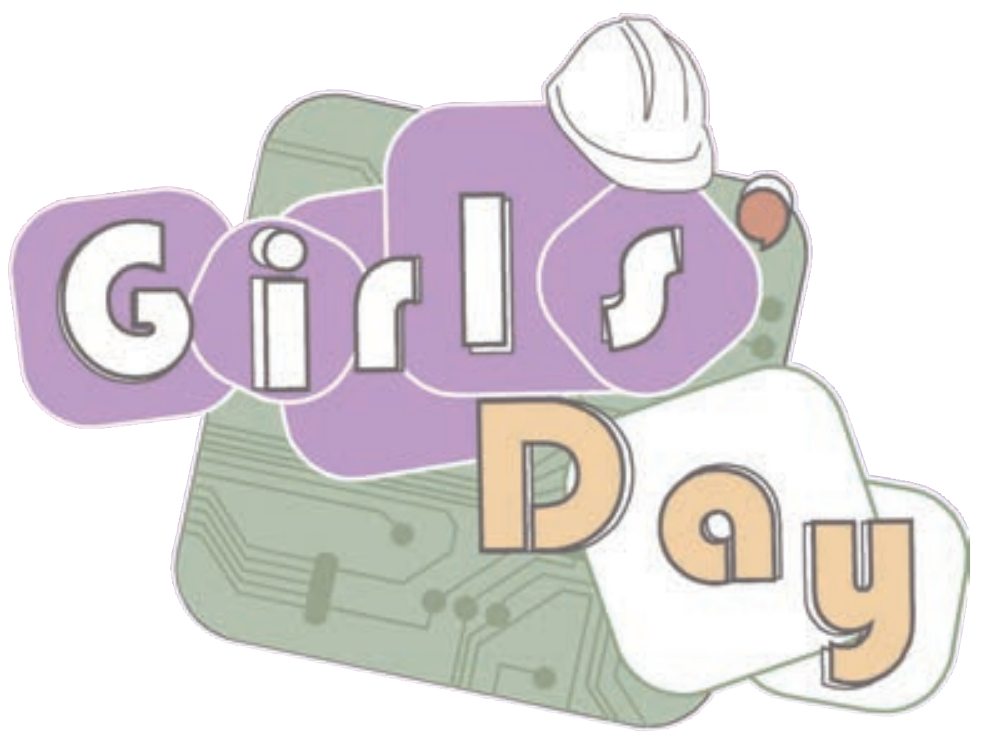




\section{Anexo B: \\ Encuesta realizada \\ a las y los participantes en la edición 2011}




\section{Cuestionario Girls’ Day 2011}

¡Hola! El objetivo de este cuestionario es ayudar a la Organización a entender tu actitud frente a los estudios de Ingeniería; es totalmente anónimo. Muchas gracias por tu cooperación.

\section{En cada cuestión, marca la respuesta correcta}

1. Nombre de tu centro educativo:

2. Localidad:

3. $\square$ Mujer / $\square$ Hombre

4. Año de nacimiento:

5. Nivel de estudios de tus progenitores: (señalar la correcta y detallar si se conoce):

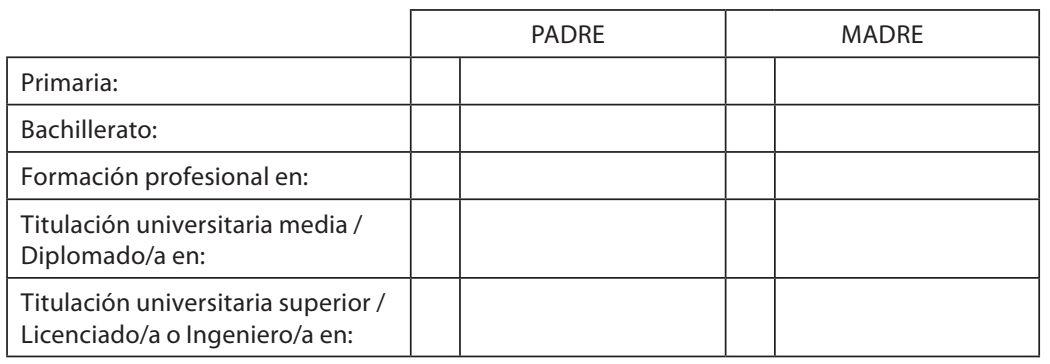

6. ¿Hay algún ingeniero/a en tu entorno familiar?

Sí (marca la/s correctas):

$\square$ Padre; $\square$ madre; $\square$ abuelo; $\square$ abuela;

$\square$ tío; $\square$ tía; $\square$ otro; $\square$ otra.

No. 
7. ¿Cómo se te dan... (marca la correcta):

\begin{tabular}{|l|l|l|l|l|l|}
\cline { 2 - 6 } \multicolumn{1}{c|}{} & Muy bien & Bien & Regular & Mal & Muy mal \\
\hline Matemáticas & & & & & \\
\hline Física y química & & & & & \\
\hline Biología y geología & & & & & \\
\hline Tecnología & & & & & \\
\hline Lengua y literatura & & & & & \\
\hline
\end{tabular}

8. Ya he decidido mi futuro, voy a:

a. $\square$ Estudiar Bachillerato (seleccionar modalidad):

$\square$ Humanidades y Ciencias Sociales

$\square$ Ciencias y Tecnología

$\square$ Artes

b. $\square$ Estudiar Formación Profesional (especificar familia profesional):

$\square$ Relacionada con la tecnología (electricidad, mecánica, electrónica, mantenimiento, imagen...)

$\square$ No relacionada con la tecnología

c. $\square$ No voy a seguir estudiando tras la ESO.

d. $\square$ No lo he decidido todavía.

\section{Valoración de la Ingeniería}

9. Indica tu grado de acuerdo con las siguientes afirmaciones (1, nada de acuerdo; 7, totalmente de acuerdo):

\begin{tabular}{|l|l|l|l|l|l|l|l|}
\cline { 2 - 7 } \multicolumn{1}{l|}{} & 1 & 2 & 3 & 4 & 5 & 6 & 7 \\
\hline A. No sé qué es la ingeniería & & & & & & & \\
\hline B. No sé a qué se dedica un ingeniero/a & & & & & & & \\
\hline C. Me gustaría estudiar una carrera de ingeniería & & & & & & & \\
\hline D. Me gustaría estudiar una carrera de otra disciplina & & & & & & \\
\hline $\begin{array}{l}\text { E. Estudiar ingeniería es muy duro, supone trabajar mu- } \\
\text { cho }\end{array}$ & & & & & & & \\
\hline
\end{tabular}




\begin{tabular}{|c|c|c|c|c|c|c|c|}
\hline & 1 & 2 & 3 & 4 & 5 & 6 & 7 \\
\hline F. La ingeniería es muy difícil & & & & & & & \\
\hline G. Para estudiar ingeniería hace falta mucha inteligencia & & & & & & & \\
\hline H. Al acabar ingeniería, es fácil encontrar trabajo & & & & & & & \\
\hline $\begin{array}{l}\text { I. La ingeniería es buena opción porque se gana mucho di- } \\
\text { nero }\end{array}$ & & & & & & & \\
\hline J. Los ingenieros tienen mucho prestigio social & & & & & & & \\
\hline K. La Humanidad avanza gracias a la ingeniería & & & & & & & \\
\hline $\begin{array}{l}\text { L. La ingeniería es una profesión muy absorbente, hay que } \\
\text { dedicar muchas horas al trabajo }\end{array}$ & & & & & & & \\
\hline M. Las ingenierías son profesiones muy competitivas & & & & & & & \\
\hline $\begin{array}{l}\text { N. La ingeniería es una profesión en la que resulta difícil } \\
\text { compatibilizar la vida familiar y la profesional }\end{array}$ & & & & & & & \\
\hline $\begin{array}{l}\text { O. Cualquier persona tiene más posibilidades de encontrar } \\
\text { trabajo, teniendo un título de ingeniería }\end{array}$ & & & & & & & \\
\hline P. Las personas con un título en ingeniería cobran más & & & & & & & \\
\hline $\begin{array}{l}\text { Q. Las personas con un título en ingeniería realizan me- } \\
\text { nos trabajo físico }\end{array}$ & & & & & & & \\
\hline
\end{tabular}

\section{Comparación de profesiones}

10. Valora las siguientes profesiones de acuerdo con el prestigio social (1, sin prestigio; 7, mucho prestigio):

\begin{tabular}{|c|c|c|c|c|c|c|c|}
\hline & 1 & 2 & 3 & 4 & 5 & 6 & 7 \\
\hline A. Ingeniero/a & & & & & & & \\
\hline B. Médico/a & & & & & & & \\
\hline C. Maestro/a o & & & & & & & \\
\hline D. Político/a & & & & & & & \\
\hline E. Arquitecto/ & & & & & & & \\
\hline F. Abogado/a & & & & & & & \\
\hline G. Policía & & & & & & & \\
\hline H. Cantante & & & & & & & \\
\hline I. Deportista & & & & & & & \\
\hline
\end{tabular}




\section{Relación ingeniería-género}

11. Indica tu grado de acuerdo con las siguientes afirmaciones (1, nada de acuerdo; 7, totalmente de acuerdo):

\begin{tabular}{|c|c|c|c|c|c|c|c|}
\hline & 1 & 2 & 3 & 4 & 5 & 6 & 7 \\
\hline $\begin{array}{l}\text { A. Hay más hombres que mujeres en las carreras y profesio- } \\
\text { nes de ingeniería }\end{array}$ & & & & & & & \\
\hline B. Las mujeres ingenieras son bichos raros & & & & & & & \\
\hline $\begin{array}{l}\text { C. Esto podría deberse a que la ingeniería es una carrera } \\
\text { académicamente difícil }\end{array}$ & & & & & & & \\
\hline $\begin{array}{l}\text { D. Esto podría deberse a que los puestos de trabajo de los y } \\
\text { las ingenier@s son de gran competitividad }\end{array}$ & & & & & & & \\
\hline E. La ingeniería es más masculina que femenina & & & & & & & \\
\hline F. Los hombres son mejores que las mujeres en ingeniería & & & & & & & \\
\hline $\begin{array}{l}\text { G. Una mujer ingeniera tiene más fácil encontrar trabajo } \\
\text { que un hombre }\end{array}$ & & & & & & & \\
\hline H. Las ingenierías no son ni masculinas ni femeninas & & & & & & & \\
\hline $\begin{array}{l}\text { I. Las carreras universitarias no son ni femeninas ni mascu- } \\
\text { linas }\end{array}$ & & & & & & & \\
\hline $\begin{array}{l}\text { J. Mis posibilidades de éxito en una ingeniería no están rela- } \\
\text { cionadas en absoluto con que yo sea hombre o mujer }\end{array}$ & & & & & & & \\
\hline $\begin{array}{l}\text { K. Mis posibilidades de éxito en una carrera universitaria y } \\
\text { profesional no están relacionadas en absoluto con que yo } \\
\text { sea hombre o mujer }\end{array}$ & & & & & & & \\
\hline
\end{tabular}

\section{Apoyos}

12. Hay personas que desaconsejan a las chicas estudiar ingeniería utilizando distintos argumentos. Indica tu grado de desacuerdo o de acuerdo con los argumentos que se exponen a continuación (1, nada de acuerdo; 7, totalmente de acuerdo):

\begin{tabular}{|l|l|l|l|l|l|l|l|}
\hline \multicolumn{1}{l|}{} & 1 & 2 & 3 & 4 & 5 & 6 & 7 \\
\hline A. Mis padres verían bien que estudiase una carrera & & & & & & & \\
\hline B. A mis padres les parecería raro que estudiase ingeniería & & & & & & & \\
\hline C. Tengo apoyo familiar para estudiar lo que yo quiera & & & & & & & \\
\hline D. Mi familia me anima a que estudie ingeniería & & & & & & & \\
\hline
\end{tabular}




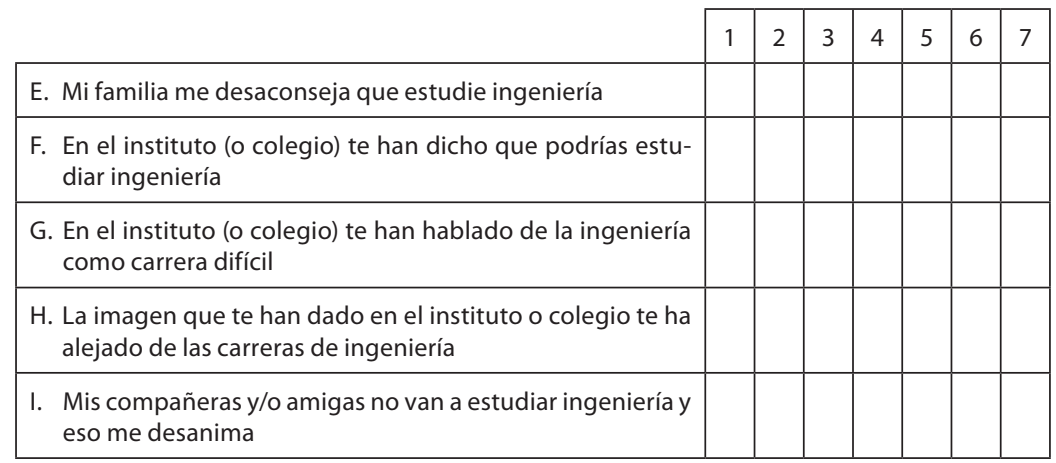

\section{Evaluación del Girls' Day}

13. Indica tu grado de acuerdo con las siguientes afirmaciones con respecto a tu valoración del Girls' Day (1, nada de acuerdo; 7, totalmente de acuerdo):

\begin{tabular}{|c|c|c|c|c|c|c|c|}
\hline & 1 & 2 & 3 & 4 & 5 & 6 & 7 \\
\hline 1. La experiencia me ha parecido divertida & & & & & & & \\
\hline 2. La experiencia me ha parecido útil & & & & & & & \\
\hline 3. La experiencia me ha parecido corta & & & & & & & \\
\hline 4. La experiencia me ha gustado & & & & & & & \\
\hline $\begin{array}{l}\text { 5. El Girls' Day me ha ayudado a entender qué es la } \\
\text { ingeniería }\end{array}$ & & & & & & & \\
\hline 6. El Girls' Day me ha mostrado estudios que no conocía & & & & & & & \\
\hline $\begin{array}{l}\text { 7. El Girls' Day me ha motivado para estudiar una carrera de } \\
\text { ingeniería }\end{array}$ & & & & & & & \\
\hline $\begin{array}{l}\text { 8. El Girls' Day me ha hecho replantearme los estudios que } \\
\text { creo voy a seguir }\end{array}$ & & & & & & & \\
\hline 9. El Girls' Day debería ser solo para chicas & & & & & & & \\
\hline $\begin{array}{l}\text { 10. La labor de las voluntarias ha sido muy importante en el } \\
\text { desarrollo de la jornada }\end{array}$ & & & & & & & \\
\hline $\begin{array}{l}\text { 11. La visita a los laboratorios me ha parecido muy intere- } \\
\text { sante }\end{array}$ & & & & & & & \\
\hline 12. La organización del evento me parece buena & & & & & & & \\
\hline 13. La información transmitida me parece muy interesante & & & & & & & \\
\hline 14. La bandolera recibida me gusta mucho & & & & & & & \\
\hline
\end{tabular}




\section{Anexo C: \\ Diferencias de género \\ en la elección \\ de estudios técnicos \\ en la Universidad \\ de Zaragoza \\ (Estudio realizado \\ con el alumnado de grado)}




\section{Encuesta realizada al alumnado de primer curso de los grados de ingeniería en la Universidad de Zaragoza}

\section{Datos personales}

1. Mujer / Hombre

2. Año de nacimiento:

3. Año de acceso a estudios en la Universidad de Zaragoza:

4. Modalidad de acceso a la Universidad:

$\square$ Bachillerato

Opción de Bachillerato que cursaste:

$\square$ Ciencias y Tecnología

$\square$ Humanidades y Ciencias Sociales

$\square$ Artes

$\square$ Formación Profesional

Familia Profesional:

Acceso mayores de 25 años

Otra titulación universitaria

$\square$ Otra modalidad de acceso (indicar):

5. Grado que cursas:

$\square$ Ingeniería de Tecnologías Industriales

$\square$ Ingeniería de Tecnologías y Servicios de Telecomunicación

$\square$ Ingeniería Eléctrica

$\square$ Ingeniería Electrónica y Automática

$\square$ Ingeniería Informática 
104 El mundo necesita ingenieras. ¿Quieres ser una?

$\square$ Ingeniería Mecánica

Ingeniería Química

$\square$ Ingeniería en Diseño Industrial y Desarrollo de Producto

6. Residencia familiar:

$\square$ Población menor de 10000 habitantes

$\square$ Población mayor de 10000 habitantes

Capital de provincia

7. Resides durante el curso:

$\square$ Con tu familia

$\square$ Residencia/Colegio Mayor

$\square$ Piso

Otro

8. Centro donde estudiaste Bachillerato o formación que ha dado acceso al Grado:

Público

Concertado

Privado

\section{Entorno familiar}

9. Nivel de estudios de tus progenitores (señalar el correcto):

\begin{tabular}{|c|c|c|}
\hline & 岂 & 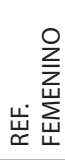 \\
\hline Primaria/Estudios obligatorios & & \\
\hline Bachillerato & & \\
\hline Formación profesional & & \\
\hline $\begin{array}{l}\text { Titulación Universitaria Media: Diplomatura, Ingeniería o Arquitectura } \\
\text { Técnica }\end{array}$ & & \\
\hline $\begin{array}{l}\text { Titulación Universitaria Superior: Licenciatura, Ingeniería Superior o Arqui- } \\
\text { tectura }\end{array}$ & & \\
\hline
\end{tabular}


10. ¿Hay algún ingeniero/a en tu entorno familiar?

Sí (marca la/s correcta/s):

$\square$ Padre

$\square$ Madre

$\square$ Abuelo

$\square$ Abuela

$\square$ Tío

$\square$ Tía

$\square$ Hermano

$\square$ Hermana

$\square$ Otro:

$\square$ Otra:

$\square$ No

11. ¿Cuál es la situación laboral de tus progenitores?

\begin{tabular}{|c|c|c|}
\hline & 点 & 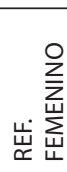 \\
\hline Trabaja actualmente & & \\
\hline Retirado/a / Pensionista / Incapacitado/a & & \\
\hline Parado/a, ha trabajado anteriormente & & \\
\hline Estudiante (que no trabaja) & & \\
\hline Trabajo no remunerado & & \\
\hline
\end{tabular}

12. Régimen de trabajo de tus progenitores:

Trabajo por cuenta ajena:

$\square$ Mandos superiores

$\square$ Mandos intermedios

$\square$ Personal cualificado

$\square$ Personal no cualificado

Tipo de trabajo por cuenta propia:

$\square$ Sin empleados a su cargo

$\square$ Con hasta cinco empleados a su cargo

$\square$ Con más de cinco empleados a su cargo 


\section{Decisión de estudios}

13. ¿Cuándo decidiste qué grado querías cursar?

$\square$ Lo supe muy pronto, en primaria

$\square$ Durante la ESO

$\square$ Durante el Bachillerato (o equivalente)

$\square$ Al realizar las solicitudes de preinscripción en la universidad

$\square$ Otro:

14. A la hora de matricularte en la universidad...

$\square$ Tenías claro qué querías estudiar

$\square$ No tenías claro qué querías estudiar

15. La elección de la carrera fue:

\section{Acertada}

$\square$ Incorrecta

Todavía es pronto para saberlo

16. Valora si estás de acuerdo o no con las siguientes afirmaciones (1, nada de acuerdo; 2 , de acuerdo; 3 , bastante de acuerdo; 4 , completamente de acuerdo):

\begin{tabular}{|c|c|c|c|c|}
\hline A la hora de matricularte en la universidad... & 1 & 2 & 3 & 4 \\
\hline No necesitaste información & & & & \\
\hline $\begin{array}{l}\text { Buscaste por tu cuenta la información que necesitabas para tomar la deci- } \\
\text { sión }\end{array}$ & & & & \\
\hline $\begin{array}{l}\text { La información y orientación del profesorado del centro donde estudiaste } \\
\text { fue muy buena }\end{array}$ & & & & \\
\hline Cuando tomaste la decisión, tenías toda la información necesaria & & & & \\
\hline Cuando tomaste la decisión, no tenías toda la información necesaria. & & & & \\
\hline
\end{tabular}

17. Quién te dio información sobre el grado que querías estudiar (marca en cada caso la opción correcta):

\begin{tabular}{|l|c|c|c|}
\cline { 2 - 4 } \multicolumn{1}{l|}{} & $\begin{array}{c}\text { Pidiendo } \\
\text { Información }\end{array}$ & $\begin{array}{c}\text { Sin pedir } \\
\text { Información }\end{array}$ & $\begin{array}{c}\text { No recibí } \\
\text { información }\end{array}$ \\
\hline Mis padres & & & \\
\hline Otras u otros familiares & & & \\
\hline Profesorado & & & \\
\hline
\end{tabular}




\begin{tabular}{|l|l|l|l|}
\cline { 2 - 4 } \multicolumn{1}{c|}{} & $\begin{array}{c}\text { Pidiendo } \\
\text { Información }\end{array}$ & $\begin{array}{c}\text { Sin pedir } \\
\text { Información }\end{array}$ & $\begin{array}{c}\text { No recibí } \\
\text { información }\end{array}$ \\
\hline Charlas en el instituto/colegio & & & \\
\hline Jornadas información & & & \\
\hline Girls' Day & & & \\
\hline Medios de comunicación & & & \\
\hline Páginas web, redes sociales, Internet... & & & \\
\hline Otro (indica cuál) & & & \\
\hline
\end{tabular}

18. Estás estudiando lo que querías

a. $\square$ Sí

b. $\square$ No (marca la que corresponda, puede ser más de una opción)

$\square$ porque no me dio la nota

$\square$ por no desplazarme a otra ciudad

$\square$ no tenía apoyo familiar

$\square$ mi opción preferida tenía menos salidas profesionales

$\square$ ninguna de mis amigas la iba a estudiar

$\square$ ninguno de mis amigos la iba a estudiar

$\square$ otro:

19. ¿Cuál era tu carrera deseada?:

La que estoy cursando actualmente

Otro grado técnico en la Universidad de Zaragoza

$\square$ Otro grado técnico que no se imparte en la Universidad de Zaragoza

$\square$ Otro grado no técnico que se imparte en la Universidad de Zaragoza

$\square$ Otro grado no técnico que no se imparte en la Universidad de Zaragoza

20. El grado que estás estudiando ¿qué lugar ocupaba de tu selección?: 
21. Cuánto te han empujado los siguientes factores a estudiar esta carrera. Valora de 1 a 4 (1, no ha influido; 2., ha influido poco; 3., ha influido bastante; 4., ha influido mucho):

\begin{tabular}{|c|c|c|c|c|}
\hline & 1 & 2 & 3 & 4 \\
\hline \multicolumn{5}{|l|}{ Hacer buenas relaciones sociales } \\
\hline \multicolumn{5}{|l|}{ Obtener un empleo de prestigio } \\
\hline \multicolumn{5}{|l|}{$\begin{array}{l}\text { Me va a permitir promocionar mejor a puestos directivos que otras } \\
\text { carreras }\end{array}$} \\
\hline \multicolumn{5}{|l|}{ Ofrece buenas perspectivas laborales } \\
\hline \multicolumn{5}{|l|}{ No estudiar asignaturas de Letras } \\
\hline \multicolumn{5}{|l|}{ Da posibilidad de ayudar a otras personas } \\
\hline \multicolumn{5}{|l|}{ Te gusta el contenido técnico de los estudios } \\
\hline \multicolumn{5}{|l|}{ Posibilitan el interés por la investigación } \\
\hline \multicolumn{5}{|l|}{ Proporcionan cultura } \\
\hline \multicolumn{5}{|l|}{ Tienes facilidad para las asignaturas relacionadas con la tecnología } \\
\hline \multicolumn{5}{|l|}{ Porque es un trabajo que me permitirá viajar } \\
\hline \multicolumn{5}{|l|}{ Porque desde pequeño/a quería ser inventor/a } \\
\hline \multicolumn{5}{|l|}{ Se puede ganar mucho dinero } \\
\hline \multicolumn{5}{|l|}{ La gente que estudiaba conmigo la eligió } \\
\hline \multicolumn{5}{|l|}{ Porque me interesa mucho saber cómo y por qué funcionan las cosas } \\
\hline \multicolumn{5}{|l|}{ Por continuar la tradición familiar } \\
\hline \multicolumn{5}{|l|}{ Por continuar con la empresa familiar } \\
\hline \multicolumn{5}{|l|}{ Mi familia me empujaba a que estudiara esto } \\
\hline \multicolumn{5}{|l|}{ Mis profesoras y profesores me alentaban a que estudiara esto } \\
\hline \multicolumn{5}{|l|}{ Mi familia me empujaba a que estudiase una carrera, la que fuese } \\
\hline \multicolumn{5}{|l|}{ Mi familia considera muy importante que reciba buena formación } \\
\hline \multicolumn{5}{|l|}{ Tenía la nota adecuada para ello } \\
\hline \multicolumn{5}{|l|}{$\begin{array}{l}\text { Sería más fácil encontrar trabajo que con una carrera de la Facultad de } \\
\text { Ciencias }\end{array}$} \\
\hline \multicolumn{5}{|l|}{ Que estaba en Zaragoza, Huesca o Teruel } \\
\hline \multicolumn{5}{|l|}{$\begin{array}{l}\text { La información que durante tu formación te han transmitido de la } \\
\text { ingeniería }\end{array}$} \\
\hline Otro (indica cuál) & & & & \\
\hline
\end{tabular}




\section{Valoración de la Ingeniería}

22. Indica tu grado de acuerdo con las siguientes afirmaciones (1, nada de acuerdo; 2, poco de acuerdo; 3, bastante de acuerdo; 4, totalmente de acuerdo):

\begin{tabular}{|c|c|c|c|c|}
\hline & 1 & 2 & 3 & 4 \\
\hline \multicolumn{5}{|l|}{ Estudiar ingeniería supone mucho esfuerzo } \\
\hline \multicolumn{5}{|l|}{ La ingeniería es divertida } \\
\hline \multicolumn{5}{|l|}{ La ingeniería es muy difícil } \\
\hline \multicolumn{5}{|l|}{ Los ingenieros tienen mucho prestigio social } \\
\hline \multicolumn{5}{|l|}{ La ingeniería es muy interesante } \\
\hline \multicolumn{5}{|l|}{ Para estudiar ingeniería hace falta mucha inteligencia } \\
\hline \multicolumn{5}{|l|}{ Al acabar ingeniería, es fácil encontrar trabajo } \\
\hline \multicolumn{5}{|l|}{ La ingeniería es buena opción porque se gana mucho dinero } \\
\hline \multicolumn{5}{|l|}{ La Humanidad avanza gracias a la ingeniería } \\
\hline \multicolumn{5}{|l|}{$\begin{array}{l}\text { La ingeniería es una profesión muy absorbente, hay que dedicar mu- } \\
\text { chas horas al trabajo }\end{array}$} \\
\hline \multicolumn{5}{|l|}{ Las ingenierías son profesiones muy competitivas } \\
\hline \multicolumn{5}{|l|}{$\begin{array}{l}\text { La ingeniería es una profesión en la que resulta difícil compatibilizar la } \\
\text { vida familiar y la profesional }\end{array}$} \\
\hline $\begin{array}{l}\text { Cualquier persona tiene más posibilidades de encontrar trabajo, te- } \\
\text { niendo un título de ingeniería }\end{array}$ & & & & \\
\hline
\end{tabular}

23. Indica tu grado de acuerdo con las siguientes afirmaciones (1, nada de acuerdo; 2, poco de acuerdo; 3, bastante de acuerdo; 4, totalmente de acuerdo):

\begin{tabular}{|l|l|l|l|l|}
\cline { 2 - 5 } \multicolumn{1}{c|}{} & 1 & 2 & 3 & 4 \\
\hline El trabajo de ingeniería es más femenino que masculino & & & & \\
\hline El trabajo de ingeniería es más masculino que femenino & & & \\
\hline $\begin{array}{c}\text { Una mujer ingeniera tiene más fácil encontrar trabajo que un hombre } \\
\text { ingeniero }\end{array}$ & & & & \\
\hline $\begin{array}{c}\text { Ciertas capacidades mentales asociadas con la ingeniería están más } \\
\text { desarrolladas, en general, en los hombres que en las mujeres }\end{array}$ & & & & \\
\hline El trabajo de ingeniería no es ni masculino ni femenino & & & \\
\hline Los hombres tienen más capacidad técnica que las mujeres, en general & & & & \\
\hline $\begin{array}{c}\text { Los hombres tienen más apoyos que las mujeres a la hora de escoger } \\
\text { una carrera de ingeniería }\end{array}$ & & & & \\
\hline
\end{tabular}


110 El mundo necesita ingenieras. ¿Quieres ser una?

\begin{tabular}{|c|c|c|c|c|}
\cline { 2 - 5 } \multicolumn{1}{c|}{} & 1 & 2 & 3 & 4 \\
\hline $\begin{array}{c}\text { Está mejor visto socialmente que un hombre estudie ingeniería a que } \\
\text { lo haga una mujer }\end{array}$ & & & \\
\hline $\begin{array}{c}\text { Un hombre ingeniero tiene más posibilidades de promocionar laboral- } \\
\text { mente que una mujer ingeniera }\end{array}$ & & & \\
\hline Las carreras universitarias no son ni femeninas ni masculinas & & & \\
\hline $\begin{array}{c}\text { Mis posibilidades de éxito en una carrera universitaria y profesional no } \\
\text { están relacionadas en absoluto con que yo sea hombre o mujer }\end{array}$ & & & \\
\hline
\end{tabular}

\section{Análisis cuantitativo de las respuestas recibidas a la encuesta del alumnado de Grado}

\section{METODOLOGIA}

Ficha técnica

Universo: alumnado de primer grado de ingenieria de la Universidad de Zaragoza.

Ámbito: Zaragoza

\section{Fechas de recogida de información:}

Metodología de recogida de información: la recogida de información se llevó a cabo mediante cuestionario autoadministrado.

Tamaño muestral: se recogleron un total de 326 cuestionarios, de los cuales sólo son válidos 320 .

Diseffo muestral: la muestra se calculo siguiendo criterios de representatividad sobre el total de estudiantes de primer grado de la Escuela de Ingenieria y Arquitectura de Zaragoza. Aunque inicialmente estaba previsto recoger un total de 290 cuestionarios, la muestra final obtenida fue de 326.

Error muestral: El error muestral para el total de la muestra al $95,5 \%$ de confianza y en el caso de más incertidumbre posible $(p=q=50 \%)$, es de $\pm 5,02 \%$, (sobre un unlverso finito de 1.287 individuos).

Se muestra a continuación los errores muestrales para la principal variable de andilisis utilizada, calculada bajo los mismos supuestos.

\begin{tabular}{|c|c|c|c|c|}
\hline VAERABL DE MALISSS & & n & $\%$ & Error \\
\hline & TOTAL & 320 & 100 & 5,02 \\
\hline \multirow{2}{*}{ ตৌहR० } & Mijers & 78 & 24,7 & 11,01 \\
\hline & tonbes & 241 & 75,3 & 6,00 \\
\hline
\end{tabular}




\section{Descripción de la muestra}

\section{Perfil sociodemográfico de los participantes}

Base: muestra de cada segmento: mujeres (79) y hombres (241)

Porcentajes verticales

\section{Género y Edad}

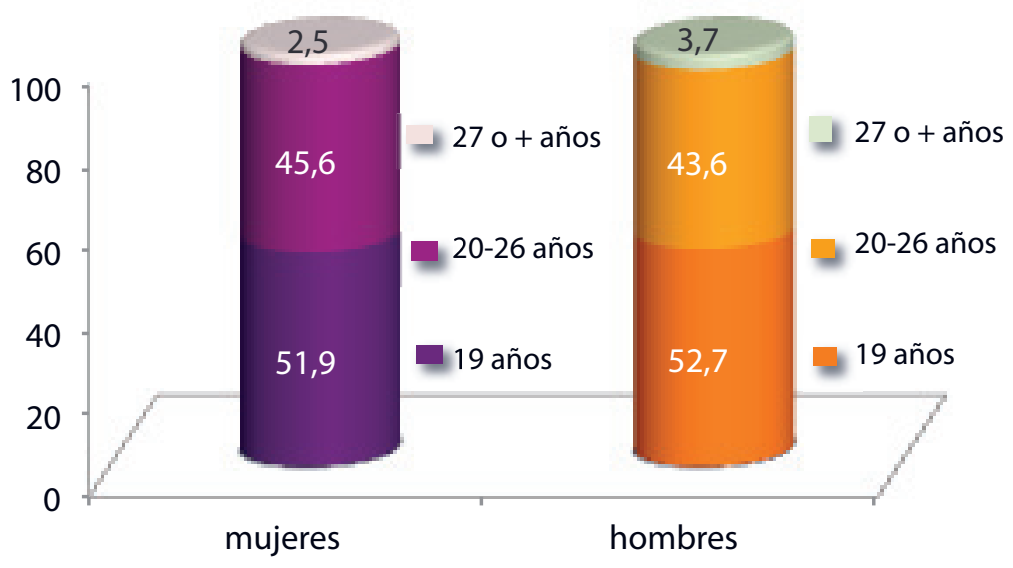

Lugar de residencia familia según género
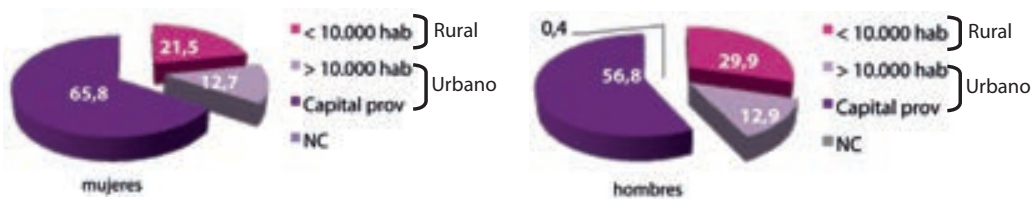

\begin{tabular}{|l|c|}
\cline { 2 - 2 } \multicolumn{1}{c|}{} & $\begin{array}{c}\text { mujeres } \\
\mathbf{( 7 9 )}\end{array}$ \\
\hline Rural & 21,5 \\
\hline Urbano & 76,5 \\
\hline NC & $\cdot$ \\
\hline
\end{tabular}

\begin{tabular}{|l|c|}
\cline { 2 - 2 } \multicolumn{1}{c|}{} & $\begin{array}{c}\text { hombres } \\
\text { (24 } \pm \text { ) }\end{array}$ \\
\hline Rural & 29,9 \\
\hline Urbano & 59,7 \\
\hline NC & 0,4 \\
\hline
\end{tabular}


112 El mundo necesita ingenieras. ¿Quieres ser una?

\section{Descripción de la muestra}

Base: muestra de cada segmento: mujeres (79) y hombres (241)

Porcentajes verticales

Año de acceso

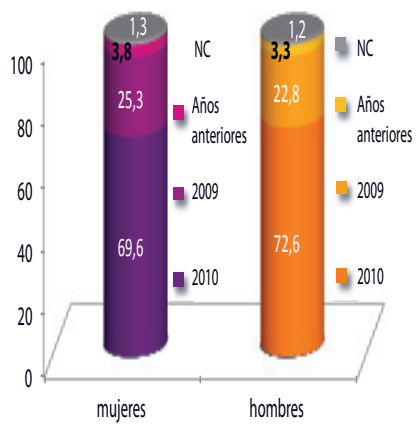

Modalidad de acceso

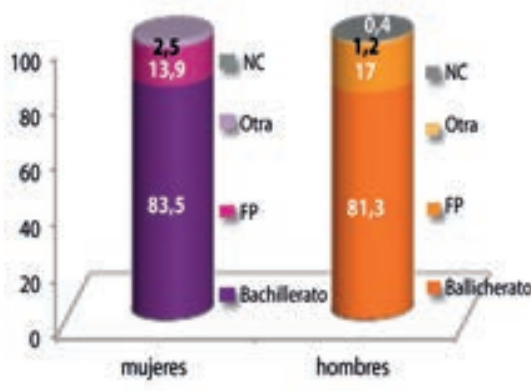

Bachillerato

\begin{tabular}{lcc}
\cline { 2 - 3 } & $\begin{array}{c}\text { mujeres } \\
\text { (79) }\end{array}$ & $\begin{array}{c}\text { hombres } \\
(\mathbf{1 9 6 )}\end{array}$ \\
\hline Tecnológico & 97,0 & 94,9 \\
\hline Humanidades & 1,5 & 0,5 \\
\hline Artes & & 0,5 \\
\hline NC & 1,5 & 4,1 \\
\hline
\end{tabular}

Grado de ingenieria que cursa

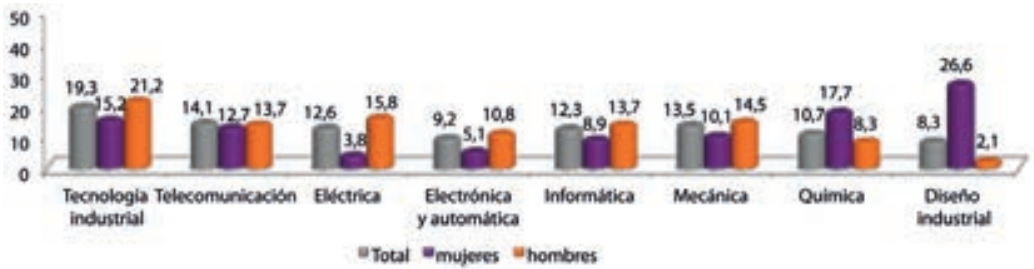




\section{Descripción del entorno familiar \\ Nivel de estudios}

Base: muestra de cada segmento: mujeres (79) y hombres (241)

Porcentajes verticales

Nivel de estudios de los progenitores

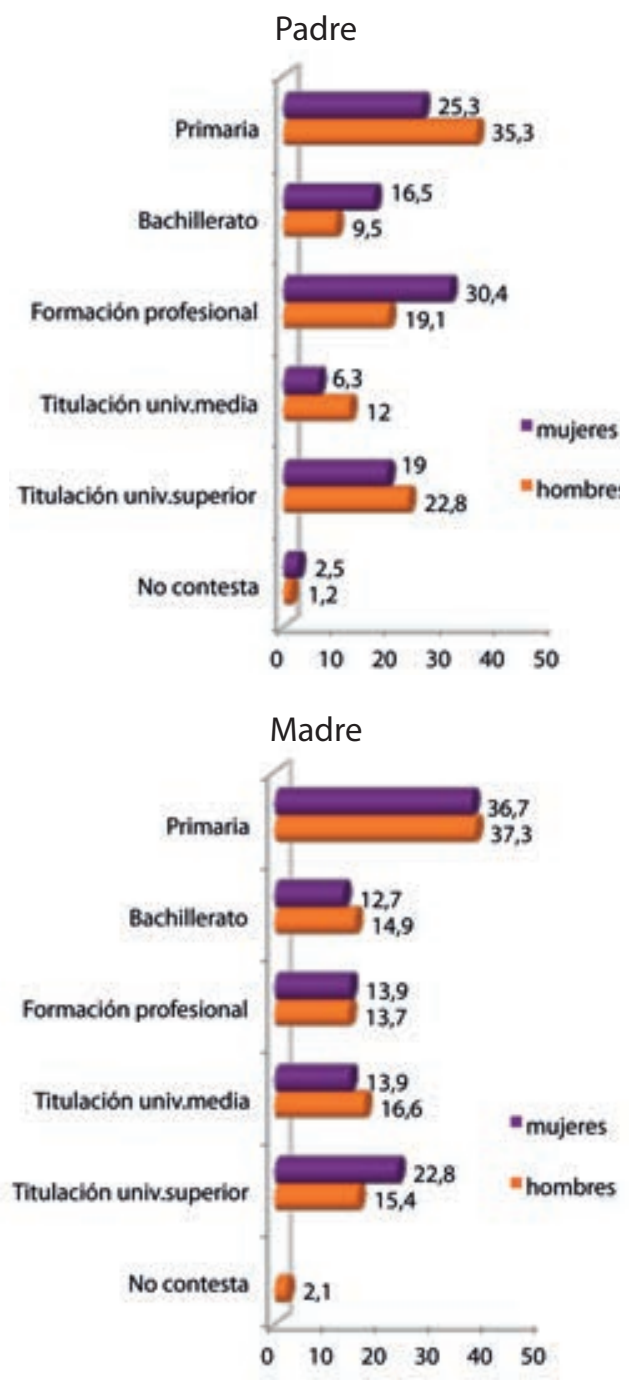




\section{Descripción del entorno familiar \\ Nivel de Estudios agrupado}

Base: muestra de cada segmento: mujeres (79) y hombres (241)

Porcentajes verticales

Nivel de estudios de los progenitores

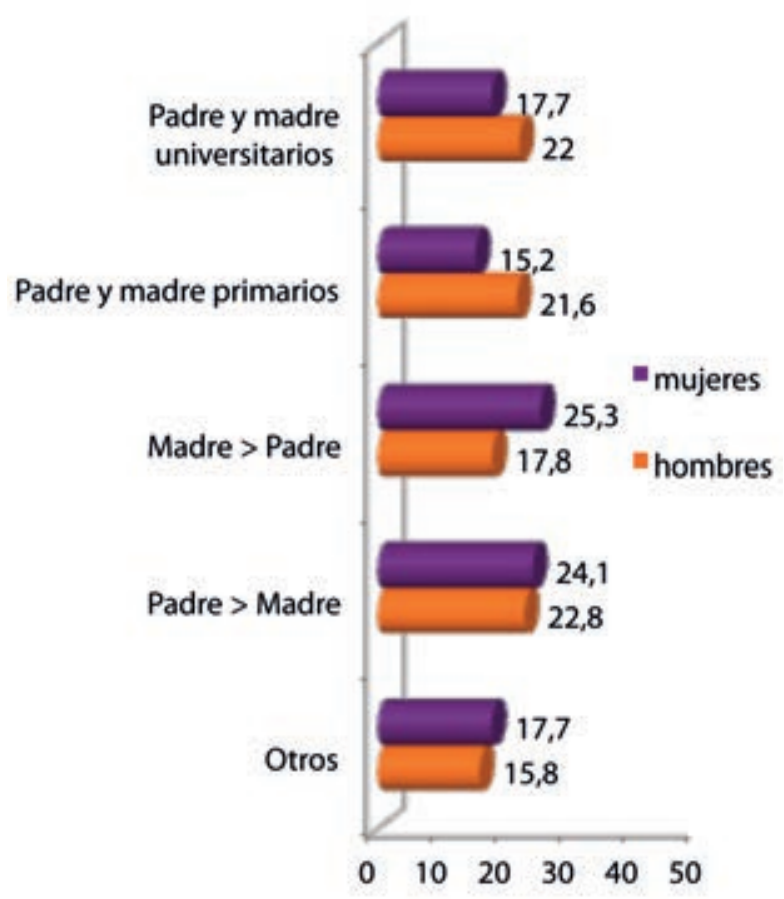

\begin{tabular}{|l|c|c|}
\cline { 2 - 3 } \multicolumn{1}{c|}{} & $\begin{array}{c}\text { Mujeres } \\
\text { (79) }\end{array}$ & $\begin{array}{c}\text { Hombres } \\
\text { (241) }\end{array}$ \\
\hline Padre o Madre universitarios & 44,3 & 44,8 \\
\hline $\begin{array}{l}\text { Ni padre ni madre } \\
\text { universitarios }\end{array}$ & 55,7 & 55,2 \\
\hline
\end{tabular}




\section{Descripción del entorno familiar \\ Situación laboral}

Base: muestra de cada segmento: mujeres (79) y hombres (241) Porcentajes verticales

Situación laboral de los progenitores
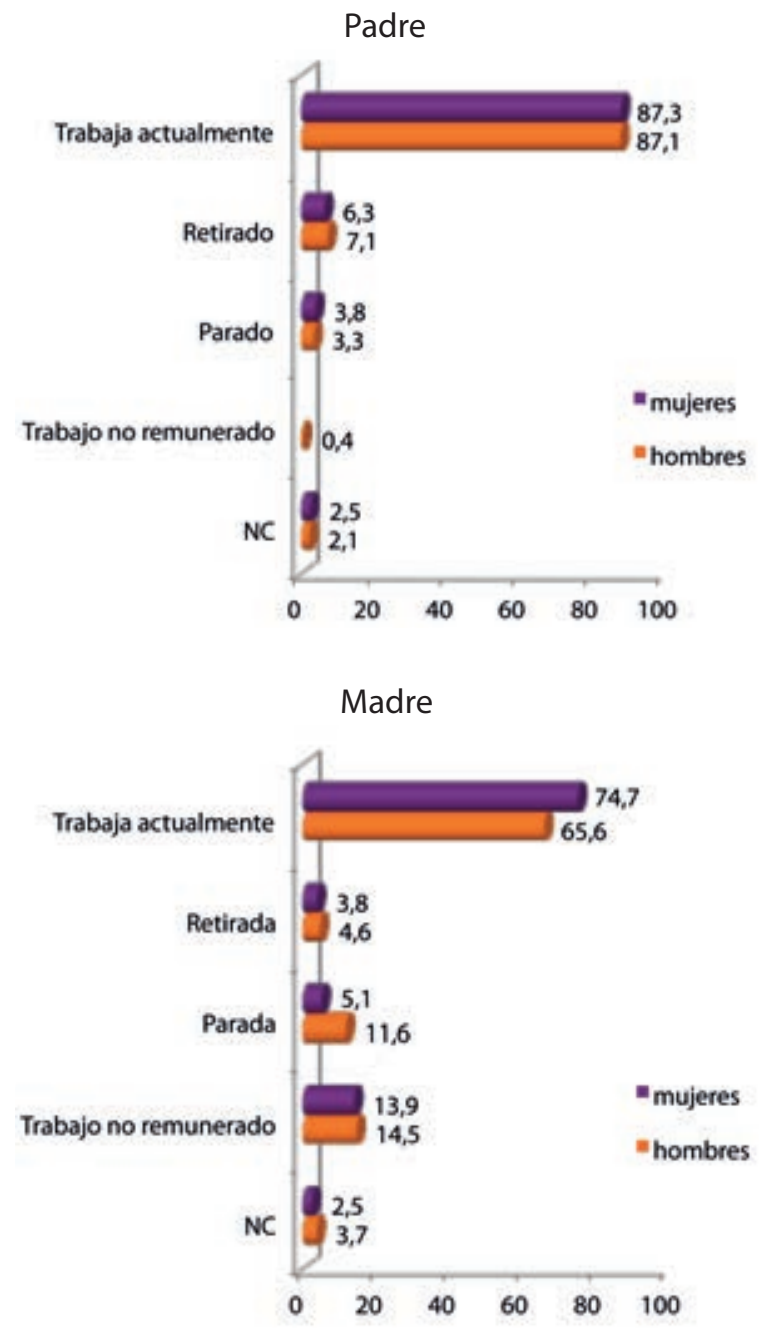


\section{Descripción del entorno familiar Ingenieros en el hogar}

Base: muestra de cada segmento: mujeres (79) y hombres (241) Porcentajes verticales

Ingenieros en el hogar

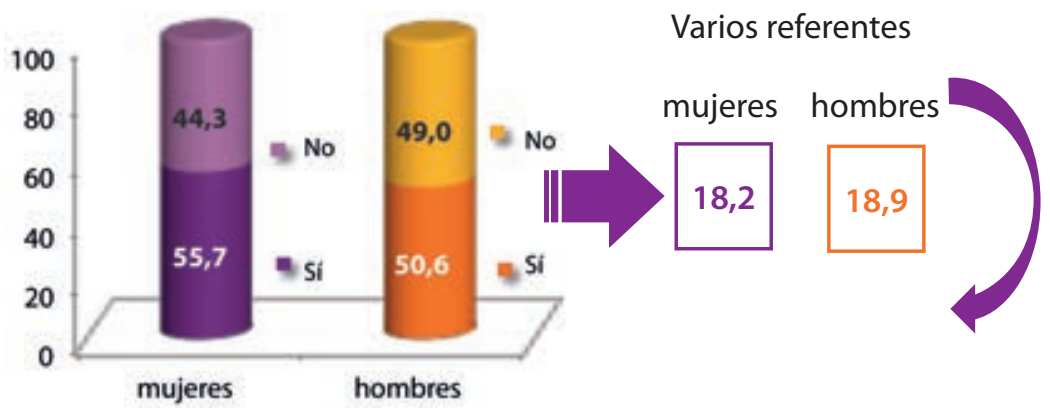

$\begin{array}{lll}\text { Progenitores } & \text { Ref. Masculinos Ref. Femeninos }\end{array}$

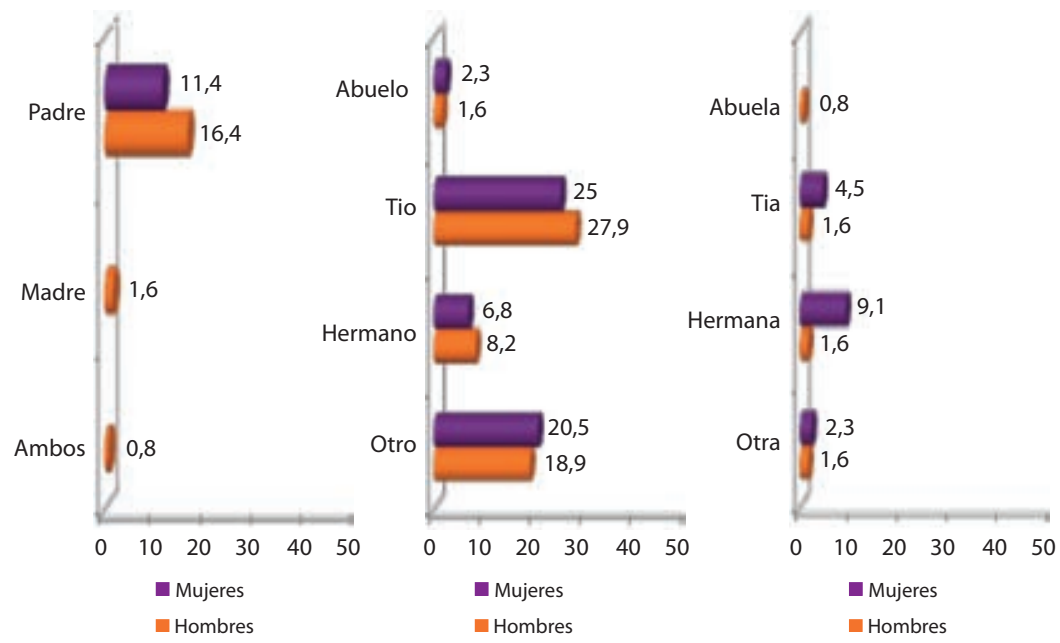




\section{Decisión de estudios}

\section{Ingenieros en el hogar}

Base: muestra de cada segmento: mujeres (79) y hombres (241)

Porcentajes verticales

Momento de la decisión de estudiar ingeniería ¿ ¿Cuándo decidiste qué grado querías cursar?
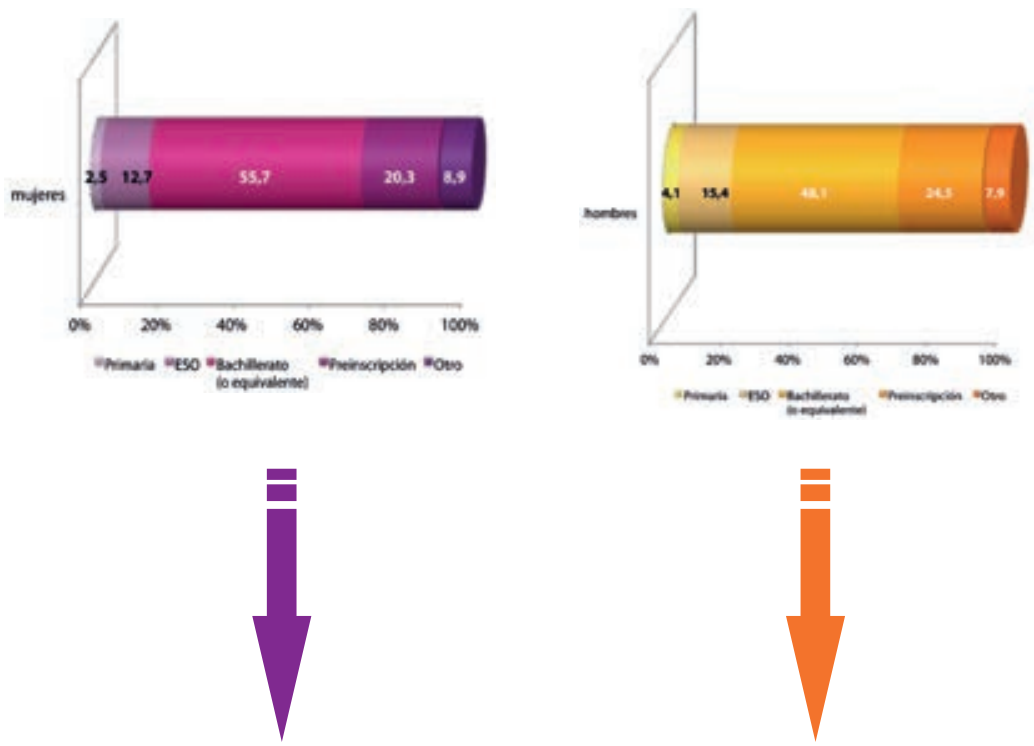

mujeres

\begin{tabular}{|l|c|c|c|c|}
\hline \multirow{2}{*}{$\begin{array}{l}\text { A la hora de matricularse en la } \\
\text { Universidad }\end{array}$} & \multicolumn{4}{|c|}{ La elección de la carrera fue... } \\
\cline { 2 - 6 } & Acertada & Incorrecta & Ns/NC & TOTAL \\
\hline Tenía claro qué quería estudiar & 91,1 & 66,7 & 54,8 & $\mathbf{7 5 , 9}$ \\
\hline No tenía claro qué quería estudiar & 8,9 & 33,3 & 45,2 & $\mathbf{2 4 , 1}$ \\
\hline TOTAL & 100 & 100 & 100 & 100 \\
\hline
\end{tabular}

hombres

\begin{tabular}{|l|c|c|c|c|}
\hline \multirow{2}{*}{$\begin{array}{l}\text { A la hora de matricularse en la } \\
\text { Universidad }\end{array}$} & \multicolumn{4}{|c|}{ La elección de la carrera fue... } \\
\cline { 2 - 6 } & Acertada & Incorrecta & NS/Nc & TOTAL \\
\hline Tenia claro qué queria estudiar & 89,6 & 28,5 & 64,5 & 73,4 \\
\hline No tenía claro qué quería estudiar & 10,4 & 64,3 & 35,5 & 26,1 \\
\hline Ns & - & 7 & - & 0 \\
\hline & 100 & 100 & 100 & 100 \\
\hline
\end{tabular}


118 El mundo necesita ingenieras. ¿Quieres ser una?

\section{Decisión de estudios}

Base: muestra de cada segmento: mujeres (79) y hombres (241)

Porcentajes verticales

Información necesaria para tomar la decisión

A la hora de matricularse

en la Universidad...

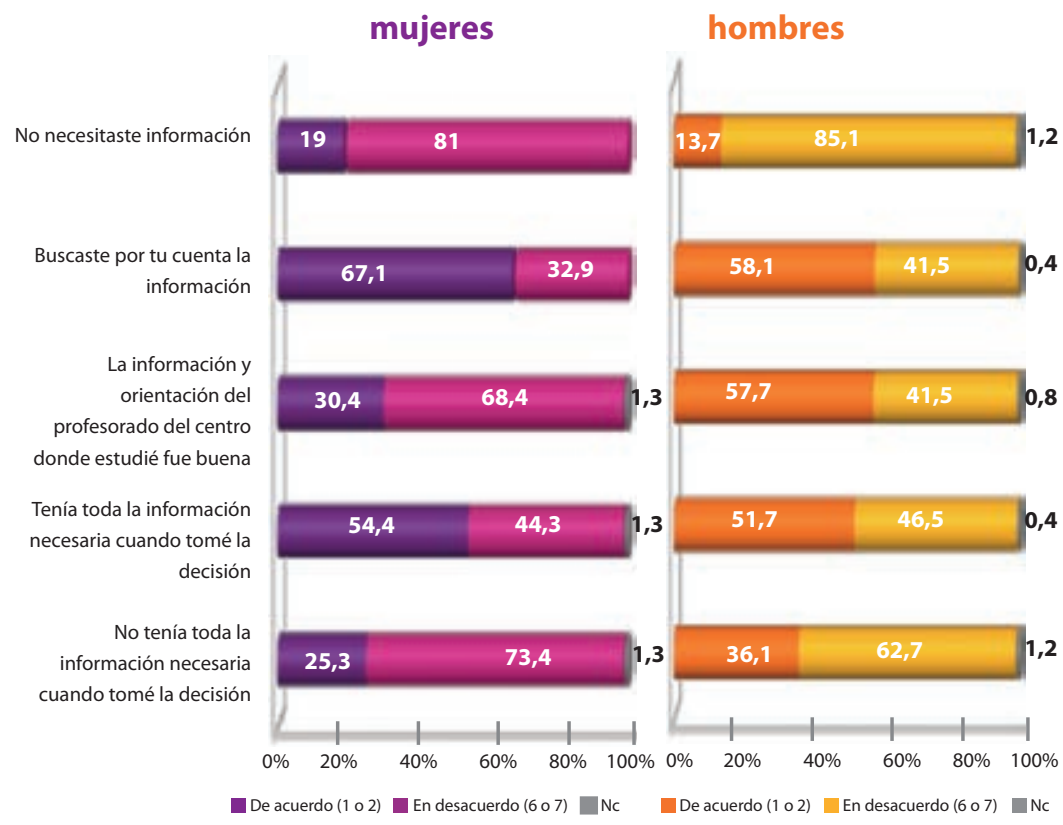




\section{Decisión de estudios}

Base: muestra de cada segmento: mujeres (79) y hombres (241)

Porcentajes verticales

Prescriptores de la ingeniería

¿Quién te dio la información sobre el grado que querías estudiar?...

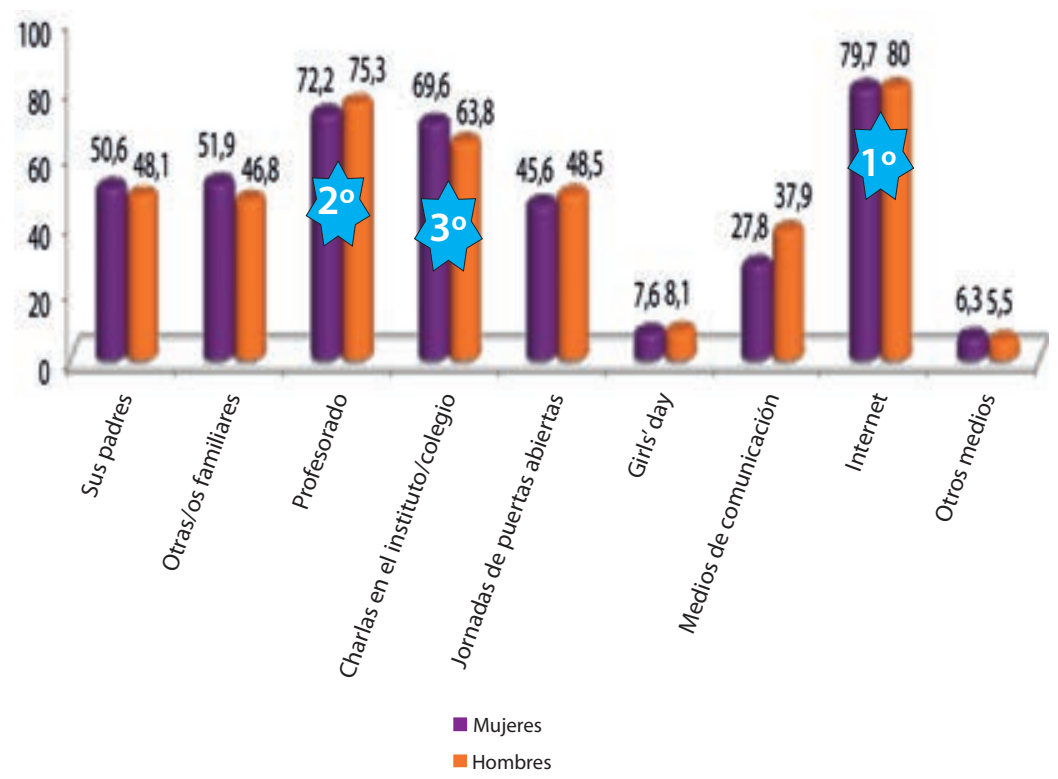


120 El mundo necesita ingenieras. ¿Quieres ser una?

\section{Decisión de estudios}

Base: muestra de cada segmento: mujeres (79) y hombres (241)

Porcentajes verticales

Elección de la ingeniería

¿Estás estudiando lo que querías?

\section{mujeres}

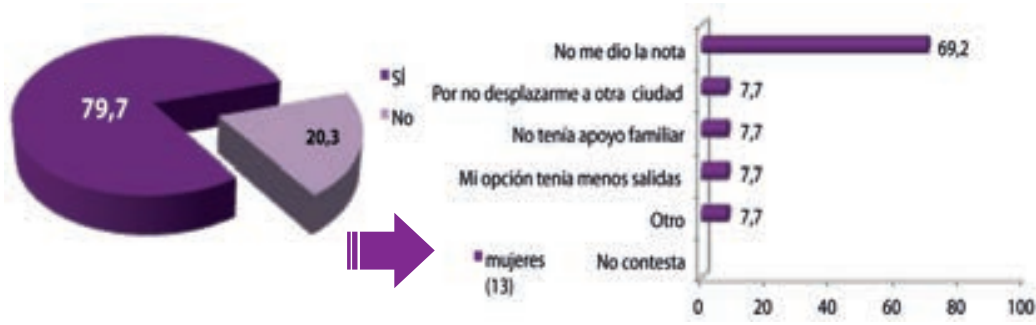

Base: no esta estudiando lo que quería

\section{hombres}

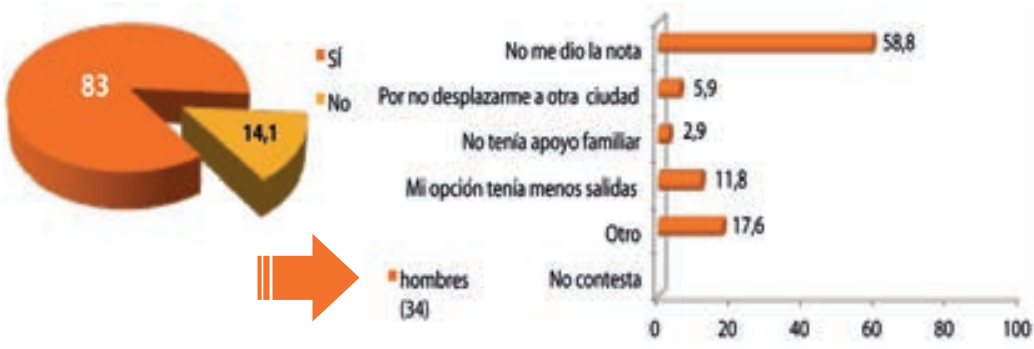




\section{Decisión de estudios}

Base: muestra de cada segmento: mujeres (79) y hombres (241)

Porcentajes verticales

Carrera deseada

¿Qué grado ocupa de tu selección el grado que estás estudiando?

\section{mujeres}

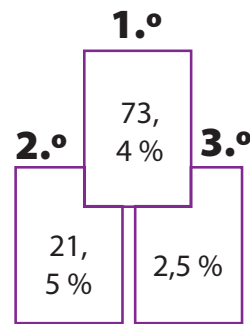

*2,5\% Otras posiciones/NC

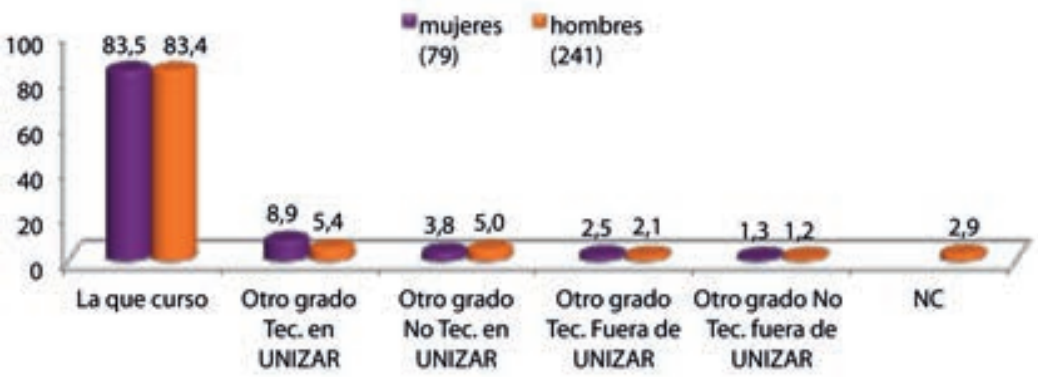

hombres

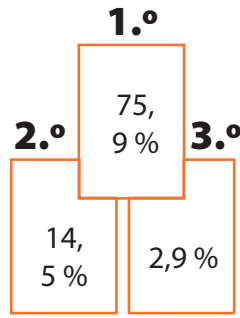

*2,9\% Otras posiciones/NC 
122 El mundo necesita ingenieras. ¿Quieres ser una?

\section{Decisión de estudios}

Base: muestra de cada segmento: mujeres (79) y hombres (241)

Porcentajes verticales

Carrera deseada

mujeres

¿Estás estudiando lo que querías?

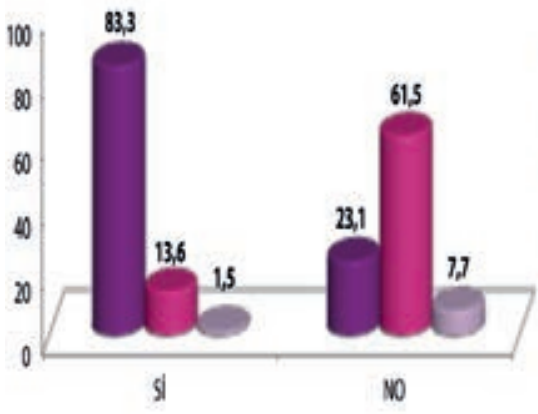

1. ${ }^{a}$ Posición $\square 2{ }^{a} \square 3 .^{a}$

¿Qué grado ocupa de tu selección el grado que estás estudiando? hombres

¿Estás estudiando lo que querías?

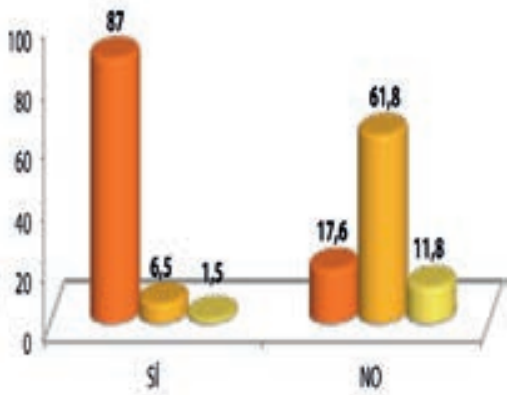

-1.a Posición $\square 2 .^{\text {a }} \square$ 3. ${ }^{\text {a }}$

¿Qué grado ocupa de tu selección el grado que estás estudiando? 


\section{Decisión de estudios}

Base: muestra de cada segmento: mujeres (79) y hombres (241) Valoraciones medias (rec. 1-4)

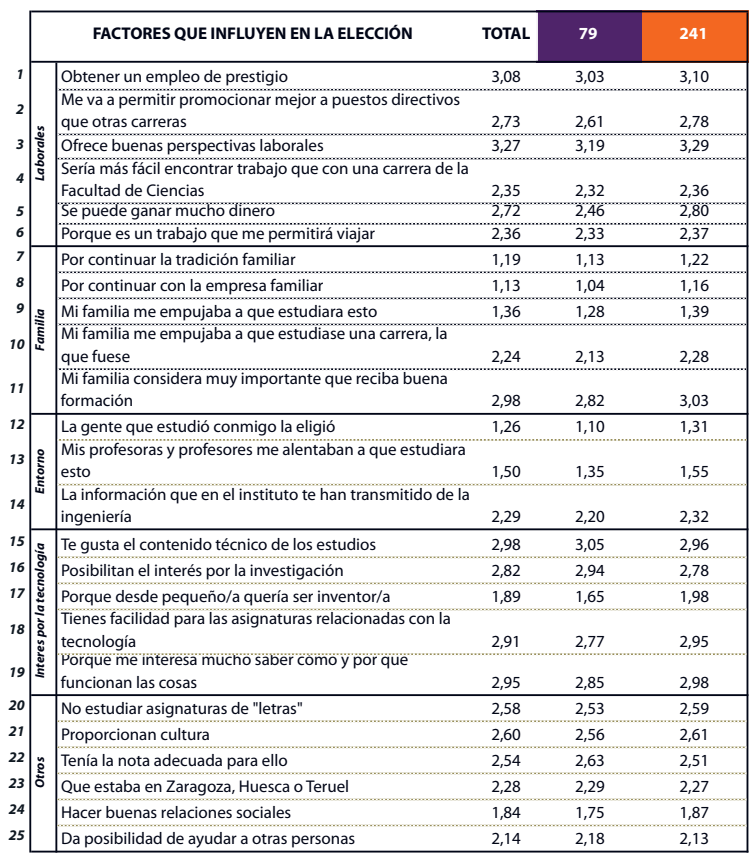

\section{mujeres-hombres}

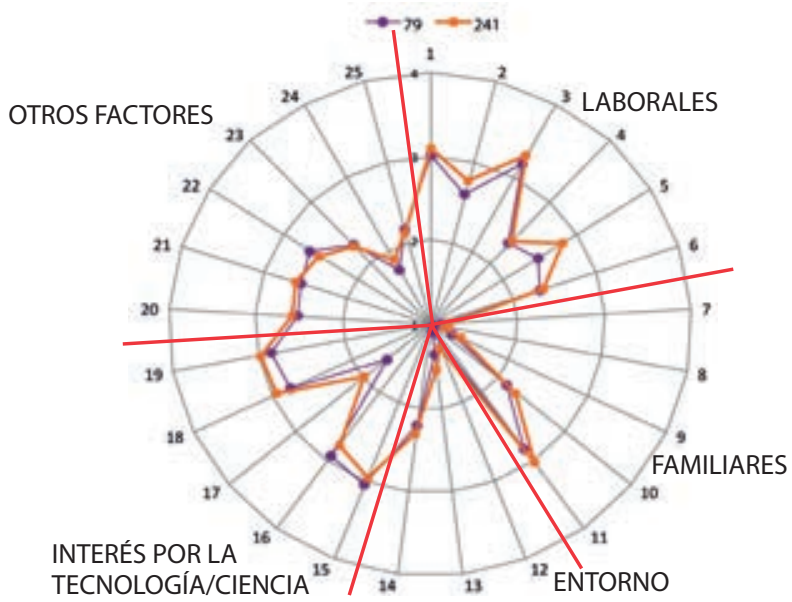




\section{Anexo D: \\ Herramienta gestora del Girls’ Day}

Piedad Garrido Picazo

José Gabriel Villar roya Lafuente

Eva Hervás Puchalt 
Se presenta, a continuación, una herramienta informática analizada, diseñada y programada por un estudiante de ingeniería. Con ello, queremos conseguir demostrar, por un lado, que estudiar una ingeniería es una aventura creativa y atractiva y, por otro lado, intentar convencer a nuestras futuras generaciones de que se animen a ser personas innovadoras, sacando un mayor partido a esos conocimientos tecnológicos de base que ya tienen adquiridos a través del uso de los smartphones, las redes sociales, las Smart TVs, tablets, etc.

GAT (Girls'dayAdministratorTool) fue el acrónimo seleccionado para dar entidad propia a la creación de una herramienta informática en línea que permitiera gestionar la logística de las Jornadas del Girls' Day. Hasta que surgió la idea de crear este software de gestión, esta se estaba llevando a cabo a través de ficheros generados con paquetes de ofimática compartidos con Google Docs. Este flujo de trabajo generaba inconsistencia y redundancia de información, además de la limitación que implicaba no tener los datos centralizados, provocando problemas al tener que trabajar con distintas versiones de un mismo documento.

Partiendo de esta premisa, surgió la necesidad de crear un sistema informático que almacenara la información de manera centralizada, y fuera lo suficientemente flexible para que permitiera administrar centros de enseñanza media, campus universitarios, empresas colaboradoras participantes, agenda de contactos, etc., y, además, planificar visitas de grupos de escolares a laboratorios, centros de investigación y empresas de ingeniería. También se pensó que, debido a la escasez de financiación y la necesidad de agradecer la participación de forma desinteresada de empresas, centros y laboratorios de investigación, se pudieran adjuntar imágenes de dichas entidades y organismos para ofrecerles visibilidad. Con el objetivo de satisfacer las necesidades citadas se optó por diseñar e implementar con software libre y alojamiento y dominio gratuitos, un sistema informático en línea, para poder tener acceso a todos los datos desde cualquier ordenador conectado a Internet, tratarlos de una manera intuitiva y unificada, y eliminar el inconveniente de manipular diferentes versiones de los mismos documentos al dejarlo todo en manos de un Sistema Gestor de Bases de Datos (SGBD). 
GAT ha sido implementado íntegramente en la Escuela Universitaria Politécnica de Teruel (EUPT) como un Trabajo Fin de Carrera (TFC) de la Ingeniería Técnica en Informática de Gestión (ITIG). En cuanto a sus características técnicas, el sistema informático está basado en una arquitectura Cliente-Servidor $(C / S)$, tal y como se puede observar en la gráfica 1. En el servidor se procede al almacenamiento de la BD (G. Day), implementada en el SGBD MySQL y del sitio web, desarrollado con el lenguaje de scripting conocido como PHP, lenguaje de programación usado generalmente en la creación de contenidos para sitios web. El cliente será cualquier ordenador con conexión a Internet que, a través de su navegador, interactúa con la aplicación web del sistema para poder realizar operaciones de inserción, actualización y borrado en la agenda de contactos, laboratorios y centros de investigación, centros de educación, empresas, y pode, así, gestionar el cuadrante de visitas del día de las Jornadas.

A continuación, se describen los aspectos más relevantes de GAT. En primer lugar, nos gustaría destacar, por un lado, un componente externo que se ha integrado en el sistema informático para poder gestionar el almacenamiento de las fotografías, y, por otro lado, el tema del alojamiento y dominio web utilizados, para poder garantizar el correcto funcionamiento de todo el sistema en línea.

- Alojamiento externo de fotografías, puesto que para almacenar la gran cantidad de fotografías y logotipos de grupos de investigación, centros educativos, las realizadas el propio día de las jornadas, etc., se tuvo que optar por utilizar un servicio externo, con la finalidad de reducir el tamaño de la BD y aprovechar las servicios ofrecidos por este tipo de alojamiento.

- Alojamiento web, se puede definir como un lugar donde la persona que lo utilice puede subir su sitio web, para que el mismo esté disponible y accesible a través de Internet. Se aloja en un servidor propio de la Universidad de Zaragoza.

- Dominio web, es el nombre con que es identificado un sitio web. Cada dominio tiene que ser único en Internet. No está permitida la duplicidad. Por ejemplo, el dominio <http://www.hola.com> es diferente al dominio <http:// www.hola.org>. Si no se hubiese ideado este sistema de nombres de dominio, los y las usuarias de Internet tendrían que acceder a un sitio web tecleando la dirección IP numérica.

Después de proporcionar una pequeña definición de cada uno de estos conceptos, vamos a pasar a explicar cómo se ha hecho uso de algunos de estos servicios en nuestro sistema informático. 


\section{flickr}

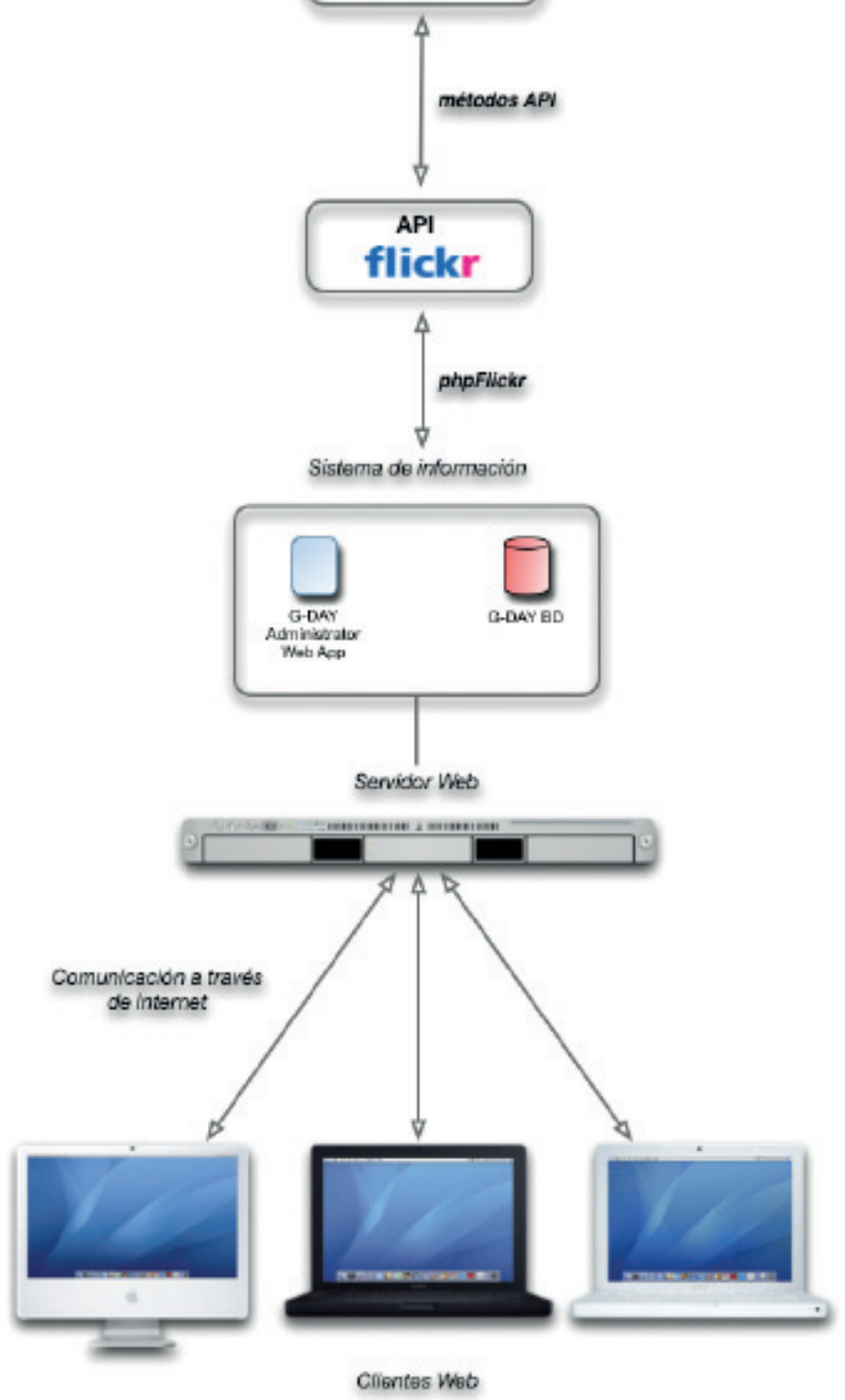

Gráfica 1. Esquema global del sistema. 
En lo que respecta al tratamiento que se hace de las imágenes, destacar que es bastante novedoso, puesto que se tomó la decisión de integrar en nuestro sistema informático un servicio web externo que, aunque no es la solución habitual, sí es la práctica más eficiente, puesto que se consigue con ella reducir el tamaño de la BD y aprovechar las ventajas de un alojamiento gestionado fuera de la aplicación. Se decidió utilizar Flickr, ya que no hay que olvidar que, para este proyecto en cuestión, se tiene que compartir información con la BD del sistema informático. Este proceso de comunicación, interoperabilidad y posterior búsqueda de información, se puede llevar a cabo gracias a la Interfaz de Programación de Aplicaciones (API) de Flickr para PHP, que se puede integrar en cualquier tipo de sistema informático programado con dicho lenguaje de programación. Al llevarse a cabo la gestión a través de la API, se puede sobrepasar la restricción de 200 fotos sin ningún tipo de problema, eso sí siempre y cuando no superen los $512 \mathrm{~Kb}$ de tamaño y sean JPG, JPEG, PNG o GIF.

La selección de alojamiento se hace en base a las siguientes características: (i) el que ofrece mayor espacio en disco, (ii) el que dispone de la mayor tasa de tráfico de datos mensual y (iii) el que ofrece cobertura para MySQL y soporte para PHP (el lenguaje de programación y el SGBD seleccionados para implementar GAT, respectivamente).

En segundo lugar, y al tratarse de un sistema gestor de información en línea, dos de los requisitos que se exigieron en la fase de diseño fueron: que se tratara de una aplicación que pudiera ser utilizada por el máximo número de personas, independientemente de sus conocimientos, capacidades personales y características técnicas del equipo utilizado para acceder a la web, y que la aplicación cumpliera con los estándares y tecnologías recomendados por el W3C, comunidad internacional que desarrolla estándares que aseguran el crecimiento de la web a largo plazo para que alcance su máximo potencial. Con ello se ha conseguido implementar un sitio web accesible cuyo beneficiario es todo el mundo (personas usuarias afectadas por circunstancias del entorno como baja iluminación, ambientes ruidosos, que acceden a servicios de Internet mediante equipos y conexiones con capacidades limitadas, que no dominen el idioma o que dispongan de un menor nivel cultural del esperado o usuarios inexpertos o que presentan inseguridad frente a la utilización de diversos dispositivos electrónicos), dejando de lado el mito de que un sitio web accesible es solo útil para usuarios de edad avanzada o que presentan algún grado de discapacidad (física, sensorial, cognitiva, etc.).

Para finalizar, comentar que tanto la propiedad industrial del sistema informático como los derechos de autor de la documentación generada están protegidos 
por licencias adecuadas a cada campo de actuación. El sistema informático se distribuye bajo la licencia de software BSD (Distribución de Software Berkeley), de tal manera que tanto el código fuente como los binarios se pueden utilizar, modificar y distribuir a terceros. Esta licencia, en comparación con otras como la GPL, tiene menos restricciones, estando muy cercana al dominio público. La licencia BSD al contrario que la GPL permite el uso del código fuente en software no libre. Mientras que la documentación generada se encuentra al amparo de una licencia CreativeCommons de tipo: Reconocimiento-No Comercial-Compartirlgual (CC-BY-NC-SA). El beneficiario de la licencia tiene el derecho de copiar, distribuir, exhibir y representar la obra y hacer obras derivadas para fines no comerciales, bajo una licencia idéntica a la licencia que regula la obra original, siempre y cuando reconozca y cite la obra de la forma especificada por el autor o el licenciante. En la actualidad, el sistema informático se encuentra en proceso de migración del dominio actual (girls-day.nixiweb.com) a uno proporcionado por la Universidad de Zaragoza (girlsday.unizar.es). Al tratarse de una aplicación de gestión interna que maneja datos de carácter personal, desde la Junta Directiva de MUCIT se tomó la decisión de cambiar su ubicación y acceso para poder cumplir con rigurosidad las directivas de la Ley Orgánica de Protección de Datos (LOPD). 
Índice 
Presentación

Manuel J. López Pérez

Prólogo

María Villarroya Gaudó....................................................................................... 10

Agradecimientos .......................................................................................... 12

Introducción

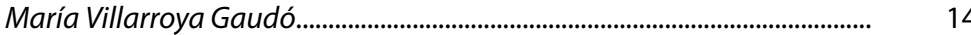

¿Por qué es necesario un Girls’ Day?

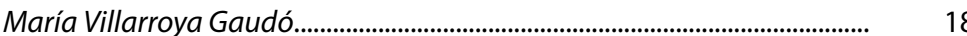

Acciones para promover la presencia de mujeres en ingeniería en el mundo

M. Carmen Mayoral Gastón y Pilar de Luis Carnicer.

¿Como se organiza el Girls' Day?

Sandra Baldassarri, Mayte Lozano Albalate, Ana Cris Murillo Arnal

y Raquel Trillo Lado

Experiencias del Girls' Day en Aragón

Percepción de la ingeniería por el alumnado de secundaria

Pilar Molina Gaudó, Sandra Baldassarri y María Villarroya

Estudiantes de ingeniería: procedencias y perfiles

María Villarroya Gaudó, Pilar Molina Gaudó y Sandra Baldassarri

Reflexiones finales a modo de conclusión

Sandra Baldassarri, Pilar Molina Gaudó y María Villarroya Gaudó .........

Anexo A: Los Girls' Day en cifras

Carmen Mayoral Gastón, Sandra Baldassarri y María Villarroya Gaudó ... 90

Anexo B: Encuesta realizada a las y los participantes en la edición 2011 .. 96

Anexo C: Diferencias de género en la elección de estudios técnicos en la Universidad de Zaragoza (Estudio realizado con el alumnado de grado).

Anexo D: Herramienta gestora del Girls' Day

Piedad Garrido Picazo, José Gabriel Villarroya Lafuente y Eva Hervás

Puchalt 

María Villarroya Gaudó es licenciada en Ciencias Físicas por la Universidad de Zaragoza; se doctoró en Ingeniería Electrónica por la Universidad Autónoma de Barcelona en el año 2005 y su tesis está centrada en el desarrollo de sensores de masa basados en sistemas micro-nano electromecánicos. Actualmente, es profesora del área de Arquitectura y Tecnología de Computadores de la Universidad de Zaragoza donde investiga en las redes de interconexión on chip y en las jerarquías de memoria de multiprocesadores.

Desde 2012 es presidenta de MUCIT, anteriormente fue vicepresidenta de esta asociación (2005-2012). Desde 2007 es vocal de la Junta Directiva de AMIT. Asociación de Mujeres Científicas y Técnicas. Desde el año 2006 es miembro de la Comisión Mujer y Ciencia del Gobierno de Aragón. Durante los años 2008-2012, ha sido directora del Observatorio de igualdad de género de la Universidad de Zaragoza.

SANDRA BaldassarRI es licenciada en Ciencias de la Computación por la Universidad de Buenos Aires (Argentina) y doctora en Ingeniería Informática por la Universidad de Zaragoza, donde actualmente es profesora del área de Lenguajes y Sistemas Informáticos. Sus intereses en investigación se centran en las áreas de interacción persona-ordenador, personajes virtuales, computación afectiva, interacción natural e interfaces multimodales y tangibles. Es cofundadora del grupo de investigación GIGA-AffectiveLab de la Universidad de Zaragoza. También, ha trabajado activamente en el área de tecnología y sociedad.

Desde 1999 hasta 2005, ha sido presidenta del capítulo español de Women in Engineering (WIE) del IEEE (Institute of Electrical and Electronics Engineers). A nivel regional, es socia fundadora de MUCIT, Asociación de Mujeres Científicas y Técnicas, siendo su secretaria desde 1999 hasta 2012, año en que pasó a ser tesorera.

Pilar Molina Gaudó es Ingeniera de Telecomunicaciones por la Universidad de Zaragoza, donde obtuvo su doctorado en el campo de la electrónica de potencia para RF en el año 2004. Actualmente, es profesora del área de Tecnología Electrónica, donde investiga en electrónica de potencia eficiente. Así mismo, es socia fundadora de la spin-off EPIC Power.

Es socia fundadora de MUCIT, Asociación de Mujeres Científicas y Técnicas, y ha sido presidenta de la misma desde su fundación en 1999 hasta 2012. Perteneció, desde el año 2000 al 2005, al comité internacional de Women in Engineering de la asociación de ingenieros global IEEE (Institute of Electrical and Electronic Engineers). También fue la presidenta del capítulo local del WIE en España desde su fundación en 1999 hasta el año 2006. 
$\underline{\underline{\mathrm{O}}}$ Prensas de la Universidad

$\overline{\underline{1542}}$ UniversidadZaragoza

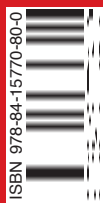

